\title{
Actores en las redes de infodiversidad yel acceso abierto
}

Coordinadora Estela Morales Campos 


\section{La presente obra está bajo una licencia de:}

\section{http://creativecommons.org/licenses/by-nc-sa/3.0/deed.es MX}

\section{Atribución-No Comercial-Licenciamiento Reciproco 3.0 Unported}

Eres libre de:

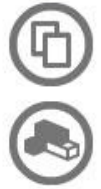

copiar, distribuir y comunicar públicamente la obra

hacer obras derivadas

Bajo las condiciones siguientes:

Atribución - Debes reconocer la autoría de la obra en los términos

especificados por el propio autor o licenciante.

No comercial - No puedes utilizar esta obra para fines comerciales.

Licenciamiento Recíproco - Si alteras, transformas o creas una obra a

partir de esta obra, solo podrás distribuir la obra resultante bajo una licencia

igual a ésta.

\section{Esto es un resumen fácilmente legible del: texto legal (de la licencia completa)}

En los casos que sea usada la presente obra, deben respetarse los términos especificados en esta licencia.
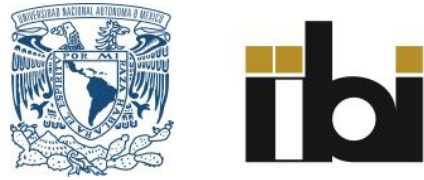
Actores en las redes de infodiversidad y el acceso abierto 


\title{
Actores en las redes de infodiversidad y el acceso abierto
}

\author{
Coordinadora \\ Estela Morales Campos
}

Universidad Nacional Autónoma de México 2015 


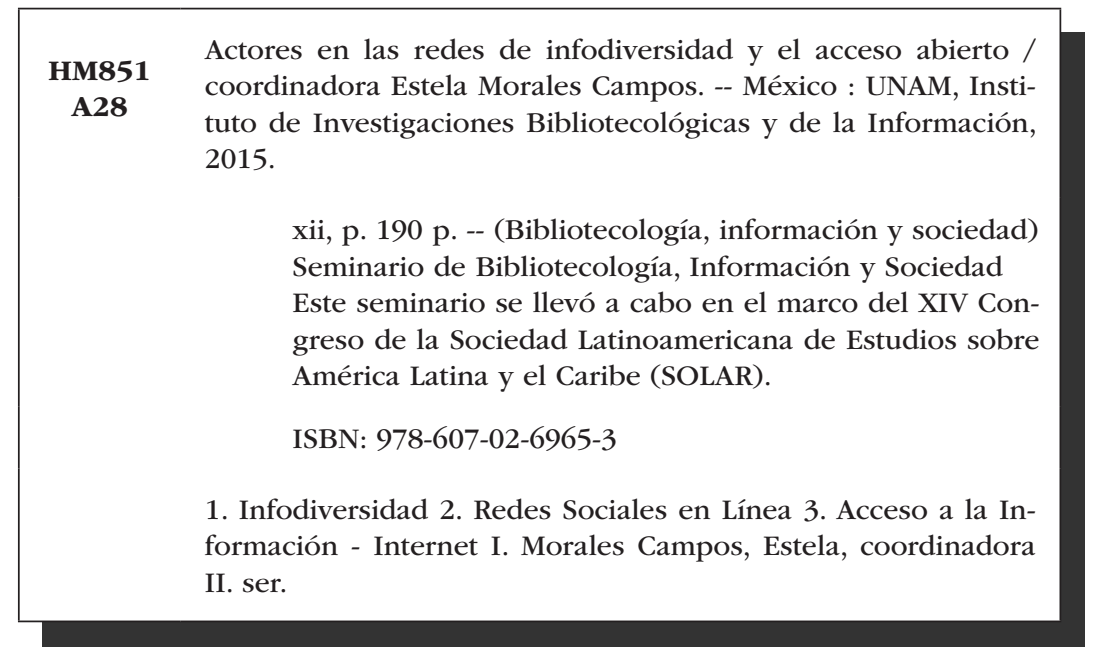

Diseño de portada: Mercedes Torres Serratos

Primera Edición 2015

DR (C UNIVERSIDAD NACIONAL AUTÓNOMA DE MÉXICO

Ciudad Universitaria, 04510, México D.F.

Impreso y hecho en México

ISBN: 978-607-02-6965-3 


\section{Tabla de contenido}

Presentación ......................... vii Estela Morales Campos

LAS NUEVAS FORMAS DE BÚSQUEDA Y CREACIÓN DEL CONOCIMIENTO Y EL ACCESO ABIERTO: UN DESAFÍO DESDE LA INFODIVERSIDAD . . . . . . 1 Beatriz Casa Tirao

APERTURA RADICAL Y LOS MOVIMIENTOS SOCIALES DE ACCESO ABIERTO A LA INFORMACIÓN Y AL CONOCIMIENTO, ELEMENTOS FUNDAMENTALES PARA FORTALECER LAS REDES DE INFODIVERSIDAD EN LA ERA DIGITAL: TENDENCIAS Y RETOS . . . . . . . . . . . . 15 Hugo Alberto Figueroa Alcántara

LAS BIBLIOTECAS DIGITALES Y EL ACCESO AL CONOCIMIENTO . . . . . . . 39 Jesús Francisco García Pérez

LA INFORMACIÓN ENTRE FUNCIONALISMO E INTEGRACIÓN, UN DILEMA ACTUAL EN AMÉRICA LATINA . . . . . . . . . . . . . 65 José de Jesús Hernández Flores

LOS ACTORES EN EL LIBRE ACCESO A LA INFORMACIÓN EN INTERNET. . . 79 Jonathan Hernández Pérez

ACTORES DE LA INFODIVERSIDAD EN EL SIGLO XX . . . . . . . . . . 103 Rosa María Martínez Rider 
LAS POLÍTICAS GUBERNAMENTALES COMO PROMOTORAS DEL ACCESO ABIERTO, LOS SERVICIOS DE INFORMACIÓN Y LA ALFABETIZACIÓN INFORMATIVA. . . . . . . . . . . . . . . . . . . . . . . . 115

Celia Mireles Cárdenas

DESARROLLO DE REDES CIUDADANAS EN UN ENTORNO DE

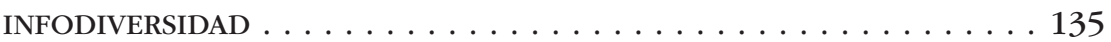
Alejandro Ramos Chávez

LA BIBLIOTECA COMO FACTOR CRÍTICO EN LAS REDES DE

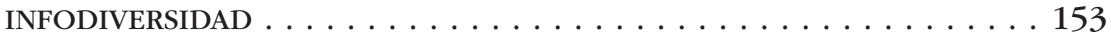
Jaime Ríos Ortega

VISIBILIDAD DE REVISTAS Y AUTORES PERUANOS EN REPOSITORIOS DE ACCESO ABIERTO: EL CASO DE LA PONTIFICIA UNIVERSIDAD CATÓlica del PERÚ (PUCP) . . . . . . . . . . . . . . . . . . . 171 Ana María Talavera Ibarra y Juanita Jara de Súmar 


\section{Presentación}

T a sociedad siempre se ha agrupado para compartir sus ideas, sus intereses, sus necesidades de defensa y protección, sus creencias, sus motivos de celebración y de fiesta, sus secretos científicos y de poder, sus entretenimientos sociales y familiares. Lo anterior nos lleva a plantear la necesidad que tienen los seres humanos de comunicarse unos con otros. A través de los siglos, esto ha ido variando de forma, de tonalidades y de intensidad, cobertura y dimensión geográfica; muchos de estos contextos son producto de los cambios sociales y de los avances de la tecnología en general, específicamente la que impacta a las comunicaciones (terrestres, marítimas o aéreas, como el telégrafo, el teléfono y otras) y, en los últimos tiempos, la relacionada con las llamadas Tecnologías de la Información y la Comunicación (TIC).

En la actualidad estos cambios nos llevan a hablar de una comunicación virtual. El ingreso masivo de la sociedad en el uso de las TIC potenció la agrupación de los usuarios en redes virtuales, que también pueden compartir sus intereses de manera personal, pero diferenciándose por tipo de usuario, cobertura geográfica y agrupación social, empresarial, gubernamental o científica. 
Esa libertad de agrupación general nos acerca a una multiplicidad de temas, enfoques, ideologías, creencias e intereses, los cuales conforman la rica infodiversidad que corre en Internet a través de las redes sociales o de las especializadas que de variadas formas alimentan ese medio informático de comunicación.

Tales redes las podemos analizar desde el punto de vista de sus actores y de la infodiversidad que éstos producen. El Internet, como medio y sello que cada grupo de usuarios imprime en la alimentación de contenidos, conforma una variada infodiversidad que cada individuo tendrá que valorar, jerarquizar y seleccionar en los procesos de búsqueda. En éstos, justamente, se va a reflejar la diversidad del mundo global, acrecentando la infodiversidad que nos rodea de manera natural en la convivencia democrática, en la libertad (con reconocimiento y respeto al otro) y en los derechos humanos y sociales.

Las formas de búsqueda de información, en papel o medio electrónico, van a estar influidas y determinadas por la lengua cotidiana de quien explore, por su identidad cultural, por su currículo académico, por su experiencia de vida y por su trayectoria de convivencia con la red, las TIC y la información buscada. La contraparte, por supuesto, será el creador del instrumento informativo electrónico, de los contenidos específicos o generales, de los motores de búsqueda y de todas las facilidades de software y hardware que faciliten la búsqueda. En la actualidad, es una obligación ineludible que los creadores y diseñadores de dispositivos, softwares y motores de búsqueda tomen en cuenta el perfil del usuario o cliente, a fin de lograr el éxito. En esa interacción de los actores (que como se puede apreciar representan diferentes sectores), el compromiso en el proceso de generación y uso de la información es de múltiple alcance; 
de modo que cada participante es indispensable en la sociedad actual, que aspira a ser una sociedad de la información y el conocimiento.

Si bien es común hablar de un amplio acceso a las TIC y de una masificación de tales tecnologías para facilitar la comunicación académica y social, también es cierto que la masificación no implica totalidad. Como todo fenómeno, se refleja en la sociedad por sectores: tanto en la historia antigua como en la actual; por ello, tenemos que tener presente, sobre todo en países que no han logrado su pleno desarrollo, que la creación de conocimiento y el uso de información tienen una base de tradición y compromiso con el progreso social, cultural, educativo, científico y económico, con fuertes raíces en la educación en todos sus niveles y con una cobertura total. Lo anterior producirá la creación del conocimiento y su aplicación, así como el uso abierto de la información con un sentido comunitario, democrático y plural.

Cuando hay un rezago en esta tradición y en esta conducta, hay que promover el cambio a través de políticas gubernamentales y sociales, de leyes y programas de educación acompañadas de acciones de socialización y sensibilización que, en muchas ocasiones, tienen que atacar debilidades básicas y emprender iniciativas, como la iniciación de la lectura y la reflexión sobre lo leído, fundamentales para todo proceso educativo, empleo de la información, y creación y uso del conocimiento.

Las redes de la infodiversidad alimentadas por los diferentes procesos educativos y creativos abarcan un sinnúmero de actores, de los cuales podríamos mencionar algunos de manera muy esquemática: 
a) los creadores e innovadores (tanto del área de las TIC como de la información, científicos, tecnólogos, desarrolladores);

b) los intermediarios (los prestadores de servicio, los educadores, los mercadólogos, los gobernantes);

c) los usuarios (todos los que se acerquen con necesidad o curiosidad sobre un tema).

Esta lista sólo es enunciativa, ya que cada actor puede moverse de posición según su necesidad o deseo; por ejemplo, los usuarios constituyen una amplia gama ya que todos, en un momento dado, podemos ser usuarios:

a) los creadores, los innovadores, los intermediarios, los promotores, los alimentadores de contenido, a la vez, son usuarios;

b) por su parte, hay quienes se acercan a la infodiversidad y a las TIC sólo como usuarios: niños, jóvenes, adultos, obreros, académicos, ejecutivos, funcionarios, científicos, humanistas, artistas, etcétera.

Los enfoques, temáticas, orientaciones y tendencias de las redes reflejan a la sociedad o grupo social que los genera, sea ésta una sociedad real (presencial) o virtual; y estas redes, al ser alimentadas por los individuos que las conforman, están expuestas en algún momento a tentaciones que no siempre se apoyan en un dicho o en una verdad comprobada o comprobable. Los objetivos de las redes son muy diferentes de acuerdo a los intereses de sus creadores y promotores, ya sean académicas o sociales. Esta característica es la que nos permite hablar de diversidad y pluralidad $y$, por lo tanto, justificar que la infodiversidad del Internet y de las redes sea el valor más preciado. 
Las redes pueden ser una tribuna de discusión científica y académica, con pares en los diferentes puntos geográficos de acción en donde se encuentren los especialistas y los centros de conocimiento; el diálogo, la discusión y la aportación de novedades, sin duda, harán que la ciencia crezca; asimismo, las redes académicas y las redes sociales pueden ser el espacio inmediato para la denuncia social, el activismo político y la defensa de derechos humanos y sociales, como la libertad intelectual, la libertad de expresión de las ideas y las creencias, y el acceso libre y abierto a la información. Pero si bien estos derechos siempre deberán ser garantizados y defendidos para vivir en libertad y democracia, también hay que hacer énfasis en el respeto que debemos tener por nosotros y por el otro. En ese sentido, la apertura de pensamiento y de acción se basa en el respeto al yo, al otro, a la comunidad a la que pertenecemos y a las otras con las que convivimos y con las que compartimos; por lo tanto, hay que tener mucho cuidado con la tentación a la difamación, el insulto, la represión, la falsedad premeditada y el robo intencional de las ideas (con fines lícitos o ilícitos).

En esta entrega del seminario de Bibliotecología, Información y Sociedad presentamos diferentes puntos de vista sobre las redes, la infodiversidad, el acceso abierto y los actores que participan en todos estos procesos. La discusión, el intercambio de ideas y la reflexión sobre estos temas se dio entre los miembros del seminario y distinguidos invitados peruanos que nos acompañaron en esta ocasión, ya que esta sesión académica se realizó en la ciudad de Lima, Perú, en el marco del XIV Congreso de la Sociedad Latinoamericana de Estudios sobre América Latina y el Caribe (SOLAR), celebrado en noviembre de 2014.

Con base en la evaluación inicial para participar en el seminario, más la discusión que se dio en la sesión abierta 
con los comentarios y sugerencias, presentamos los resultados. Agradecemos las aportaciones de los participantes y ofrecemos en este volumen sus reflexiones. Nuestro reconocimiento a los colegas que han hecho posible esta publicación: Beatriz Casa Tirao, Hugo Alberto Figueroa Alcántara, Jesús Francisco García Pérez, José de Jesús Hernández Flores, Jonathan Hernández Pérez, Juanita Jara de Súmar, Rosa María Martínez Rider, Celia Mireles Cárdenas, Alejandro Ramos Chávez, Jaime Ríos Ortega y Ana María Talavera Ibarra.

Estela Morales Campos 


\title{
Las nuevas formas de búsqueda y creación del conocimiento y el acceso abierto: un desafío desde la infodiversidad
}

\author{
BEATRIZ CASA TIRAO \\ Universidad Nacional Autónoma de México
}

\section{INTRODUCCIÓN}

T a educación es la base del sistema social. Esto parece una verdad sabida, pero vale la pena recordarlo en función de los nuevos giros que ha tomado la educación, en consonancia con el desarrollo y las ventajas que hoy ofrece la tecnología. El tema es esgrimido frecuentemente por los gobiernos como caballito de batalla para proponer o justificar sus propias acciones. Sin embargo, hoy, hablar de reforma educativa implica abordar un proceso complejo cuyas normas se fijan en las demandas de una sociedad global y multicultural a la que hay que atender.

El contenido de la formación de los individuos de hoy recoge intereses que han surgido con el devenir de las naciones y con el involucramiento cada vez mayor de los ciudadanos en los hechos que se dan en el complejo social. Esos intereses se traducen en pedidos concretos acerca de temas como la educación sobre derechos humanos, el anti- 
rracismo, la democracia, la paz, la no violencia, el respeto por el medio ambiente, la educación multicultural, la libertad de expresión y otros.

Todos estos fenómenos tienen lugar en una sociedad global donde la dialéctica entre las diferentes formas de pensamiento y de acción están presentes. Así pues, el servicio de una información comprometida con la búsqueda del bien común, como dice Philippe Quéau, ${ }^{1}$ la revolución de la información, profundamente ligada con la tecnología, tiene un rol protagónico en la sociedad en la que nos tocó vivir.

Dentro de este panorama surge el concepto de multiculturalidad, el cual revela la capacidad de la cultura actual para multiplicarse e insertarse en las "sociedades del conocimiento", término adoptado por la UNESCO como el más adecuado ya que no es posible pensar en una sociedad del conocimiento teniendo en cuenta que cada una de ellas guarda sus propias características. De esta manera, el hecho de la pluralidad aparece opuesto al de un modelo único e indiscutible, y surge entonces la imagen de la "otredad", es decir, de lo "distinto", o sea, la multiculturalidad. Y un agente imprescindible para difundir las informaciones y conocimientos que esa multiculturalidad ofrece es la infodiversidad, o sea, el instrumento preciso para transmitir lo que la propia diversidad ofrece.

Aunque el hecho de la diversidad no es nuevo entre los seres humanos, el mundo actual tiene mayores posibilidades para que exista interrelación entre las diversas culturas: los medios de información y comunicación son facilitadores de ello y su existencia es hoy notoria.

1 Philippe Quéau, "La revolución de la información: en la búsqueda de un bien común" [en línea]. 


\section{EL MULTICULTURALISMO}

El fenómeno del multiculturalismo responde sin duda a las distintas formas de desplazamiento y de establecimiento de relaciones que hoy tienen los individuos. Si bien se ha producido en distintas épocas de la humanidad, nunca como ahora ha sido tan conflictivo, tan demandante y, a la vez, tan necesitado de comprensión y de una consideración reflexiva.

El multiculturalismo como tal es objeto de la crítica de diversos autores, algunos de los cuales lo señalan como parte importante del proceso neoliberal y porque, además, está basado en principios de conmiseración, perdón y tolerancia, privando así a los individuos de la posibilidad de ser protagonistas de procesos que los empoderan de sus circunstancias vitales. Sin embargo, es necesario reconocer la existencia de una forma de multiculturalismo que corresponde a una realidad humana que se vincula con el otro y con la diversidad. De esta manera es posible llegar al multiculturalismo, que parece ser la forma más válida de integración ya que supone un programa de acción que tiende a la integración de las minorías étnicas y culturales en una sociedad que no es la suya de origen y conservando y compartiendo la propia cultura. Esto es una forma de que los grupos se integren a sociedades distintas de la suya sin olvidar sus orígenes y puedan tener con ellas una "unidad en la diferencia" que permita la convivencia entre distintas culturas.

Arroyo señala que la diversidad cultural forma parte importante de los cambios que se registren en el siglo XXI, ya que ella misma es receptora y emisora de esos cambios. ${ }^{2}$

2 Rocío Arroyo Belmonte (2006), "La diversidad cultural y las crisis del mundo en el siglo XXI: ¿la antesala de la revolución?”, p. 195. 


\section{EN LA SOCIEDAD DEL CONOCIMIENTO}

En las últimas décadas del siglo Xx, junto con la globalización, se agregaron a la realidad social otros fenómenos que tienen que ver con la actividad intelectual, el desarrollo de las Tecnologías de la Información y la Comunicación (TIC), la multiplicación de todas las actividades, más nuevos objetos del conocimiento y nuevas modalidades para su obtención, difusión y aprovechamiento. Esto significa, en lo general, el surgimiento de nuevos conceptos en el ámbito del pensamiento y el quehacer humanos, con lo cual el campo del conocimiento se ha ampliado y enriquecido de manera notable y así la información y el conocimiento mismo adquirieron un rol protagónico en el nuevo escenario: la sociedad del conocimiento. Esta sociedad conjuga el conocimiento humano logrado en distintas culturas y muestra que entre ellas es posible la comunicación y el intercambio, dado el desarrollo de los medios respectivos.

Por otro lado, los grandes movimientos migratorios que corresponden a las necesidades de los grupos humanos por diversas causas, llevan consigo su cultura en el más amplio sentido de la expresión y la misma conoce y se relaciona con la cultura del lugar que los recibe:

Este encuentro cultural está relacionado con la armonización de las relaciones humanas que permite pensar que este encuentro propone una revolución de las sociedades en el terreno del entendimiento a través de la comprensión y la empatía. La interculturalidad permite reflejar la dinámica social y formular el objetivo de nuevas síntesis socioculturales. ${ }^{3}$

3 Beatriz Casa Tirao (2007), "Bibliotecas e información en la diversidad cultural." 
Desde esta perspectiva es posible deducir que, en la circunstancia del encuentro de culturas, la infodiversidad tiene un importante papel que jugar. Otra conclusión a la que es posible llegar es que la sociedad que predomina hoy es una sociedad multicultural, con una interrelación que aún debe ampliar en su beneficio y en el de las demás sociedades. Llegamos a la conclusión de que vivimos en una sociedad del conocimiento multicultural.

Con respecto a la sociedad del conocimiento, Fernando Lema afirma que los países subdesarrollados transitan de la sociedad de la información a la del conocimiento sin haber solucionado las dificultades que origina el cambio; se pregunta si los países en desarrollo deben seguir el mismo camino, y termina su reflexión afirmando que para los países en desarrollo será más difícil salvar los problemas que la sociedad del conocimiento plantea dadas las dificultades económicas que estos países tienen. ${ }^{4}$

Los trabajadores de la información hemos sido agobiados con una valoración exagerada, y a veces equivocada, de la sociedad del conocimiento. Ésta no es en manera alguna la panacea para todos los males ni el único objetivo que debemos alcanzar. Pienso que en ese terreno deberíamos comprometernos con un análisis más profundo del concepto sociedad del conocimiento. Existe la posibilidad de darle un sentido más global y comprehensivo y evitar dotarla de un sentido totalmente tecnologizado. No debemos olvidar la visión y la misión que nuestra profesión tiene, y en este sentido debemos volver nuestra mirada hacia las humanidades como contraparte importante de una tecnologización excesiva. La sociedad del conocimiento no es posible si no disponemos, a la vez, del acceso libre a la información, que

4 Fernando Lema (2003), La educación superior en la sociedad del conocimiento. Algunas claves para un futuro incierto. 
será lo que nos permita crear un mundo informativo, capaz, veraz y valiente.

\section{EL ACCESO LIBRE A LA INFORMACIÓN}

La información es, entre otras cosas, un elemento de poder que puede ser manejado de diversas maneras por los medios de comunicación. Una breve recapitulación nos permitirá ilustrarnos en ese sentido. Durante muchos años el ciudadano tuvo como reclamo legítimo el del acceso a una información veraz y legítima; el pedido de una información verdadera y objetiva fue un hecho que permaneció por años y que aún hoy es eludido por algunos gobiernos. Es indudable que vivimos en otro momento en el cual no es tan fácil regatearle al ciudadano sus derechos, incluido ese derecho a la información. No obstante, otros recursos son empleados para alejar al usuario de la información que busca. Por ejemplo, por sobre la información misma tiene más poder la organización de donde proviene; de manera que esto favorece la distorsión de la información cuando ello favorece intereses económicos, políticos o de cualquier otra índole que lleguen a sesgarla. Estamos hablando de la información que en general es útil para todo tipo de usuario y también la información científica, producto de la investigación.

Es cierto que la cultura no es sólo información; sin embargo, es también información y la acumulación de una buena cantidad de ella promoverá la formación de una cultura participativa y también, en otras circunstancias, de una cultura científica. Todo esto hace a la cultura de un pueblo.

Como sabemos, las administraciones públicas son las que difunden la información; por ello, es de esperar que otras de sus funciones sean promoverla, defenderla y difundirla 
y, sobre todo, hacerla accesible a los diferentes usuarios, es decir, a los ciudadanos en general. Éstos deberían comprender que el extraordinario avance que ha conocido la tecnología de la información y de la comunicación, ha hecho que los usuarios, a la vez que han adquirido más conocimiento, han logrado también mayor poder a través de los nuevos derechos adquiridos. En especial, es necesario dejar claramente establecido que todo aquello que tiene un financiamiento con dineros públicos es propiedad de la comunidad y no de los funcionarios en turno.

Otro aspecto del acceso libre es el que se refiere a la investigación científica. En este sentido la UNESCO realiza campañas casi permanentes para que los organismos de los diferentes países aseguren los resultados de la investigación científica como material de primera prioridad y de acceso libre para los interesados.

La protección que de la información científica hace la UNESCO tiene como consecuencia un uso más racional de la misma; accesibilidad académica; libertad de la mayoría de las barreras impositivas por las licencias y derechos de autor, lo cual permitirá el intercambio de conocimientos tanto en el plano local y regional como en el mundial, así como en la innovación y desarrollo.

El Programa de acceso a la información de la UNESCO está dirigido principalmente a los países de África y en general a los países subdesarrollados. No obstante, países con economías que poseen mejores perspectivas también participan del mismo. A través de su red mundial de oficinas, la UNESCO promueve en los distintos países sus políticas de libre acceso y coopera con iniciativas locales, regionales y mundiales de apoyo. Al mismo tiempo promueve el desarrollo y empleo de las TIC. 
El acceso libre tiene muchos beneficiarios, desde los investigadores, docentes, estudiantes, innovadores, hasta los profesionales de los medios de comunicación así como el público en general, quienes se benefician ampliamente con el acceso libre a la información. De igual manera, el acceso libre promueve el intercambio de conocimientos en el plano mundial y alienta los descubrimientos científicos, la innovación y el desarrollo socioeconómico.

En cuanto al mayor o menor éxito de la aplicación del derecho a la información en los diversos países latinoamericanos, una investigación realizada en Uruguay a un número limitado de países mostró que en tanto que algunos de ellos muestran un relativo éxito, otros enfrentan dificultades en cuanto a la puesta en marcha de las acciones respectivas. Las dificultades estriban, por lo general, en el aspecto legal por la falta de leyes dirigidas a proteger al usuario en cuanto al acceso a la información; otras veces, por el incumplimiento o insuficiencia de las mismas. En casi todos existen organismos dedicados exclusivamente a cumplir con el objetivo de acceso a la información y en algunos, en lugar de leyes, existen decretos.

Entre los países con historia de éxitos en este renglón se cuentan Chile y Uruguay, en tanto que en otros como Argentina, Perú y Ecuador, dificultades de diferentes tipos obstruyen el buen funcionamiento del sistema. Por fin, y hablando de los organismos que vigilan el cumplimiento de la disposición de acceso a la información, en México, por ejemplo, se creó el Instituto Federal de Acceso a la Información y Protección de Datos, IFAI (a partir de 2015, Instituto Nacional de Transparencia, Acceso a la Información y Protección de Datos Personales, INAI), en el cual en el año 2010 se presentaron más de 4,700 recursos de inconformidad. Debe recordarse que en el nivel público el acceso libre 
a la información está íntimamente ligado con la obligación de transparencia y las leyes que la rigen, lo cual, en algunos casos, suele dificultarse el acceso a la información por razones relacionadas con intereses diversos. Un caso es el de la información clasificada y que permanece en reserva sin ser dada al conocimiento público durante un período determinado, que suele ser de considerable duración. Esta clasificación suele aplicarse a documentos que deberían ser públicos desde el inicio de su proceso.

\section{EL PROFESIONAL DE LA INFORMACIÓN: SU ROL PROTAGÓNICO Y LA INFODIVERSIDAD}

Al hacer un análisis del siglo Xx desde una visión holística e integradora, es posible reflexionar acerca de su contraparte, la especialización, que tanto marcó al siglo pasado y su conflictivo encuentro con la integración del conocimiento cuya demanda comenzaba a percibirse. Desde entonces pudo percibirse que para la investigación enfocada hacia la transdisciplinariedad existe un inconveniente: el necesario equilibrio que debe existir entre las diversas disciplinas para que el resultado final sea un todo interactuante, ya que el nuevo conocimiento exige una forma de apreciación diferente: la transdisciplinariedad o la interdisciplinariedad: "El llegar a la sociedad del conocimiento o a la del saber permitirá eliminar los mitos creados alrededor de la información y la tecnología que la apoya, para llegar a la comprensión de esta última como un instrumento que permite llegar al conocimiento pero que no es el conocimiento mismo". 5

Como señala la UNESCO, el concepto de sociedad de la información se relaciona con el progreso tecnológico, en

5 Beatriz Casa Tirao, Op. cit., p.157. 
tanto que la sociedad del conocimiento supone dimensiones de tipo social y, por ende, éticas y políticas. A esa característica particular de cada sociedad hay que agregar el carácter complejo de las sociedades actuales, donde todo se encuentra entrelazado, entretejido, enmarañado. ${ }^{6}$

En estos grupos donde han surgido sociedades complejas es necesario que la ciudadanía se pronuncie. Una de las conclusiones a que se llegó sostiene la necesidad de un espacio relacional que supere el enfoque unilateral y disciplinario y que vaya encaminado a crear equipos de trabajo de diversas disciplinas conectadas por un eje común y sin descuidar la sustantividad o identidad de cada una de las ciencias. ${ }^{7}$ Esto significaba reconocer que en ese momento la interdisciplinariedad era necesaria. Esto responde a la primera época del nuevo pensamiento: aproximadamente 1970.

La segunda etapa se da hacia 1987 , y se refiere a "entre" y "más allá" de las disciplinas con investigaciones de tipo orientado/aplicado.

A partir de 1990 se produce un cambio en el manejo de la interdisciplinariedad y surge entonces la investigación orientada más allá de lo disciplinario, práctica y participativa, en campos donde el desarrollo social, técnico y económico interactúan con componentes de valores y de cultura. Ésta es la transdisciplinariedad.

El anterior es el panorama con el que deben familiarizarse los especialistas en información teniendo en cuenta que, además, también está presente el proceso de la infodiversidad. En este último sentido es donde el bibliotecólogo o documentalista o especialista en el área debe capacitarse para relacionarse con lo "distinto". Hay que tener en cuenta que capacitarse puede significar, en general, hacer una

6 Rafael Domingo (2004), Sociedades complejas.

7 Oscar Picardo (2003), "El escenario actual de las ciencias sociales: la sociedad del conocimiento” [en línea]. 
apertura hacia el mundo para poder dar sus servicios y sus conocimientos y, a la vez, recibir la retroalimentación que proviene del usuario.

El enorme crecimiento del campo del conocimiento ha provocado que los antiguos instrumentos de análisis e investigación resulten insuficientes. Las dinámicas disciplinarias, interdisciplinarias y multidisciplinarias requieren de la acción transdisciplinaria como recurso de complementariedad.

El área de la infodiversidad se enriquece con estas alternativas para trabajar el campo del conocimiento. A ellas concurren diversas disciplinas y distintos conocimientos que conjugan diversos orígenes y que hacen más fructífero el quehacer intelectual. En el campo de la información es necesario ampliar la acción para abordar, con mayor profundidad, estos temas acerca de los cuales hemos venido hablando. Con respecto a la integración de América Latina, si bien se ha avanzado considerablemente en el terreno de las relaciones, pienso que a la infodiversidad le corresponde un papel importante en el plano de las relaciones entre los países y en el del conocimiento.

Termino con algunas reflexiones acerca de la formación integral de aquellos que tienen la responsabilidad de actuar en el campo de la información. Se debe tener en cuenta que las disciplinas ya no constituyen compartimentos estancos, sino que en las sociedades complejas como las que hoy predominan los límites disciplinares se diluyen para permitir que las extensiones y ampliaciones de las disciplinas se comuniquen e interactúen en el proceso de creación y búsqueda del conocimiento. Por lo tanto, es necesario cultivar espíritus abiertos a otras disciplinas además de la propia.

Se debe fomentar el trabajo en equipo con conexiones dentro y fuera del campo particular al que pertenezca el estudiante o el profesional, y en el proceso de formación 
se deberán estimular las relaciones académicas con otros estudiantes.

Debe recordarse la necesidad frecuente de reforma de planes y programas y, por consiguiente, su evaluación frecuente. Cada vez más los conocimientos crecen y se modifican aceleradamente. Por último, deseo señalar que ciertamente los profesionales de la información no tenemos ni todo el saber ni todas las verdades en nuestras manos, pero sí la capacidad de abrir nuestra mente y nuestro espíritu al saber y la posibilidad de compartirlo con los demás. Conocemos, además, las instancias que permiten llegar al saber, al objeto del conocimiento y, conjuntamente, con profesionales de otras disciplinas, conformar un aparato cognitivo incluyente.

\section{REFERENCIAS BIBLIOGRÁFICAS}

Arroyo Belmonte, Rocío (2006), "La diversidad cultural y las crisis del mundo en el siglo XXI: ¿la antesala de la revolución?”, en Graciela Arroyo Pichardo (comp.), La dinámica mundial del siglo XXI. Revoluciones, procesos, agentes y transformaciones. Una nueva respectiva de estudio, México, Cenzontle.

Casa Tirao, Beatriz (2007), "Bibliotecas e información en la diversidad cultural", en Estela Morales Campos (comp.), El multiculturalismo y los servicios de información, México, UNAM / Centro Universitario de Investigaciones Bibliotecológicas.

Lema, Fernando (2003), La educación superior en la sociedad del conocimiento. Algunas claves para un futuro incierto, París, UNESCO.

Picardo, Oscar (2003), "El escenario actual de las ciencias sociales: la sociedad del conocimiento" [en línea], htpp:wwdoc.edu/ dt/20318/dex/index.htmnl 
Las nuevas formas de búsqueda y creación del conocimiento...

Quéau, Philippe, "La revolución de la información: en la búsqueda de un bien común" [en línea], http://www.bvs.sld.cu/revistas/ aci/vol9_s_01/sci15100.pdf

Rafael Domingo (2004), Sociedades complejas, Navarra, Publicación ABC. 
Apertura radical y los movimientos sociales de acceso abierto a la información y al conocimiento, elementos fundamentales para fortalecer las redes de infodiversidad en la era digital: tendencias y retos

Hugo AlBerto Figueroa AlCÁNTARA

Universidad Nacional Autónoma de México

\section{INTRODUCCIÓN}

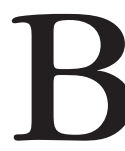

ajo la premisa fundamental de que el mundo crecientemente digital en que vivimos tiende hacia una apertura radical en todas las actividades cruciales de la civilización humana, se explica una serie de tendencias visibles en sectores tales como tecnología, gobierno, ciencia, educación, sociedad, cultura y bibliotecas, que a su vez guardan estrecha relación con los movimientos sociales de acceso abierto a la información y al conocimiento. Todas estas tendencias inciden decisivamente en el fortalecimiento de las redes de infodiversidad en la era digital. 


\section{APERTURA RADICAL, FACTOR CLAVE EN EL DESARROLLO Y CONSOLIDACIÓN DE LAS REDES DE INFODIVERSIDAD EN LA ERA DIGITAL}

En los tiempos actuales, cuando Internet, la interconectividad a gran escala y el universo digital cobran cada vez mayor importancia, podemos percibir que existen diversas tendencias y fenómenos globales de gran complejidad que afectan todas las actividades que realizamos, a la vez que influyen de manera determinante en el devenir de la civilización humana.

En este contexto, una de las tendencias más sobresalientes es que nos estamos trasladando vertiginosamente de escenarios centralizados y cerrados a contextos descentralizados, abiertos e interconectados. Es decir, nos movemos de una sociedad industrial tradicional a una sociedad red digital interconectada y abierta, donde las redes de infodiversidad son elementos fundamentales que favorecen los procesos de proclividad hacia lo abierto.

En tal cambio, la plataforma tecnológica y social representada por Internet (sobre todo en su faceta de web 2.0) ha jugado un papel trascendental, porque facilita, en un ambiente eminentemente digital, la producción y difusión horizontal de datos, información, contenidos y conocimientos abiertos entre personas que comparten intereses comunes, que se consideran integrantes de comunidades y, por lo tanto, se fomenta una cultura de la participación (Fuchs, 2010).

Esta transición mundial y multifacética hacia lo abierto la podemos denominar apertura radical, de acuerdo con Don Tapscott (2013). El eje en común es la transformación exponencialmente acelerada hacia lo abierto: tecnología abierta, software abierto, gobierno abierto, ciencia abierta, educación abierta, sistemas de acceso abierto (open access), recursos educativos abiertos, entre varios otros ejemplos (Vessuri, 
2011); tendencias en las que los datos, contenidos, información, productos, etcétera (en modalidad abierta) son esenciales para que las personas puedan, entre otros aspectos, acceder, usar, reutilizar, colaborar y compartir dichos recursos, y que todo ello pueda ayudar a robustecer sociedades más abiertas, democráticas y justas, así como facilitar la creación cultural y la multiplicación de nuevo conocimiento.

Dichos procesos de apertura se manifiestan en diferentes prácticas sociales, culturales y científicas, en diversas políticas públicas, etcétera, y son cruciales en la evolución de la humanidad.

Por ejemplo, en cuanto a las tecnologías abiertas, un caso paradigmático es Internet y la web, pues su base tecnológica es de naturaleza pública no propietaria, por ejemplo el protocolo de internet (ip, internet protocol), protocolo de transferencia de hipertexto (http, hypertext transfer protocol), lenguaje de marcado de hipertexto (html, hypertext markup language) y lenguaje de marcado extensible (xml, extensible markup language), además de que permite la convergencia con otros estándares abiertos y la interoperabilidad (no importa qué tipo de sistema operativo ni qué tipo de computadoras, tabletas, teléfonos celulares, etcétera, se usen para acceder a internet o la web).

Asimismo, su diseño primigenio fue conscientemente descentralizado, fundamentado en una cultura libertaria (Contreras, 2003: 26-27), con la gran cualidad de poder conectar todo con todo (Berners-Lee, 2000) y distribuir el poder de la información por todos los espacios de la interacción humana, por lo que se ha convertido en la plataforma tecnológica y de comunicación esencial de la sociedad red digital (Castells, 2001: 15).

En relación con el gobierno abierto, podemos percibir varias tendencias, entre las que podemos destacar: 
- Acceso a la información gubernamental. Existe una tendencia global a reconocer que los ciudadanos tienen derecho (conceptuado como derecho a la información) de solicitar diversos tipos de información a las entidades gubernamentales y éstas tienen la obligación de proporcionarla. Para ello se ha legislado al respecto (a la fecha, de acuerdo con el Global right to information rating: Access Info Europe (España), 2015) noventa y cinco países han proclamado leyes sobre acceso a la información pública. En México, además de la Ley federal de transparencia y acceso a la información pública gubernamental (vigente desde 2002), se han organizado los fondos documentales (archivos físicos, archivos digitales, etcétera) y se han desarrollado las plataformas de consulta ciudadana pertinentes a través de Internet. Esta tendencia no sólo implica acceso abierto a la información, sino que permite una mayor transparencia de las acciones del gobierno y le da poder a la gente para estar mejor informada y para monitorear y denunciar actos anómalos, con la finalidad de que el gobierno rectifique o sea más escrupuloso en sus actuaciones. Permite, en suma, ayudar a construir sociedades más democráticas y abiertas.

- Datos abiertos del gobierno. Esta tendencia forma parte del movimiento más amplio de datos abiertos. Aunque guarda relación con el acceso a la información gubernamental y con el e-gobierno, tiene sus singularidades, pues busca ir más allá de obtener información o emplear servicios gubernamentales, al pretender que los datos, en este caso provenientes de entidades gubernamentales, estén basados en estándares abiertos, sean interoperables y puedan ser utilizados, reutilizados, combinados, redistribuidos libremente y de mane- 
ra universal por cualquier persona. De lo que se trata es que estos datos sean más accesibles y compartibles, con el propósito de ofrecer nuevos servicios, mejorar el bienestar social, fomentar una cultura de la participación y lograr una mayor colaboración entre el gobierno y la sociedad, además de que se facilite la generación de nuevo conocimiento, a partir del análisis e interpretación de grandes volúmenes de datos e información provenientes de diversas fuentes (Fundación para el Conocimiento Abierto, 2012).

- E-gobierno o gobierno digital. Esta tendencia forma parte esencial de la transición hacia la sociedad de la información y del conocimiento, por lo que los gobiernos están empleando distintas tecnologías de la información para que los ciudadanos accedan a productos y servicios gubernamentales, con el propósito de atender de manera más oportuna y con mayor calidad las peticiones ciudadanas. Las plataformas de acceso desarrolladas poseen varias cualidades, por ejemplo, transparencia, facilidad de uso, interactividad, seguridad, actualidad y confidencialidad de los datos, etcétera. Este modelo fomenta mayor acercamiento entre las personas y el gobierno y favorece una cultura participativa (Meier, 2012).

En lo que respecta a la ciencia abierta, esta tendencia contempla horizontes más amplios y ambiciosos que los delimitados por los sistemas de acceso abierto a la información académica y científica (open access), los cuales son uno de sus componentes más valiosos, pues permiten generar recursos de información de acceso libre y universal para cualquier persona.

En el marco específico de la ciencia abierta, existen múltiples evidencias de cambios drásticos en las formas de hacer 
ciencia, realizar investigaciones, acopiar datos, organizar y compartir información, e interpretar y comunicar los resultados a las comunidades científicas, a los gobiernos, a otras entidades patrocinadoras y al público en general.

Por ejemplo, en la actualidad la ciencia refleja cada vez con mayor frecuencia modelos de trabajo colaborativo a escala internacional, se utilizan potentes programas de cómputo para analizar, simular y visualizar resultados, basados en cantidades ingentes de información que está distribuida en diversas bases de datos a nivel global, o bien, desde diversas comunidades se nutren bases de datos comunes.

Paralelamente, la investigación científica actual demanda otro tipo de datos que antes no se distribuían, como por ejemplo los datos base, que emplean tecnologías abiertas interoperables para que se puedan compartir, reutilizar, contrastar, verificar, etcétera (Pérez González, 2012: 30).

En síntesis, en un entorno científico altamente colaborativo, que maneja cada vez mayor cantidad de datos y de información y que está fuertemente mediado por tecnologías digitales, es imprescindible que la ciencia se abra al máximo, para permitir su visibilidad, transparencia y sostenibilidad.

Otra perspectiva de apertura de la ciencia se relaciona con su conceptuación como bien público y con procesos de democracia y transparencia sociales.

Así, en varios países se ha legislado para que todas las publicaciones que son resultado de investigaciones financiadas con recursos públicos, estén disponibles mediante acceso público en línea; por ejemplo: Estados Unidos (Federal research public access act, 2006), España (Ley 14/2011, de junio, de la ciencia, la tecnología y la innovación, 2011), Perú (Ley que regula el repositorio nacional digital de ciencia, tecnología e innovación de acceso abierto, 2013), Argentina (Ley 26899: creación de repositorios digitales ins- 
titucionales de acceso abierto, propios o compartidos, 2013) y México (Decreto por el que se reforman y adicionan diversas disposiciones de la Ley de ciencia y tecnología, de la Ley general de educación y de la Ley orgánica del Consejo Nacional de Ciencia y Tecnología).

También se han llevado a cabo iniciativas para que la ciencia sea más abierta y democrática, donde los ciudadanos tomen parte activa en los grandes debates de políticas públicas científicas y educativas, y donde se evidencien procesos de transparencia y rendición de cuentas (Cribb, 2010: 13-14).

En lo que concierne a la educación abierta, un novedoso paradigma emergente (que va mucho más allá de los esquemas tradicionales de educación a distancia y de los sistemas abiertos de educación) está cobrando gran trascendencia. Igual que con la ciencia abierta, la tendencia de la educación abierta cuenta con sus recursos de información abiertos, los cuales son, en este caso, los recursos educativos abiertos, disponibles a través de dos modalidades frecuentes: OpenCourseWare y repositorios de acceso abierto. Pero esta tendencia no se circunscribe exclusivamente a poner a disposición de todo el público, en cualquier parte del mundo, materiales educativos abiertos y reutilizables, pues su radio de acción es más amplio.

Mediante el uso de plataformas educativas abiertas y colaborativas, así como recursos educativos abiertos, universidades de gran prestigio a nivel mundial, entre ellas la Universidad de Stanford, la Universidad de Harvard, la Universidad de Yale, el MIT, la UNAM, entre otras instituciones educativas, ofrecen cursos abiertos, gratuitos, masivos e interactivos a través de Internet, disponibles para personas de todo el mundo, además de que si se acreditan, se otorgan las constancias o diplomas correspondientes. Un ejemplo 
sobresaliente es Coursera (creada en 2011), plataforma educativa en línea, que a través de cursos en línea masivos y abiertos (massive open online courses, MOOC) ofrece cursos organizados por distinguidas universidades, como las previamente mencionadas.

Para darnos una idea de las dimensiones de este fenómeno emergente y de sus patrones de crecimiento exponencial, de 2011 a la fecha, a través de Coursera se han ofrecido 1028 MOOC, han participado 117 entidades y se han inscrito a algún curso más de 22, 232, 448 personas de todo el mundo (Coursera, 2015).

Este paradigma emergente de educación abierta está vinculado estrechamente con otras tendencias educativas globales, entre las cuales podemos resaltar: desarrollo de modelos de aprendizaje basados en el conectivismo y en la colaboración y participación en línea, mayor acceso a la información y a la educación por parte de la población en general, masificación y globalización de la educación superior, etcétera (OECD, 2010). En tal marco, la educación abierta responde a esas tendencias, bajo el principio fundamental de liberar la educación y el conocimiento para que irradie a audiencias más amplias a nivel global. Sin lugar a dudas, cada vez tendrá mayor importancia y alcances.

Como podemos constatar con el panorama previo, en sectores cruciales de la humanidad (tecnología, gobierno, ciencia, educación, etcétera), hay una serie de tendencias que tienen como punto en común una apertura radical, una metamorfosis multifacética hacia lo abierto. Pero hay otro elemento en común involucrado en estas tendencias: el acceso abierto a la información y al conocimiento, paradigma que se trata a continuación. 
LOS MOVIMIENTOS SOCIALES DE ACCESO ABIERTO

A LA INFORMACIÓN Y AL CONOCIMIENTO Y SU

REPERCUSIÓN EN EL ROBUSTECIMIENTO DE

LAS REDES DE INFODIVERSIDAD

EN LA ERA DIGITAL

A partir de las temáticas tratadas en el apartado previo, podemos afirmar que un conjunto de tendencias visibles de apertura en el universo digital hipervinculado está incrementando drásticamente la diversidad de opciones en que la gente colabora, comparte, participa y utiliza la información (Turow, 2008), crea nuevo conocimiento de manera mancomunada (Hess, 2007) y contribuye a la construcción y fortalecimiento de una sociedad y cultura libres (Lessig, 2005); todo esto a través de dinámicas relacionales distribuidas (Bauwens, 2005).

Pero esto no ocurre sin fricciones, pues vivimos en un sistema capitalista, caracterizado, en su etapa actual, por el debilitamiento del Estado-nación de bienestar social, el auge de las corrientes neoliberales, la concentración de la riqueza en unas cuantas manos y el agobiante poder económico y político de las empresas (Tejerina, 2003: 8-16). Éstas, muchas con presencia en todo el mundo, han logrado impulsar políticas globales cada más restrictivas en materia de propiedad intelectual (Boyle, 2003), las cuales se oponen o limitan significativamente el libre acceso a la información, el conocimiento y la cultura (Krikorian, 2010a), entre otros elementos vitales para edificar y sostener sociedades abiertas, democráticas, progresistas, interconectadas y estables, que requieren una máxima capacidad para compartir y colaborar (Vaidhyanathan, 2004), en una era en que la información representa un valor fundamental en la sociedad red (Castells, 1999) y es el corazón de la economía (Gómez, 2012). 
En esta trama de apertura social, tecnológica, cultural, política, etcétera, el acceso abierto a la información y al conocimiento juega un papel de primordial importancia (Bollier, 2002) y forma parte de los complejos debates y batallas de muy diversa índole que se dan entre quienes pugnan por la privatización y el lucro de la información y el conocimiento, y aquellos que promueven su acceso abierto, mediante el impulso de alternativas comunitarias que generen bienes compartidos (Ostrom, 2011).

Para comprender de modo más detallado esta problemática es necesario explicar un conjunto de conceptos clave, que representan una serie de tendencias notables que se desarrollan actualmente en los planos ideológicos, políticos, sociales, culturales y jurídicos de la convivencia humana: acceso al conocimiento y dominio público. El discurso de estos componentes se vincula a su vez, de manera recurrente, con temáticas cruciales de nuestro devenir actual: libertad, derechos humanos, desarrollo humano, justicia, democracia, diversidad cultural. A continuación se tratan dichos conceptos.

El concepto emergente de acceso al conocimiento (access to knowledge, en inglés, también conocido como $A 2 K$ ) permite fusionar, bajo una sola idea, un conjunto heterogéneo de nuevos movimientos sociales, tendencias, iniciativas y políticas que tienen como fin primordial contribuir al desarrollo humano, el acceso igualitario a la información y al conocimiento, a las tecnologías de información e Internet, así como lograr una justicia distributiva, que permitan globalmente mejorar las capacidades humanas para acceder, usar, compartir, colaborar y contribuir con la creación de información y conocimiento.

Actualmente representa un frente de batalla relevante ante las excesivas regulaciones en materia de propiedad in- 
telectual y telecomunicaciones, así como el abusivo control de la información, a la vez que ofrece una crítica sólida y una alternativa a los discursos ideológicos y políticos que legitiman el poder cada vez más desproporcionado que ostentan las corporaciones en relación con la propiedad intelectual. Entre sus principales teóricos podemos mencionar a Benkler (2006), Balkin (2010), Shaver (2007), Kapczynski (2010) y Krikorian (2010).

En acceso al conocimiento, el término conocimiento posee cuatro capas o significados. El primero tiene que ver con productos derivados del conocimiento, bienes que no son por sí mismos información o conocimiento, pero que requieren de conocimiento científico o tecnológico significativo para su creación e innovación, como es el caso de los medicamentos, los autos, los aviones, etcétera. La segunda categoría se relaciona con las herramientas empleadas para crear conocimiento y productos derivados del conocimiento, como por ejemplo las herramientas, técnicas y métodos de investigación científica y tecnológica, o el software, Internet y otras tecnologías de información y comunicación. El tercer tipo se vincula con la información en cualquiera de sus variedades, entendida como el insumo indispensable para difundir el conocimiento, así como para producir nuevo conocimiento. El cuarto elemento es el conocimiento en sí (Benkler, 2006: 311-315).

Por otra parte, el término acceso, en acceso al conocimiento, implica que la finalidad esencial no es incrementar el conocimiento en cualquiera de sus cuatro facetas, sino que lo más importante es lograr una distribución justa y equitativa a través del mundo, a la par de fomentar en las personas las habilidades y oportunidades para usar imaginativamente las tecnologías de información, con el fin de crear, innovar y comunicarse con otros integrantes de sus 
comunidades, y contribuir con nuevo conocimiento, para un mejor desarrollo humano, una expansión de la libertad humana, en su sentido más pleno, una mayor justicia distributiva y un cumplimiento más integral de los derechos humanos (Balkin, 2010: xx).

Sin duda, el fortalecimiento del acceso al conocimiento abre nuevos horizontes y oportunidades a todas las personas, y puede concebirse simultáneamente como un requerimiento indispensable para el desarrollo humano sustentable y una demanda global de justicia y derechos humanos (Balkin, 2010: xxi). El conocimiento es un recurso de importancia fundamental para el desarrollo humano, por lo que debe promoverse su accesibilidad para poder acelerar los ciclos de innovación y generación de nuevo conocimiento, así como lograr, como un imperativo ético, una mayor equidad social a nivel mundial (Shaver, 2007: 4-6). Pero las buenas acciones emprendidas desde la perspectiva del A2K se enfrentan cotidianamente a la voracidad de las empresas de la iniciativa privada, al control por parte del gobierno, a entidades globales como la Organización Mundial del Comercio (OMC), quienes a través de diversos mecanismos a escala local y planetaria, como por ejemplo leyes globales de propiedad intelectual altamente coercitivas, limitan significativamente el acceso al conocimiento en cualquiera de sus cuatro categorías previamente explicadas (Krikorian, 2010a: 69).

Por ejemplo, en el caso de la industria farmacéutica vía la exclusividad de patentes, se ofrecen muchos medicamentos (productos derivados del conocimiento) a precios desmedidamente altos, absolutamente distantes de sus costos de investigación y de producción, sin considerar el bienestar social y económico de las poblaciones, sino sólo sus ganancias. Esto ha provocado el crecimiento de nuevos movimien- 
tos sociales, de fuerte presencia a nivel internacional, que reclaman un acceso más justo a las medicinas, los cuales forman parte del $\mathrm{A} 2 \mathrm{~K}$; tan es así que varias de las primeras reivindicaciones del $\mathrm{A} 2 \mathrm{~K}$ provienen de esta esfera, exigiendo, por ejemplo, el derecho (entendido como un derecho humano) al acceso a copias económicas, vía versiones genéricas libres de propiedad intelectual, de los medicamentos necesarios para combatir el sida (Kapczynski, 2010: 37). Las siguientes contribuciones, incluidas en el libro Access to knowledge in the age of intellectual property (Krikorian, 2010), nos dan una idea del tipo de temáticas tratadas: "The revised drug strategy: access to essential medicines, intellectual property, and the World Health Organization" (Hoen, 2010), "The Doha declaration on TRIPS and public health: an impetus for access to medicines" (Shashikant, 2010), "New medicines and vaccines: access, incentives to investment, and freedom to innovate" (Gombe, 2010).

En cuanto a las herramientas para crear conocimiento y productos derivados del conocimiento, podemos notar, por un lado, el enorme potencial económico y grandes ganancias que representa la industria del software propietario y cómo, por otro lado, el movimiento de software libre va ganando cada vez más terreno, ofreciendo alternativas adecuadas para diferentes sectores de la actividad humana: educación, ciencia, gobierno, etcétera. También podemos observar, por ejemplo, cómo la industria de la investigación genética, por medio del desarrollo de técnicas científicas sofisticadas, pretende patentar diversos segmentos del ADN humano, o por medio de la manipulación genética ha creado semillas transgénicas, con efectos negativos para la agricultura tradicional; todo ello con la finalidad principal de obtener ganancias multimillonarias, moviendo además bienes comunes de la naturaleza a la esfera privada (Boyle, 
2003). Asimismo, en lo que concierne al uso de tecnologías de información, resulta revelador del espíritu de nuestros tiempos la disyuntiva entre control de la información por parte de las grandes corporaciones y los gobiernos versus la apertura a todo el mundo de información clasificada de esas entidades, como lo ha mostrado claramente Wikileaks, cuya figura más emblemática es Julian Assange, quien en una entrevista de junio de 2013, entre otros aspectos, destacaba que uno de los principales aportes de Wikileaks ha sido politizar la red, cambiar el sistema de conocimientos y el flujo de información, así como revelar las grandes mentiras del establishment mundial (Assange, 2013).

En lo que concierne a la información, elemento vital de la economía de la sociedad red, bien sabemos que por medio de crecientes restricciones en materia de copyright y otros mecanismos, obtenerla, usarla y compartirla resulta cada vez más caro, complicado o legal y tecnológicamente imposible. Afortunadamente se han desarrollado modelos alternativos que permiten abrir los flujos de información y la cultura, para disfrute de todos, mediante sistemas de acceso abierto (open access), datos abiertos, copyleft, bienes comunes creativos, recursos educativos abiertos, entre otros bienes comunes de información.

En lo que respecta al conocimiento por sí mismo, resulta evidente que todas las tendencias restrictivas o de apertura que se den en cualquiera de las otras tres categorías, causan un impacto directo en la difusión y producción de conocimiento, con efectos negativos o positivos para el bienestar humano. Pero no debemos perder de vista que las sociedades serán mejores y más libres en la medida en que más personas estén educadas, informadas y cuenten con acceso irrestricto al conocimiento y a la cultura (Balkin, 2010: xix). 
Ahora bien, el movimiento A2K, y dentro de éste los bienes comunes de información, requieren construir un discurso que lo legitime en las esferas política, ideológica y jurídica de la convivencia humana. En tal contexto, un concepto central es el de dominio público.

En el plano jurídico, tradicionalmente se ha entendido que el dominio público abarca los recursos de información y las obras intelectuales que no están sujetos a propiedad intelectual (patentes o copyright), ya sea porque los derechos de exclusividad han expirado o porque son bienes intangibles no sujetos a propiedad intelectual, como sucede en el caso de las leyes, o de la mayor parte de la información gubernamental. También tradicionalmente, el dominio público se conceptúa como lo opuesto o la cara negativa de la propiedad intelectual. Pero en el marco del A2K, una tendencia clara es reinventar (Boyle, 2008: xv) y enriquecer (Samuelson, 2006) el concepto de dominio público, además de ampliar su influencia a las esferas política e ideológica y plantear estrategias de defensa positiva del dominio público, ante los embates del discurso y acciones provenientes del espectro normativo de la propiedad intelectual.

Para este proceso de redimensionamiento del dominio público, diversos estudios recientes han tomado como base el trabajo pionero de David Lange (1981), quien, como una respuesta lúcida a la ampliación creciente de la protección a la propiedad intelectual y de los bienes a incluir (muchos de ellos anteriormente considerados bienes públicos), efectuada en Estados Unidos durante la década de los sesenta y setenta, afirma que dicha ampliación irresponsable, que va en detrimento de la sociedad, debe tener un límite. Al reinterpretar el dominio público, Lange argumenta que así como se reconocen los intereses de la propiedad intelectual, en la misma medida deben reconocerse los derechos individuales 
y colectivos para acceder, usar y compartir bienes que se ubican en el dominio público. Es decir, destaca que ningún interés exclusivo puede tener un reconocimiento positivo, a menos que su contraparte conceptual también la tenga.

Este argumento crucial es retomado como una eje fundamental por parte del $\mathrm{A} 2 \mathrm{~K}$, de tal manera que el gran aporte radica entonces en valorar el dominio público como un universo de recursos de información y del conocimiento que coexiste junto con el de la propiedad intelectual, y no como algo residual o excluyente, convirtiéndose en un componente imprescindible para la creatividad, la innovación y el acceso al conocimiento (Kapczynski, 2010: 30) y como el espacio en que construimos socialmente las piezas fundamentales de nuestra cultura (Boyle, 2008: 38).

Una segunda perspectiva de gran transcendencia en la reinterpretación del dominio público se relaciona con enfatizar el valor social y público que el concepto implica. De esta manera el dominio público se consolida como una categoría ética, de derechos humanos, justicia distributiva y de libertad, que se opone al dominio privado, privilegiando sobre todo el bien común.

Un tercer enfoque, que concuerda con los principios fundamentales del movimiento A2K, consiste en definir el dominio público como el conjunto de datos, información, descubrimientos e invenciones científicas y tecnológicas, y obras del intelecto humano, que están abiertos y libres para todos, sin tener que pedir permiso y sin tener que pagar por usarlos, compartirlos, derivar otras creaciones, etcétera (Kapczynski, 2010: 31-32). En este espectro ampliado del dominio público se hallan los sistemas de acceso abierto (open access), los sistemas de datos abiertos, los sistemas de recursos educativos abiertos, los sistemas wiki, el soft- 
ware libre, etcétera, amparados mediante licencias tipo copyleft, creative commons, entre otras.

En síntesis, mientras los regímenes de propiedad intelectual se basan en una cultura del permiso y del lucro, las nuevas perspectivas del dominio público se apoyan en una cultura de libertad y del bien común, con la meta de contribuir en la construcción de sociedades más libres, abiertas, justas y democráticas.

El principio fundamental que guía todo este complejo proceso de integración es que para cumplir con sus objetivos esenciales el A2K necesita resignificar y recuperar, hasta donde sea posible, los bienes de información y conocimiento que están sujetos a propiedad intelectual, trasladándolos al dominio público mediante modelos de producción, gobierno, propiedad y gestión basados en las comunidades, en las redes de infodiversidad y en el interés público.

Tal tendencia integradora emergente es perentoria debido a que en las últimas dos décadas uno de los efectos notables de la globalización es que los derechos de propiedad intelectual se han incrementado (al cubrir más tipos de información y de productos, herramientas, técnicas, etcétera, derivados del conocimiento, muchos de ellos concebidos previamente como bienes públicos); se han profundizado (al darse mayores derechos a sus poseedores o al ampliarse significativamente la vigencia de la exclusividad); son más punitivos (al imponerse mayores castigos, penas y multas y al criminalizarse diversos actos de aparente violación a tales derechos, tanto a nivel individual, institucional e incluso naciones enteras); y tienen alcance mundial, cuando hasta hace poco el ámbito era estrictamente nacional, respetándose la soberanía de cada Estado-nación.

Esta radicalización restrictiva de la propiedad intelectual tiene su punto culminante en el Acuerdo sobre los Aspec- 
tos de los Derechos de Propiedad Intelectual relacionados con el Comercio (1994) (Acuerdo sobre los ADPIC, en inglés TRIPS: Agreement on Trade Related Aspects of Intellectual Property Rights), el cual es el Anexo 1C del Convenio por el que se crea la Organización Mundial del Comercio (OMC). En este acuerdo internacional se delimita un conjunto de principios básicos sobre propiedad intelectual, de cumplimiento obligatorio para todos los países miembros de dicha entidad. De no cumplirse, se establecen sanciones para las naciones.

Al respecto, es importante tomar en cuenta el hecho histórico de que las primeras legislaciones relacionadas con la propiedad intelectual (por ejemplo el Estatuto de la reina Anna (1710), sobre copyright) se basaron en la idea fundamental de proteger los derechos de la sociedad, mediante la creación de un sistema concebido para alimentar el dominio público (otorgando derechos temporarios y con límites estrictos a los autores y casas editoriales, como una manera de incentivar la creatividad), con el objetivo primordial de fomentar el libre acceso. En esa época el dominio público era la figura principal, lo prioritario, mientras que los derechos de autor el fondo, el complemento (Boyle, 2003).

Tal contraste histórico nos evidencia que con el paso del tiempo la idea original de elaborar normas legales vinculadas con la propiedad intelectual para proteger los intereses de la sociedad se fue pervirtiendo, en aras del beneficio de la iniciativa privada y las grandes corporaciones.

El paradigma integrador del A2K y el dominio público busca recobrar ese espíritu primigenio, con la meta esencial de conceptuar a la información y al conocimiento como bienes públicos, indispensables para una mayor creatividad, innovación, así como una aceleración de los ciclos sociales de creación y desarrollo de información, conocimiento y 
Apertura radical y los movimientos sociales de acceso abierto...

cultura, a través de múltiples redes de infodiversidad, actuantes en todas las esferas del quehacer humano.

\section{REFERENCIAS BIBLIOGRÁFICAS}

Access Info Europe (España) y Centre for Law and Democracy (Canadá) (2015), Global right to information rating [en línea], http://www.rti-rating.org/index.php

Acuerdo sobre los Aspectos de los Derechos de Propiedad Intelectual relacionados con el Comercio (1994), Ginebra, Organización Mundial del Comercio [en línea], http://www.wto.org/spanish/ docs_s/legal_s/27-trips.pdf

Argentina (2013), Ley 26899: creación de repositorios digitales institucionales de acceso abierto, propios o compartidos [en línea], http://repositorios.mincyt.gob.ar/recursos.php

Assange, Julian (2013), Entrevista concedida a La Jornada (en dos partes), realizada por Pedro Miguel, La Jornada, México, D.F., 12 y 13 de junio de 2013.

Balkin, Jack (2010), "Foreword", en Nagla Rizk y Lea Shaver (Editors) (2010), Access to knowledge in Egypt: new research in intellectual property, innovation and development (pp. xix-xxi), London, Bloomsbury Academic.

Bauwens, Michel (2005), The political economy of peer production [en línea], http://www.ctheory.net/articles.aspx?id=499

Benkler, Yochai (2006), The wealth of the networks: how social production transforms markets and freedom, New Haven, Yale University Press.

Berners-Lee, Tim (2000), Tejiendo la red, Madrid, Siglo XXI Edit.

Bollier, David y Watts, Tim (2002), Saving the information commons: a public interest agenda in digital media, Washington, DC, New America Foundation \& Public Knowledge. 
Boyle, James (2003), El segundo movimiento de cercamiento y la construcción del dominio público [en línea], http://www.arielvercelli.org/documentos/E2MDCYLCDDP-BOYLE.pdf

Boyle, James (2008), The public domain: enclosing the commons of the mind, New Haven, Yale University Press.

Castells, Manuel (1999), La sociedad red, México, Siglo XXI Edit.

Castells, Manuel (2001), La galaxia internet: reflexiones sobre internet: empresa y sociedad, Barcelona, Areté.

Contreras, Pau (2003), Me llamo Kohfam: identidad hacker, una aproximación antropológica, Barcelona, Gedisa.

Coursera (plataforma interinstituconal de cursos en línea masivos y abiertos, MOOC) (2015) [en línea], https://www.coursera.org/

Cribb, Julian y Sari, Tjempaka (2010), Open science: sharing knowledge in the global century, Collingwood, Victoria [Australia], CSIRO Publishing.

España (2007), Ley 37/2007, de 16 de noviembre, sobre reutilización de la información del sector público [en línea], http://boe. es/buscar/pdf/2007/BOE-A-2007-19814-consolidado.pdf

Estados Unidos. Congress. Senate (2006), Federal research public access act [en línea], http://cornyn.senate.gov/doc_archive/05-02-2006_COE06461_xml.pdf

Fuchs, Christian (2010), "Theoretical foundations of defining the participatory, co-operative, sustainable information society", en Information, Communication E Society, 13, pp. 23-47.

Fundación para el Conocimiento Abierto (2012). Manual de los datos abiertos, Cambridge, Fundación para el Conocimiento Abierto. 
Apertura radical y los movimientos sociales de acceso abierto...

Gombe, Spring y Love, James (2010), "New medicines and vaccines: access, incentives to investment, and freedom to innovate", en Gaëlle Krikorian y Amy Kapczynski (Editors), Access to knowledge in the age of intellectual property (pp. 531-546), New York, Zone Books (Distribuited by The MIT University Press).

Gómez, Nancy y Bongiovani, Paola C. (2012), "Open access and A2K: collaborative experiences in Latin America", en Jesús Lau, Anna Maria Tammaro y Theo J. D. Bothma (Editors), Libraries Driving Access to Knowledge (pp. 343-372), Berlin, De Gruyter.

Hess, Charlotte y Ostrom, Elinor (Editors) (2007), Understanding knowledge as a commons: from theory to practice, Cambridge, Massachusetts, The MIT Press.

Hoen, Ellen (2010), "The revised drug strategy: access to essential medicines, intellectual property, and the World Health Organization", en Gaëlle Krikorian y Amy Kapczynski (Editors), Access to knowledge in the age of intellectual property (pp. 127-140). New York, Zone Books (Distribuited by The MIT University Press).

Kapczynski, Amy. (2010), "Access to knowledge: a conceptual genealogy", en Gaëlle Krikorian y Amy Kapczynski (Editors), Access to knowledge in the age of intellectual property (pp. 17-56), New York, Zone Books (Distribuited by The MIT University Press).

Katsirikou, Anthi (Editor) (2011), Open access to STM information: trends, models and strategies for libraries, Berlin, De Gruyter Saur.

Krikorian, Gaëlle y Kapczynski, Amy (Editors) (2010), Access to knowledge in the age of intellectual property, New York, Zone Books (Distribuited by The MIT University Press). 
Krikorian, Gaëlle (2010a), "Access to knowledge as a field of activism”, en Gaëlle Krikorian y Amy Kapczynski (Editors), Access to knowledge in the age of intellectual property (pp. 57-95), New York, Zone Books (Distribuited by The MIT University Press).

Lange, David (1981), "Recognizing the public domain", en Law and Contemporary Problems, 44 (4), pp. 147-178.

Lessig, Lawrence (2005), Por una cultura libre: cómo los grandes grupos de comunicación utilizan la tecnología y la ley para clausurar la cultura y controlar la creatividad, Madrid, Traficantes de Sueños [en línea], http://www.traficantes.net/sites/ default/files/pdfs/Por\%20una\%20cultura\%20libre-TdS.pdf

Meier, Andreas (2012), eDemocracy \& eGovernment: stages of a democratic knowledge society, Berlin, Springer.

México (2002), "Ley federal de transparencia y acceso a la información pública gubernamental", en Diario Oficial de la Federación, 11 de junio de 2002 [en línea], http://www.diputados. gob.mx/LeyesBiblio/pdf/244_140714.pdf

México. Secretaría de Educación Pública (2014), "Decreto por el que se reforman y adicionan diversas disposiciones de la Ley de ciencia y tecnología, de la Ley general de educación y de la Ley orgánica del Consejo Nacional de Ciencia y Tecnología”, en Diario Oficial de la Federación, 728 (15), martes 20 de mayo de 2014, edición vespertina, 2-6 [en línea], http://www. dof.gob.mx/index.php?year $=2014 \&$ month $=05 \&$ day $=20$

Organización para la Cooperación y Desarrollo Económicos. Centro para la Investigación y la Innovación Educativas (2010), Trends shaping education, 2010, París, OECD.

Ostrom, Elinor (2011), El gobierno de los bienes comunes: la evolución de las instituciones de acción colectiva, México, Fondo de Cultura Económica. 
Apertura radical y los movimientos sociales de acceso abierto...

Pérez González, Lourdes (2012), Ciencia en abierto en el LHC (CERN): discursos proclamados y conductas, Tesis, Maestría, Estudios de Humanidades y Filología, Universitat Oberta de Catalunya.

Perú (2013), Ley que regula el repositorio nacional digital de ciencia, tecnología e innovación de acceso abierto [en línea], http://www2.congreso.gob.pe/sicr/comisiones/2012/com2012ciencia.nsf/0/cb7c863ded37261e05257b3b007c029c/\$FI LE/1188_Sustitutoria_27MAR2013.pdf

Samuelson, Pamela (2006), "Enriching discourse on public domains", en Duke Law Journal, 55, pp. 783-834.

Shashikant, Sangeeta (2010), "The Doha declaration on TRIPS and public health: an impetus for access to medicines", en Gaëlle Krikorian y Amy Kapczynski (Editors), Access to knowledge in the age of intellectual property (pp. 141-159), New York, Zone Books (Distribuited by The MIT University Press).

Shaver, Lea (2007), "Defining and measuring access to knowledge: towards an A2K index", en Faculty Scholarship Series (Yale Law School), paper 22.

Tapscott, Don y Williams, Anthony D. (2013), Radical openness: four unexpected principles for success, New York, Ted Books.

Tejerina, B. (2003), Multiculturalismo, movilización social y procesos de construcción de la identidad en el contexto de la globalización, Universidad del País Vasco, Facultad de Ciencias Sociales y de la Comunicación, Departamento de Sociología [en línea], http://www.ces.fe.uc.pt/publicacoes/oficina/187/187.pdf

Turow, Joseph y Tsui, Lokman (Editors) (2008), The hyperlinked society: questioning connections in the digital age, Ann Arbor, University of Michigan Press / University of Michigan Library 
Vaidhyanathan, S. (2004), The anarchist in the library: how the clash between freedom and control is hacking the real world and crashing the system, New York, Basic Books.

Vessuri, Hebe (2011), "Impacto del acceso abierto (open access) en la educación superior en América Latina y el Caribe”, en $E d u$ cación Superior y Sociedad, 16 (2) [en línea], http://ess.iesalc. unesco.org.ve/index.php/ess 


\title{
Las bibliotecas digitales y el acceso al conocimiento
}

\author{
JESÚS FrANCISCO GARCÍA PÉREZ \\ Universidad Nacional Autónoma de México
}

\section{INTRODUCCIÓN}

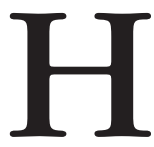

oy presenciamos el avance más vertiginoso en la era de las telecomunicaciones, pues Internet ha permitido que un sinnúmero de personas y bibliotecas en todo el planeta compartan, difundan y produzcan obras en colaboración con un gran número de personas con el propósito de ponerlas a su disposición vía red. Esta afirmación presupone que cualquier persona, desde cualquier lugar del planeta, si cuenta con el equipo de cómputo idóneo, podrá tener acceso a documentos e información diseminada en redes de teleproceso y que, en muchas ocasiones, podrá apropiarse de esta información indebidamente a pesar de que en la realidad virtual pertenece a otra persona. "Evidentemente, los autores de obras intelectuales ven reflejada en la red una oportunidad única para promocionar, publicar y difundir sus obras al menor costo (o sin ningún costo en muchos casos) y con el mayor alcance posible. Sin embargo, 
¿habrán advertido los riesgos en que incurren al no proteger celosamente sus obras?"1

La historia la hace la sociedad, y la biblioteca en general ha representado un papel primordial en sus teorías y en las formas de gobierno, que a través de los años han quedado plasmadas en libros que hoy podemos consultar en las bibliotecas.

La selección de documentos, la sistematización y recuperación como actividades básicas de las bibliotecas, constituyen tareas que apoyan de manera importante a los sistemas educativos y a los sistemas de la investigación científica y humanística. Estos aspectos son quizá los que convierten a las bibliotecas en un común denominador para tener acceso al conocimiento.

La proliferación de información en el medio virtual ha suscitado diversas problemáticas entre las que se destacan:

- La difusión masiva de documentos sustentados en la tecnología virtual y digital.

- La cantidad de información que circula, en ocasiones, tiene poca calidad de contenido, lo cual repercute en la selección de documentos no relevantes para la investigación y la educación.

- Con la utilización de las TIC, las bibliotecas utilizan una red de telecomunicaciones para lograr su interconexión y lograr presentarles a los usuarios una vista unificada de sus colecciones y recursos disponibles.

Si retomamos el concepto tradicional del derecho de autor, se observa que las raíces del término procedían y se referían a la tecnología analógica, que permitía reproduc-

1 Erica Baum (2000), "Argentina: derechos de autor en internet: un dilema no resuelto", p. 1. 
ciones en las que su menor precio se compensaba con la inferior calidad en relación con el original, las fotocopias.

Estas situaciones de reproducción para los derechos de autor en el entorno virtual, la incorporación a la red y la rápida propagación de las redes y autopistas de la información, hacen posible, entre otras cosas, que la información que se trasmite por la autopista y que se obtiene por medio de copia tenga igual o mejor calidad que el original.

\section{LAS TECNOLOGÍAS DE LA INFORMACIÓN Y LA COMUNICACIÓN}

Respecto a las problemáticas que presentan las Tecnologías de la Información y la Comunicación (en adelante, TIC) en el entorno digital, podemos destacar las nuevas formas de explotación que se han dado de las obras registradas como propiedad intelectual. Las TIC y los avances tecnológicos que se desarrollan constantemente representan nuevas problemáticas en los entornos bibliotecológicos, en el de desarrollo de colecciones, en las bibliotecas digitales y en las legislaciones en el ámbito internacional. 
Figura 1

Elementos de la red global y el desarrollo de colecciones digitales

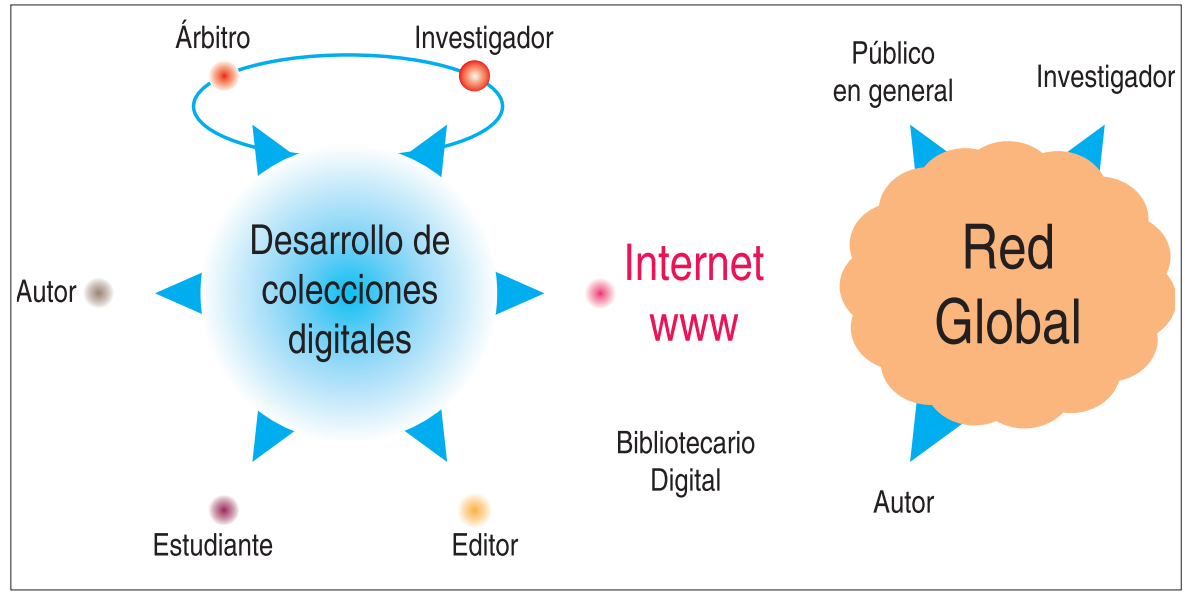

Como se observa en la Figura 1, las TIC y los entornos tecnológicos digitales y virtuales están transformando la vida laboral, la organización de las empresas y la sociedad en su conjunto. Las empresas editoriales y de la información (bibliotecas) deberán dejar de ser organizaciones jerarquizadas y complejas para convertirse en organizaciones descentralizadas y comunicadas en redes con puestos de trabajo más complejos. Las empresas de más éxito combinan, en un planteamiento integrado, las TIC con la educación, la formación y la transformación organizativa.

Las redes digitales y virtuales, consecuencia de la combinación entre la informática y las telecomunicaciones, no sólo son una novedosa herramienta para la transmisión de datos e información, sino que marcaron el inicio de una nueva sociedad, la denominada sociedad de la información, lo que está originando y generando alteraciones en las relaciones económicas, políticas, sociales y culturales.

Lo anterior se refiere a un aspecto globalizador, el cual se relaciona con las tendencias del mundo actual en cuanto a 
eliminar barreras de comunicación para "facilitar los flujos de información"; esto impulsado principalmente por la tecnología electrónica, la informática y las telecomunicaciones.

En esta era virtual, digital y de telecomunicaciones, en que la información de bases de datos, el manejo e incorporación del documento digital y la revista electrónica e Internet apuntan hacia una nueva visión, conceptualización e impulso de las bibliotecas digitales, los derechos de autor y el acceso al conocimiento toman nuevas vertientes en sus procedimientos y modos de ejecución; por ejemplo: fundamentan la importancia para que los desarrollos tecnológicos aplicados en los sistemas de información sean analizados y estudiados desde la perspectiva bibliotecológica, haciendo posibles las gestiones y adecuaciones necesarias frente al derecho de autor, los modelos de acceso en yuxtaposición a la protección electrónica de los derechos.

Dentro de los aspectos que afectan el libre acceso, la reproducción y la distribución de los documentos en Internet, se encuentra el que emana de los derechos de autor. La cesión de derechos entre el autor y el editor es un convenio entre dos partes en las que se establecen los términos de reproducción, distribución, uso de la publicación y la normal explotación de la misma. Sin embargo, para que el autor pueda disponer y hacer uso de sus derechos patrimoniales en lo que respecta a sus trabajos publicados, es necesario que esos derechos queden en manos del autor o de instituciones públicas, con miras a crear repositorios institucionales ${ }^{2} \mathrm{o}$ páginas web personales, donde el autor podrá disponer de sus documentos.

2 Recomendación hecha por el Open Archives Initiative; el término repositorio se entiende como un archivo donde se almacenan recursos digitales. 


\section{LAS BIBLIOTECAS VIRTUALES}

Para Torres, el concepto y la terminología de biblioteca $d i$ gital, "[...] se ha utilizado frecuentemente como sinónimo de biblioteca virtual, sobre todo en los últimos años. Es común ver en la literatura especializada que se hace referencia de manera indistinta a una y otra expresión sin dar una idea clara sobre ellas." 3 Por ello, analiza el concepto de biblioteca virtual, y destaca como características principales, las siguientes:

- Puede entenderse como una colección digital de materiales no libros, o como una colección digitalizada de una biblioteca o que está en proceso de digitalización.

- Toda la información que contienen las bibliotecas digitales está en formato digital. Junto con la información textual puede contar con información no textual (fotografías, dibujos, ilustraciones, obras de arte), datos numéricos (información satelital, cosmológica), sonidos digitalizados, representaciones multidimensionales e imágenes en movimiento, todo ello integrado.

- No contienen libros convencionales. Los tipos de publicaciones que posee son libros y publicaciones electrónicas que están organizados sistemáticamente.

- La Association of Research Libraries afirma que las colecciones de la biblioteca digital no están limitadas a los documentos impresos, sino que abarcan también a los documentos digitales que no pueden ser representados o distribuidos en formato impreso. Para la Association Ressearch Libraries (ARL), la biblioteca digital no es una sola entidad o biblioteca, requiere de tecnología para integrar diferentes recursos y tiene como meta el acceso universal.

- Para acceder a la información digital es necesario usar medios especiales. Puede tener acceso a ella de manera remota, vía teléfono o módems, por medios computadorizados y redes de comunicación.

3 Georgina Araceli Torres Vargas (2000), La biblioteca virtual: ¿qué es y qué promete?, p. 22. 
- La biblioteca digital es una biblioteca tradicional que cuenta con terminales para que los usuarios tengan acceso a los servicios de consulta en red $[\ldots]^{4}$

\section{Cuadro 1}

Comparativo entre bibliotecas tradicionales y bibliotecas digitales

\begin{tabular}{|l|l|}
\hline \multicolumn{1}{|c|}{ Bibliotecas digitales } & \multicolumn{1}{c|}{ Bibliotecas tradicionales } \\
\hline Ocupan un espacio virtual & Ocupan muchos estantes \\
\hline Son de acceso rápido a los libros & $\begin{array}{l}\text { Hay que buscar los libros demorando así su } \\
\text { acceso }\end{array}$ \\
\hline $\begin{array}{l}\text { Son accesibles desde cualquier parte del } \\
\text { mundo }\end{array}$ & $\begin{array}{l}\text { Sólo son accesibles desde el punto donde se } \\
\text { encuentra el libro }\end{array}$ \\
\hline No cuenta con una sala de lectura & Cuenta con una sala de lectura \\
\hline
\end{tabular}

Para fines de este trabajo, se utilizará el término biblioteca digital, ya que lo virtual alude y se refiere al:

[...] uso de tecnología de realidad virtual (RV), que permite la simulación o creación de mundos ficticios a través de la computadora. Los individuos pueden meterse y quedar totalmente inmersos en estos mundos a través de herramientas tecnológicas especiales. La interacción con ese mundo ficticio puede logarse mediante el uso de guantes, sensores, audífonos y gafas cuyos efectos especiales reproducen los del tacto, oído y la vista de quien los utiliza [...] La utilización de la RV va desde la alta tecnología hasta los videos juegos virtuales, sin olvidar las aplicaciones en la medicina, la aeronáutica y el arte, entre otras. ${ }^{5}$

Asimismo, debemos tomar en consideración que el uso, desarrollo y utilización dentro del contexto bibliotecológico de bibliotecas virtuales (BV), debido a los altos costos que implica la tecnología requerida, impide, entre otros aspectos, su proyección y utilización a gran escala. En la bibliotecología ha encontrado aplicación en la "[...] simulación de los recursos bibliotecarios y del edificio mismo.

$4 \quad$ Ibid., pp. 22-23.

5 Ibid., pp.30-31. 
De esta forma la biblioteca de realidad virtual se refiere a la representación por medio de una interface virtual y espacial de aquello que constituye la biblioteca en particular. Mediante esta representación el usuario puede simular un viaje a través de ella y recorrer tanto el edifico que alberga a las colecciones, como acceder a las mismas y revisar los documentos." ${ }^{\prime 6}$ Hasta el momento no se ha desarrollado y presenta problemáticas conceptuales y de perfeccionamiento en su implementación.

Bajo esta premisa, el entorno digital ha propiciado que quien tiene acceso a las TIC pueda publicar lo que escribe y las editoriales retomen perspectivas diferentes en cuanto a la venta, distribución y disponibilidad de los libros electrónicos. Las facilidades de difundir, publicar y reutilizar documentos que conlleva la www, y la transmisión de la obra, debilitan y ponen en riesgo diversos aspectos como lo referente al desarrollo de colecciones y los derechos de autor en ese entorno de virtualidad.

Está claro que la tecnología afecta a nuestros sistemas bibliotecarios tradicionales y más aún a las de bibliotecas digitales, y el conocimiento no puede ser una excepción. Desde hace años, muchas de las instituciones educativas más importantes del mundo, y también asociaciones y colectivos de diversos rangos, luchan por conseguir la digitalización de grandes obras, artículos y contenidos que sirven de apoyo a la educación e investigación en todos los niveles. Los proyectos de bibliotecas digitales se perfilan como una de las grandes novedades que nos aporta la red y también como uno de los instrumentos que nos ayudará a universalizar el conocimiento. Estas bibliotecas no sólo deberán percibirse y definirse como entendidas y simples bases de datos, sino como herramientas que facilitan a instituciones

6 Ibíd. 
de toda índole el acceso al conocimiento desde todas las partes del mundo y al mayor número de obras posibles.

\section{EL ACCESO AL CONOCIMIENTO Y LOS DERECHOS DE AUTOR EN LAS COLECCIONES DE LAS BIBLIOTECAS DIGITALES}

Los sistemas de protección y los sistemas de gestión se han desarrollado con la finalidad de controlar el acceso, la impresión y en algunos casos la visualización de los textos completos.

Estas limitaciones y excepciones no surgen como fenómeno jurídico a partir del advenimiento de la era virtual y digital, sino que han modificado sus formas, ya que son tan antiguas como el derecho de autor. En relación con este asunto, Baum afirma que:

[...] la ausencia de una normativa específica en la materia, que logre armonizar las legislaciones de los distintos países, la tecnología está intentando cerrar este vacío legal a través del desarrollo de sistemas de gestión de los derechos de autor, más conocidos como Electronic Copyright Management Systems (ECMS) o Electronic Rights Management Systems (ERMS). ${ }^{7}$

7 Erica Baum, Op. cit., p. 1. 
Figura 2

Permisos que establecen los ECMS

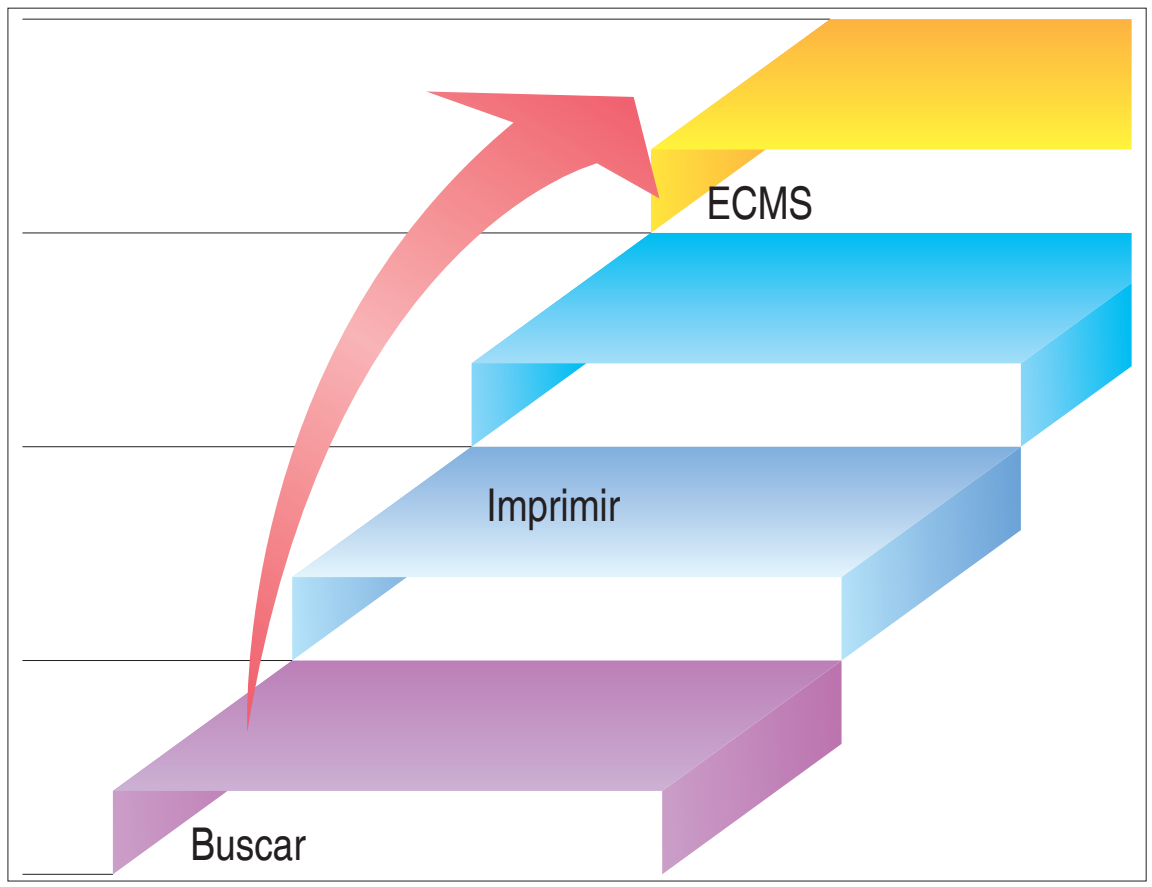

Los programas de cómputo ECMS pretenden ser una de las soluciones a las diversas inquietudes sobre los problemas del desarrollo de colecciones virtuales, acceso al conocimiento y los derechos de autor y, así, sistematizar los procesos de gestión de información sobre documentos como control de acceso, comunicación con el autor y disponibilidad de información.

Surgen en forma paralela a la denominada biblioteca digital, principalmente en los Estados Unidos, y resulta interesante vislumbrar cómo es que estas bibliotecas regularán los problemas de propiedad intelectual [...] Un gran debate tuvo lugar en los Estados Unidos y Europa sobre si se debe reforzar la legislación, o 
incluso crear nuevas leyes, o si se deben desarrollar y utilizar los ECMS como una manera natural de imponer el derecho de autor. ${ }^{8}$

Para Hassan Montero los ECMS "[...] son sistemas informáticos cuya función es controlar y, en caso de que sea necesario, impedir o restringir el uso que se hace de las obras protegidas, rastreando para ello la red". La OMPI los define como:

[...] sistemas tecnológicos en línea que posibilitan la gestión, explotación y observancia del derecho de autor [...] los ECMS establecen permisos sobre las obras (leer, imprimir, modificar, copiar, etc.), y en caso de que se concedan dichos permisos, controlan el uso que se hace de éstos, por ejemplo: controlando el número de copias que se realizan para que no superen el límite permitido.?

En este sentido, entidades de carácter público y privado han incidido en diversos proyectos y productos; sin embargo, hasta nuestros días el control de datos vía red, tanto de parte de autores como de usuarios, no ha sido resuelto. En consecuencia, esta situación dificulta a las bibliotecas digitales regular la problemática de la propiedad intelectual. Por lo tanto, quedan muchas acciones por realizar, a pesar de la importante labor de organizaciones internacionales como la OMPI respecto a este asunto. Algunas de las ventajas de los ECMS radican en que:

- Los autores obtienen estadísticas sobre la lectura/búsqueda de sus obras en tiempo real.

- Representan una fuente de ingreso para los autores.

8 Pedro Isaias, "Sistemas electrónicos de gestión de derechos de autor: aspectos a considerar" [en línea].

9 Yusef Hassan Montero (2001), ECMS: Sistemas Electrónicos de Gestión del Derecho de Autor [en línea]. 
- Representan en ciertos casos un incentivo para no realizar copias.

- Se tiene un estricto control de acceso.

Algunas desventajas radican en:

- Restricción en la recuperación y acceso a documentos y contenido.

- Gastos de hardware y software.

Por lo anterior, es importante tomar en consideración que el material cuyo estatus de derechos de autor no ha sido aclarado no se deberá incluir en la colección digital. Aun cuando se puede cumplir con todos los demás criterios para lo que sería, potencialmente, una colección exitosa, si la biblioteca no ha resuelto totalmente las cuestiones de propiedad intelectual, no se puede lanzar la colección al público. Hablando estrictamente, si la biblioteca ignora las cuestiones de propiedad intelectual se podrían estar llevando a cabo actividades ilegales.

LEYES DE DERECHO DE AUTOR NACIONALES Y COLECCIONES DIGITALES

Cada país tiene sus propias leyes de derechos de autor; así pues, la forma específica en que las leyes de derechos de autor impactarán la capacidad de una biblioteca de crear colecciones digitales variará de país a país. Además, las leyes de derecho de autor cambian frecuentemente, y la interpretación que por parte de las juristas se pueda hacer sobre las leyes de derecho de autor en cada país, dificulta que se pueda generalizar acerca de los derechos de autor. 
"En la mayoría de los casos, la ubicación de la biblioteca y no la ubicación de origen de la obra o de su publicación, determina la jurisdicción." ${ }^{10}$ Jordan $^{11}$ reliza un cuadro muy interesante en el cual ejemplifica e ilustra algunos aspectos relevantes que deben considerar las bibliotecas en cuanto a los derechos de autor se refiere. Presenta la comparación de tres países: Gran Bretaña, Estados Unidos y Canadá (como aporte se adiciona México). En el Cuadro 2, se comparan tres aspectos de las legislaciones de dichos pases que, considera el autor, deben de tomarse en consideración cuando se tienen proyectos para desarrollar colecciones digitales.

- Periodo. La cantidad de tiempo que una obra está protegida por los derechos de autor. Dentro de la ley de una nación, varios factores determinan la duración de la protección de derechos de autor.

- Trato justo y uso justo. Trato justo define los usos específicos a los que se puede someter una obra bajo la protección de derechos de autor, sin el permiso explícito del dueño de dichos derechos de autor, y está definida en las leyes de derechos de autor de Gran Bretaña, Canadá y otros países. Uso justo es el equivalente en los Estados Unidos, pero es menos específico que el trato justo.

- Obras huérfanas. Trabajos cuyos estatus de derechos de autor es difícil o imposible de determinar, porque el creador es desconocido o no puede encontrarse.

10 Mark Jordan (2006), Putting content online: a practical guide for libraries, p. 38.

11 Ibíd., pp. 39-40. 


\section{Cuadro 2}

Resumen comparativo de periodo, trato justo/uso justo y obras huérfanas en las leyes de derecho de autor de Gran Bretaña, Estados Unidos,

Canadá y México

\begin{tabular}{|c|c|c|c|c|}
\hline & Gran Bretaña & Estados Unidos & Canadá & México \\
\hline 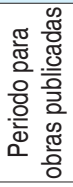 & $\begin{array}{l}70 \text { años después } \\
\text { de la muerte del } \\
\text { autor. }\end{array}$ & $\begin{array}{l}70 \text { años después de la } \\
\text { muerte del autor. }\end{array}$ & $\begin{array}{l}50 \text { años después de la } \\
\text { muerte del autor. }\end{array}$ & $\begin{array}{l}100 \text { años después de la } \\
\text { muerte del autor. }\end{array}$ \\
\hline 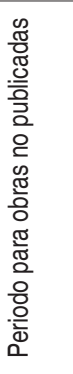 & $\begin{array}{l}\text { Hasta por lo } \\
\text { menos } 2039 .\end{array}$ & $\begin{array}{l}\text { Igual que para obras } \\
\text { publicadas. }\end{array}$ & $\begin{array}{l}\text { Si el autor murió antes } \\
\text { de 1948, la obra es del } \\
\text { dominio público; si el } \\
\text { autor murió entre } 1949 \\
\text { y 1998, la obra entrará } \\
\text { al dominio público en } \\
\text { 2049; si el autor murió } \\
\text { después de 1998, la } \\
\text { obra entrará al dominio } \\
\text { público } 50 \text { años des- } \\
\text { pués de su muerte. }\end{array}$ & $\begin{array}{l}\text { Igual que para obras } \\
\text { publicadas. }\end{array}$ \\
\hline 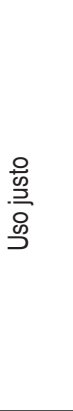 & $\begin{array}{l}\text { El uso justo } \\
\text { está limitado } \\
\text { a actividades } \\
\text { que incluyan } \\
\text { investigación y } \\
\text { estudio privado, } \\
\text { crítica; ciertos } \\
\text { usos educaciona- } \\
\text { les y representa- } \\
\text { ción pública de } \\
\text { grabaciones de } \\
\text { sonido. }\end{array}$ & $\begin{array}{l}\text { El uso justo cubre la } \\
\text { reproducción de la obra } \\
\text { para los propósitos } \\
\text { de crítica, comentario, } \\
\text { reporte de noticias, } \\
\text { enseñanza, academia } \\
\text { e investigación, pero } \\
\text { determinar si una } \\
\text { actividad está dentro de } \\
\text { los límites del Uso Justo } \\
\text { se hace por un grupo de } \\
\text { "factores" o de criterios. }\end{array}$ & $\begin{array}{l}\text { El uso justo se limita a } \\
\text { actividades que incluyan } \\
\text { investigación, estudio } \\
\text { privado y crítica. }\end{array}$ & $\begin{array}{l}\text { El uso justo se } \\
\text { limita para la crítica e } \\
\text { investigación científica, } \\
\text { literaria o artística, para } \\
\text { uso personal y privado } \\
\text { de quien la hace y sin } \\
\text { fines de lucro. }\end{array}$ \\
\hline 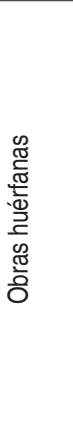 & $\begin{array}{l}\text { No se infringe el } \\
\text { derecho de autor } \\
\text { si "no es posible } \\
\text { mediante una } \\
\text { investigación } \\
\text { razonable obte- } \\
\text { ner la identidad } \\
\text { del autor" y } \\
\text { es razonable } \\
\text { asumir que dicho } \\
\text { derecho de autor } \\
\text { ha expirado. }\end{array}$ & $\begin{array}{l}\text { No hay excepciones } \\
\text { especiales; esta política } \\
\text { se está revisando. }\end{array}$ & $\begin{array}{l}\text { La licencia se puede } \\
\text { obtener del gobierno } \\
\text { federal. }\end{array}$ & $\begin{array}{l}\text { Protege las obras litera- } \\
\text { rias, artísticas, de arte } \\
\text { popular o artesanal, así } \\
\text { como todas las mani- } \\
\text { festaciones primigenias } \\
\text { en sus propias lenguas, } \\
\text { y los usos, costumbres } \\
\text { y tradiciones de la } \\
\text { composición pluricul- } \\
\text { tural que conforman al } \\
\text { Estado Mexicano, que } \\
\text { no cuenten con autor } \\
\text { identificable. }\end{array}$ \\
\hline
\end{tabular}

Tomado de Mark Jordan (2006), Op. cit., p.39. 
La gran variedad entre periodo, trato justo/uso justo y las reglamentaciones que gobiernan las obras huérfanas ilustra por qué es importante que las bibliotecas busquen la asesoría legal profesional para evaluar las cuestiones de derecho de autor. En general, una obra no puede digitalizarse o distribuirse legalmente a menos que se reciba el permiso del titular de los derechos de autor, o que el uso de la obra cumpla con ciertas condiciones para permitir su acceso y consulta.

\section{LAS BIBLIOTECAS COMO GENERADORAS DE COLECCIONES DIGITALES}

Las bibliotecas y los bibliotecólogos, al desarrollar colecciones digitales, deben tomar en consideración las excepciones legales que se especifican en las legislaciones de derechos de autor. Como es bien sabido, las leyes de derechos de autor otorgan a los poseedores del derecho patrimonial controlar la distribución de las obras; sin embargo, hay que tomar en cuenta que también los usuarios y bibliotecas tienen derechos. Por lo anterior, para desarrollar colecciones digitales, debe tomarse en consideración los aspectos señalados por Jordan. ${ }^{12}$

\section{Aspecto 1. Material de dominio público}

Comúnmente, los derechos de autor permanecen vigentes por un número específico de años. Una vez que este periodo se cumple, los derechos de autor expiran y el trabajo pasa al dominio público, lo que significa que nadie es dueño de los derechos de autor y que cualquiera puede utilizarlos. Los periodos específicos para cada país se indican en

12 Ibíd., p. 40. 
la legislación sobre derechos de autor, y pueden variar aun dentro de un mismo país, dependiendo del tipo de obra. En algunos países, ciertas obras pasan a dominio público tan pronto como son creadas.

\section{Aspecto 2. El material protegido con un acuerdo por escrito}

Si una obra está protegida por derechos de autor, las bibliotecas deben obtener el permiso del titular de los derechos de autor para digitalizar la obra. Comúnmente, este permiso es una declaración por escrito. Algunas bibliotecas crean colecciones que contienen material autorizado por los editores o editoriales.

A diferencia del contenido que los editores albergan en sus servidores y al que le da acceso a la biblioteca a través de la Red, algunos sólo aportan el contenido y la biblioteca es la responsable para subirlo a la Red (o distribuirle de alguna otra forma), para asegurar que el acceso se restrinja sólo a usuarios autorizados, y en algunos casos, para crear metadatos descriptivos o de otro tipo. El contenido común que está disponible de esta forma son fotos, archivos de audio, datos científicos crudos y estadísticos y el texto completo de revistas y de libros. En estos casos, la biblioteca firma un acuerdo de permiso con el vendedor, que le permite a la biblioteca usar el contenido en formas específicas, como hacer que el material esté disponible para usuarios remotos; en esos casos la biblioteca no tiene que obtener permiso del creador de cada trabajo individual en la colección. ${ }^{13}$

\section{Aspecto 3. Material distribuido con un permiso explícito}

Aunque los creadores siempre han sido capaces de agregar declaraciones a sus obras, tales como "Este libro es parte

13 Ibíd., pp. 41-42. 
del dominio público", en años recientes el número de permisos formales ha evolucionado para permitir a los creadores y a las editoriales especificar qué derechos se reservan y qué derechos le conceden al usuario. Sin una licencia explícita, las bibliotecas o los usuarios deben contactar al titular de los derechos de autor y obtener el permiso antes de usar las obras, sobre todo cuando se requiere digitalizar, ya que este aspecto no está contemplado. Los autores que anexan licencias explícitas ${ }^{14}$ a sus trabajos simplemente indican que los usuarios podrán hacer uso legal de sus obras en formas específicas sin necesidad de recibir un permiso por escrito.

Las licencias Creative Commons (CC) son importantes para desarrollar colecciones de bibliotecas digitales ya que los permisos permiten la redistribución de obras; así que es completamente legal para una biblioteca permitir el acceso a sus usuarios de obras bajo esta licencia, y la licencia CC define claramente qué sí y qué no puede hacer el usuario con la obra. Esto les permite a las bibliotecas evitar la necesidad de desarrollar políticas distintas sobre cómo pueden utilizarse las obras, y les permite a las bibliotecas y a los autores evitar realizar negociaciones complicadas y posiblemente de alto costo sobre lo que pueden poner en sus colecciones digitales las bibliotecas. Actualmente, pocas colecciones digitales hospedadas en servidores de bibliotecas contienen un número amplio de trabajos que se encuentren bajo los permisos de Creative Commons. Sin embargo, este tipo de permiso comienza a aparecer en los repositorios institucionales, y las herramientas para escoger los permi-

14 Desde la perspectiva y el marco internacional han existido diversas normativas que han favorecido la evolución y puesta en práctica de los derechos de propiedad intelectual, dando pie a modelos de planeación diversos en cuanto a la propiedad intelectual se refiere. Estas licencias son Creative Commns, Fair Use, Open Access y Copyleft. 
sos de Creative Commons se integran a la plataforma de repositorio institucional DSpace.

Manejar los permisos para digitalizar y distribuir el material es un componente esencial al desarrollar una colección digital. El estatus de cada objeto que una biblioteca intenta poner a disponibilidad de los usuarios debe ser clarificado, y si es necesario, el titular de los derechos debe dar permiso para que se utilice el objeto.

A continuación se presenta una serie de pasos que, según Jordan, ${ }^{15}$ se requieren para llevar a cabo lo anterior:

1. Determine el estatus de derecho de autor del objeto. Generalmente, los dos estatus serán (a) este objeto pertenece al dominio público o (b) este objeto está protegido por derechos de autor.

2. Si el objeto está protegido bajo derechos de autor, determine si el trato justo o el uso justo le permite a la biblioteca incluirlo en la colección en línea.

3. Si el trato justo o si el uso justo no tienen cabida, determine quién es el titular de los derechos de autor y contáctelo para solicitar el permiso de incluir el objeto en una colección en línea.

4. Si el dueño de los derechos de autor concede el permiso, el objeto podrá ser incluido en la colección en línea.

Existen dos elementos importantes a considerar en el desarrollo de colecciones digitales; el primero se constituye por las TPMs:

[...] las TPMs (que también se conocen como tecnologías de Manejo de Derechos Digitales, o DRM) restringen cómo se puede usar el contenido y los medios digitales. Un ejemplo común es los códigos de región que se insertan en los DVDs comerciales que, en conjunto con el reproductor, trabajan para prohibir el uso de DVDs en países en los que no se venden. Este tipo de TPM hace que los DVDs comprados en Europa sean inútiles en

15 Mark Jordan, Op. cit., pp.45-46. 
reproductores vendidos en América del Norte (siempre y cuando estos reproductores respeten los códigos de región, la mayoría de las marcas conocidas sí lo hacen). Otro ejemplo de TPMs son las características de algunos formatos de música comercial descargable, como FairPlay de Apple y el DRM de Windows Media, de Microsoft, que restringen el número de aparatos en el que se podrá reproducir la música.

La segunda cuestión de propiedad intelectual que impacta en las colecciones de bibliotecas digitales es el copyfraud. El copyfraud es cuando se declara falsamente tener los derechos de autor de trabajos que ya forman parte del dominio público. El término copyfraud viene de un artículo publicado en 2005 por Jason Mazzone, en el cual se discute que las bibliotecas, archivos, museos, editores y otras organizaciones son culpables de copyfraud cuando declaran que son los dueños de los derechos de autor de copias de una obra que es parte del dominio público. El artículo de Mazzone describe el copyfraud dentro del contexto de la ley de derechos de autor de los Estados Unidos, pero señala que "[...] como resultado de la Convención de Berna, hay muchas similitudes básicas alrededor del mundo."16

\section{¿QUÉ PUEDEN PONER EN LÍNEA LAS BIBLIOTECAS?}

Las condiciones que describe Jordan son o excepciones legales a los derechos normales de los creadores dentro de la mayoría de las leyes de las naciones, o se anteponen a las reglamentaciones de derechos de autor porque han sido cubiertas bajo un contrato legal. Las leyes de derechos de autor les da a los creadores el derecho a controlar la distribución de sus trabajos (por eso el nombre "derecho de

\section{6 Ídem.}


autor", aunque en la práctica la editorial es quien tiene esta prerrogativa), pero dándole también al usuario ciertos derechos. Las primeras dos condiciones describen los derechos de los usuarios, y las últimas dos describen los derechos de los creadores para controlar la distribución de sus trabajos.

- Trato justo y uso justo. Es difícil argumentar que el trato justo, como lo define la ley de varios países, permite la digitalización de material y su distribución a los usuarios finales, porque los usos que se identifican dentro de trato justo son relativamente explícitos: investigación, estudio privado y crítica. Una excepción importante a destacar y que se permite (bajo las leyes de muchos países) es digitalizar el material con derechos de autor sin el permiso del titular de dichos derechos para hacer que los materiales sean más accesibles para los usuarios que tengan algún tipo de discapacidad.

- Material de dominio público. Comúnmente, los derechos de autor permanecen vigentes por un número específico de años. Una vez que este periodos se cumple, los derechos de autor expiran y el trabajo pasa al dominio público, lo que significa que nadie es dueño de los derechos de autor y que cualquiera puede utilizarlos. Los periodos específicos para cada país se indican en la legislación sobre derechos de autor, y pueden variar aun dentro de un mismo país, dependiendo del tipo de obra. Las bibliotecas tienen la libertad de digitalizar el material que es del dominio público sin recibir permiso del titular original de los derechos de autor. Sin embargo, a veces es difícil determinar si el derecho de autor de una obra ha expirado, porque para la mayoría de las obras, el periodo se define por un número de años después de la muerte del autor. 
- El material protegido con un acuerdo por escrito. Si una obra está protegida por derechos de autor, las bibliotecas deben obtener el permiso del titular de los derechos de autor para digitalizar la obra (salvo en los casos trato justo y uso justo). Comúnmente, este permiso es una declaración por escrito. Algunas bibliotecas crean colecciones que contienen material autorizado por los editores. A diferencia del contenido que la editorial alberga en sus servidores y al que le da acceso a la biblioteca a través de la red, algunas editoriales sólo aportan el contenido y la biblioteca es la responsable para subirlo a la Red (o distribuirle de alguna otra forma).

- Material distribuido con un permiso explícito. Aunque los creadores siempre han sido capaces de agregar declaraciones a sus obras, tales como: "Este libro es parte del dominio público", en años recientes el número de permisos formales ha evolucionado para permitir a los creadores indicar específicamente qué derechos se reservan y qué derechos le conceden al usuario. Sin una licencia explícita, los usuarios deben contactar al titular de los derechos de autor y recibir permiso antes de usar obras de formas que no están contempladas por trato justo o uso justo. Los autores que anexan licencias explícitas a sus trabajos simplemente indican que los usuarios podrán hacer uso legal de sus obras en formas específicas sin necesidad de recibir un permiso por escrito.

\section{REFLEXIONES FINALES}

Todo indica que el nacimiento del documento digital es el punto de inicio de una trascendental etapa de trans- 
formación de la información. En sus inicios se basó en la documentación de la cultura impresa, la cual posee fundamentaciones teóricas en el valor jurídico y probatorio de documentos soportados en el formato tradicional, el papel. Sin embargo, ahora, los documentos en las redes y en los soportes virtuales y digitales conllevan a un nuevo paradigma al respecto.

Las técnicas de producción y reproducción, la impresionante proliferación de estos instrumentos y documentos en este soporte, y la necesidad de su organización y recuperación eficiente, se han transformado en un problema central a resolver por distintos motivos, entre los que se destacan:

- La necesidad de constituir estas grandes cantidades de información en pequeños archivos digitalizados, o en formato electrónico.

- Conservarlos.

- Proteger los originales.

- Garantizar su durabilidad por los lapsos establecidos en la práctica, en las regulaciones administrativas y en la legislación vigente.

- Recuperar la documentación y la información contenida en ella, en forma rápida y efectiva.

- Ponerla a disposición de los usuarios para su consulta.

Las TIC y el ingreso en la sociedad de la información repercuten ineludiblemente y de forma directa en el derecho de autor y en los derechos afines. La digitalización a todas las formas de obras literarias, musicales y audiovisuales, lleva inevitablemente a tratar cualquier obra como información desde el punto de vista objetivo y con base en la Ley Federal de Derechos de Autor vigente. 
Podemos afirmar que no existe equilibrio entre el libre acceso a la información y los derechos de autor. Los progresivos avances tecnológicos, desde la invención de la imprenta, la reprografía y los cada vez más sofisticados medios digitales, han desequilibrado las regulaciones de estos derechos en los entornos virtuales.

Por ello, el análisis y la gestión de colecciones digitales son sumamente importante para que las bibliotecas den acceso al conocimiento a sus usuarios. La biblioteca digital será el principal medio de acceso al conocimiento de las sociedades de la aldea global.

\section{REFERENCIAS BIBLIOGRÁFICAS}

Baum, Erica (2000), "Argentina: derechos de autor en internet: un dilema no resuelto", en Revista Electrónica de Derecho Informático, núm. 27, oct.

Biblioteca del Congreso de los Estados Unidos (2012), Introducción a los derechos de propiedad intelectual, Library of Congress [en línea], http://www.lcweb.loc.gov/copyright/

Clayton, Peter Robert (2006), Managing information resources in libraries: collection management in theory and practice, London, Facet Publishing.

"Desarrollan un protocolo para proteger derechos de autor en Internet" (2007), en World Site [en línea], http://www.periodico. ws/2007/12/01/desarrollan-un-protocolo-para-proteger-derechos-de-autor-en-internet/

DSpace (2010) [en línea], http://www.dspace.org

EPrints: creating Open Access Repositories (2012), Electronic Information for Libraries (EIFL) [en línea], http://www.eifl.net/ eprints-creating-open-access-repositories 
García Camarero, Ernesto (2001), La biblioteca digital, Madrid, Arco Libros.

Gómez Dueñas, Laureano F. (2008), "Repositorios documentales y la iniciativa de archivos abiertos en Latinoamérica”, en Bid. Textos Universitarios de Biblioteconomia i Documentació, núm. 20 [en línea], http://www.ub.es/bid/20gomez2.htm

Gómez Segade, José A. (1999), "El derecho de autor en el entorno digital", en Revista General de Legislación y Jurisprudencia, mayo-junio [en línea], https://bddoc.csic.es:8180/buscarIndice.html?ordenacion $O p 1=$ desc \&tabla $=$ docu $\& S Q L I n d i c e=R F+$ ha s+\%27\%27REVISTA+GENERAL+DE+LEGISLACION+Y+JURISP RUDENCIA $\% 27 \% 27 \& b d=J U R I D O C \&$ ordenacionCampo=PU

Governing the Internet (2007), The Representative on Freedom of the Media Organization for Security and Co-operation in Europe (OSCE) [en línea], http://www.aui.es/biblio/bolet/bole005/ lverde.htm

Hassan Montero, Yusef (2001), ECMS: Sistemas Electrónicos de Gestión del Derecho de Autor [en línea], http://www.nosolousabilidad.com/articulos/ecms.htm\#sthash.VvPEMEVb.dpuf

Hoffmann, Frank W. (2007), Library collection development policies: school libraries and learning resource centers, Lanham, The Scarecrow Press.

Isaias, Pedro, "Sistemas electrónicos de gestión de derechos de autor: aspectos a considerar" [en línea], http://www.bibnal.edu. ar/paginas/recursosbiblio/system.htm

Jordan, Mark (2006), Putting content online: a practical guide for libraries, Oxford, Chandos.

"La comunicación y el derecho de autor en la sociedad de la información: infraestructura de base, protección de los derechos e impacto social y cultural" (1996), en Centro Regional para el Fomento del Libro en América Latina y El Caribe, CERLALC, Comité de Expertos de América Latina, el Caribe y Canadá, núm. 82., Canadá, UnESCO, CERLALC. 
Labastida I. Juan, Ignasi (2007), "El copyleft y su aplicación en el mundo universitario", en VI Congreso de Editores Universitarios de América Latina y el Caribe. Costa Rica, Facultad de Biblioteconomía y Documentación, agosto de 2007 [en línea], http://diposit.ub.edu/dspace/bitstream/2445/32578/1/IgLabCopyleft.pdf

Le droit d'auteur et l' Internet (2001), Paris, Presses Universitaries de France.

Legislación de derechos de autor (2000), Comentario y revisión de Luis Caballero y Mauricio Daher, México, Sista.

López, Clara (2004), "Publicación electrónica", en Gaceta UNAM, 19:2, 29 de mayo. Suplemento Enter@te_Internet, cómputo y telecomunicaciones.

Morales A., Fernando (2000), "Globalización: conceptos, características y contradicciones”, en Educación. Revista de la Universidad de Costa Rica, vol. 24, núm., 1 [en línea], http://revistas. ucr.ac.cr/index.php/educacion/article/view/1045/1110

Negrete Gutiérrez, Ma. del Carmen (2003), El desarrollo de colecciones, México, UNAM / Centro Universitario de Investigaciones Bibliotecológicas.

Ramírez Godoy, María Esther y Díaz Escoto, Alma Silvia (2010), "Desarrollo de colecciones digitales especializadas", en Libr. E Info. Sci. Critique, vol. 3, núm. 2, Jul.-Dec., pp. 37-50 [en línea], http://eprints.rclis.org/15703/1/c.b.vol.3.no.2.ramirezgodoy\%26diaz-escoto.pdf

Ranking Web of World Universities (2012), Consejo Superior de Investigaciones Científicas (CSIC) [en línea], http://www.webometrics.info/

Rethinking collection development and management (2014), Santa Barbara, California, Libraries Unlimited. 
Rodríguez López, Joaquín (2005), “Ciencia y comunicación científica: edición digital y otros fundamentos del libre acceso al conocimiento", en El profesional de la información, vol. 4, núm. 14, julio-agosto, pp. 246-254.

Sánchez Vignau, Bárbara Susana; Alfonso Espinosa, Leidy; Guerra Santana, Yadira (2008), "Tecnologías, comunicación y desarrollo de colecciones", en Ciencias de la Información, 39, abril [en línea], http://www.redalyc.org/articulo.oa?id=181418336006

The Directory of Open Acces Repositories - Opendoar [en línea], http://www.opendoar.org

Torres Vargas, Georgina Araceli (2000), La biblioteca virtual: ¿qué es y qué promete?, México, UNAM / Centro Universitario de Investigaciones Bibliotecológicas.

Torres Vargas, Georgina Araceli (2005), La biblioteca digital, México, UNAM / Centro Universitario de Investigaciones Bibliotecológicas.

Valera Orol, Concha; García Melero, Luis Ángel; González Guitián, Carlos (1988), "Redes de bibliotecas", en Boletín de la Anabad, vol. 38, núm. 1-2, pp. 215-242.

Voutssás M., Juan (2006), Bibliotecas y publicaciones digitales, México, UNAM / Centro Universitario de Investigaciones Bibliotecológicas. 


\title{
La información entre funcionalismo e integración, un dilema actual en América Latina
}

\author{
JOSÉ DE JESÚS HERNÁNDEZ FLORES \\ Universidad Nacional Autónoma de México
}

\section{INTRODUCCIÓN}

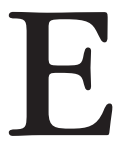

n los anales de la historia han ocurrido acontecimientos e ideas que generan conocimiento, lo cual nos ha obligado a realizar su registro. A partir de la Segunda Guerra Mundial, cuando la humanidad vivió el poder destructivo que alcanzó el conocimiento en ciencia y tecnología, las ideas se reorientaron a buscar y alcanzar, con ese potencial, una nueva era para la humanidad. Una manera de lograrlo ha sido la integración o cooperación entre naciones que comparten territorios en común, aunque en otros casos esto se podría calificar de conquista o sometimiento.

En la actualidad vivimos permeados por un mundo globalizado, bajo un modelo económico considerado como un proceso destructivo. "Aunque algunos lo consideran una intensificación de las relaciones sociales en todo el mundo, a ello se suma una visión de que la globalización es política y cultura." (Infante, 2007: 58) 
El alcance de tal fenómeno fue innegable al final del siglo XX y su avance aún continúa, sólo que ahora han aparecido diversas formas de organización. Las naciones buscan conformar grupos para integrarse por regiones, con la finalidad de lograr mayores beneficios. Ejemplo de ello es el Mercado Común del Sur (MERCOSUR), el Tratado de Libre Comercio de América del Norte (TLCAN), el de la Unión Europea (UE), el Grupo de los 20 (G-20) y el Foro de Cooperación Económica Asia Pacífico (APEC). El objetivo en común es una cooperación de sus integrantes para satisfacer requerimientos, buscando una funcionalidad en aspectos de intercambio comercial y cooperación económica. Los tratados involucran a muchas disciplinas y la interdependencia repercute en aspectos culturales, políticos y sociales a escala mundial; además, se emplea técnica, ciencia y tecnología de vanguardia que requieren implícitamente información y conocimiento.

Un ejemplo representativo es el de la Unión Europea, cuyos logros le han permitido estar en una evolución permanente, así como alcanzar un fortalecimiento económico en sus instituciones y el desarrollo industrial en la región, todo con base en la información y el conocimiento, y desde una perspectiva funcionalista e incluyente. Proyectos semejantes pueden aminorar la desigualdad en nuestra región. A nivel mundial podemos pensar en una paz mundial estable para seguir avanzando con mayores beneficios para la humanidad, en un marco de desarrollo armónico internacional pensando en sociedades más homogéneas y democráticas.

Vivimos en una revolución informática permanente, que nos obliga a pensar y a buscar una democracia social y una libertad basada y relacionada directamente con la creciente demanda de información y accesos, factores que avanzan y buscan germinar en una cultura de derechos en la sociedad. 


\section{ANTECEDENTES}

Somos una generación privilegiada que, por nuestra actividad profesional, nos tocó ser actores y parte de la historia en la revolución tecnológica que vive la humanidad. Transitamos por una senda histórica de crecimiento científico, de un raudo desarrollo tecnológico y de una expansión de las redes globales de comunicación, un hecho sin precedentes. Si bien éstos son factores que han afectado la tranquilidad de la vida cotidiana, la actividad profesional y social de las mayorías también se ha beneficiado.

Vivimos en una época con gran flujo de información en las redes en donde un alto porcentaje es sin regulación ni control; en este sentido, coincido con la idea de que actualmente, con la tecnología, "El hombre moderno difunde sus propuestas e ideas desde un foro intangible, que magnifica las posibilidades de engaño y manipulación.” (Savater, 2014) Para reafirmar lo anterior, rescato la idea y las palabras de Ramón de la Fuente, quien formuló recientemente en España la pregunta en relación a las redes sociales, planteando, si "[...] se trata de un quinto poder." Todo esto es posible cuando vemos la influencia que tiene los medios en la sociedad actual y cuando las redes permiten hacer circular de manera masiva críticas, ideas que dictan tendencias ideológicas e imponen modas, con el poder de enaltecer o segregar a personas o grupos.

Tenemos la contraparte, la información formal que se hace circular en la red, la cual está editada con lineamientos establecidos por las instituciones académicas o respaldada por organismos de prestigio en sus áreas; generalmente en ambos casos se cuenta con arbitraje internacional, uso de normas y de criterios metodológicos en la edición de artículos. Lo anterior da certeza a la información y fortalece a las 
instituciones académicas, empresas o sectores productivos que usan la información como un insumo para la investigación por su alto valor tanto para la ciencia y la tecnología como para las ciencias sociales y las humanidades. Quienes no se apremien a adaptarse al uso de las Tecnologías de la Información y la Comunicación (TIC), se enfrentarán a un futuro de marginación social conjugado con un rezago en su desarrollo personal y hasta global.

Con las TIC, aparece un nuevo territorio de lo social, nuevos patrones de conducta en la vida cotidiana. Independiente de la visión acerca del ciberespacio, unos lo ven con gran beneplácito, otros las desaprueban, es una realidad que el calor humano se desvanece ante relaciones de "me gusta" o "no me gusta", una frialdad implícita. Esta forma de interactuar en la sociedad tiene sus ventajas cuando hablamos de servicios, ya que "Estamos frente a escenarios competitivos y para ser eficientes se requiere de mucha honestidad en su funcionamiento." (Galindo, 2008: 39)

Al conjugarse todo lo anterior, surge prácticamente un nuevo ser social con nuevas demandas, nuevo ordenamiento ideológico; los espacios que ocupamos (casa, departamento, escuela, trabajo, entretenimiento, etcétera) son los mismos, pero al sumar a nuestras vidas las redes nuestros espacios virtuales no tienen límites.

Vivimos con inestabilidad social, padecemos disminución de la calidad de la educación, nos hundimos en el rezago del desarrollo, se afecta el bienestar en la población. Las naciones que carecen o no han actualizado su infraestructura tecnológica en sus comunicaciones sufren limitaciones para integrarse al mundo actual de las redes, tan indispensables para la generación, manejo, difusión y acceso al nuevo conocimiento. Dentro del mundo contemporáneo, todo el pro- 
ceso de flujo de información y conocimiento se encuentra concatenado a través de las TIC.

Nos enfrentamos también a la necesidad de contar con habilidades indispensables para el manejo de las redes. Habilidades que, a la postre, se convierten en competencias valiosas y parte del bagaje cultural que nos permitirá ser cada vez más independientes para analizar, seleccionar y usar eficazmente los contenidos y reducir la brecha digital, avanzando hacia un desarrollo incluyente y una cohesión social más activa y productiva.

El hombre ha generado conocimiento y lo ha representado en diversos soportes (tablillas de arcilla, papel y bits), con lo cual ha surgido la necesidad de acumularlo en repositorios (conservarlo y preservarlo), para transmitirlo de generación a generación (difundirlo) y finalmente usarlo (creación de accesos) para la generación de más conocimiento que beneficie a la sociedad. Hasta mediados del siglo pasado los medios de comunicación eran insípidos (no se conocían), estrechos (por la tecnología) y elitistas (caros), lo cual daba como resultado que la información generada sólo se divulgara entre un reducido núcleo de personas privilegiadas por tener la posibilidad de acceder a la información. Para generar nuevo conocimiento, éste se constituía en una cuasi herencia intelectual para algunos de los miembros afiliados a grupos del poder o a personas encumbradas con los eruditos, o involucrados en ámbitos de universidades e investigación.

Actualmente podemos acceder y dar respuestas satisfactorias a las crecientes demandas de información sin importar horario o ubicación física del usuario. Las TIC y las redes han acentuado el valor de la información, por su poder para generar movimientos ideológicos y sociales a nivel global, y tienen la virtud de facilitar para compartir recursos; por 
ejemplo, avanzar conjuntamente en investigaciones, conocer los resultados de las mismas, analizar datos, distribuir estadísticas para concretar investigaciones, beneficiando a los proyectos conjuntos y permitiendo una actualización e innovación permanente en diversas áreas del conocimiento.

Con alianzas estratégicas en la región, podríamos accesar todo el conocimiento existente y que se va generando, buscando reducir el grado de consumo de recursos económicos por la dependencia que se tiene de los productores y proveedores de información internacional de naciones desarrolladas. Con lo anterior se tendría la posibilidad de sumar nuestra presencia a la producción intelectual mundial y se se abriría la oportunidad de proponer intercambios de información con equidad en el contexto universal, un hecho que se presenta y va en aumento en varias instituciones universitarias latinoamericanas, lo que debemos aprovechar para darle más prisa a nuestra presencia.

Dadas las características que compartimos, como idioma, antecedentes históricos, requerimientos similares en materia de educación e incluso necesidades en investigación (que en nuestras naciones es financiada con fondos públicos según la UNESCO en 2010), sería lógico que para reportar mayores beneficios se debería contar con los resultados de las investigaciones de manera inmediata; sin embargo, su difusión y hasta su consulta se dificultan por las limitaciones que se padecen en los sistemas de comunicación académica y científica; la situación se agudiza por falta de políticas de información o políticas institucionales que apoyen el desarrollo.

En este sentido coincido con la Campaña de CLACSO por el Acceso Abierto al Conocimiento. Dice Gentilli (2009 [en línea]):

La producción académica de nuestras universidades no puede estar subordinada a los intereses o vaivenes del mercado editorial. 
Son nuestras sociedades las que pagan el trabajo que realizan los académicos en América Latina, no las empresas o el sector privado. Todos (pertenezcan o no al mundo universitario) deben tener derecho a acceder gratuitamente y libremente a las producciones que las universidades y los centros de investigación realizan. No se trata de generosidad. Se trata de una obligación, de un compromiso mínimo en defensa del espacio público. Simplemente porque el conocimiento, en una sociedad democrática, debe ser un bien común.

Con el informe de la UNESCO de 2005, se reafirma lo anterior cuando se señala que el progreso tecnológico ha dado sustento al concepto de sociedad de la información, que a su vez da paso a la sociedad del conocimiento y cuya acepción es más amplia. En conjunto las naciones y algunos de sus sectores aspiran a participar en la sociedad del conocimiento, en donde la información es el insumo determinante que beneficia a todos y permea el funcionamiento de la sociedad.

En una planeación en pro de la generación de conocimiento, es imposible no mencionar a las bibliotecas por su rol con la información. Aunque se discute el futuro de la biblioteca y el libro, ambos siguen teniendo vigencia. A los bibliotecarios profesionales nos toca hacer resaltar la importancia de la biblioteca, como el medio ideal para democratizar la información y el conocimiento, instancia responsable de reunir, organizar, resguardar y difundir el conocimiento generado por la sociedad. Es, per se, un punto de acceso a la información, por la necesidad de la misma, es un pretexto perfecto para ser un punto de reunión. Tiene que preservar y conservar los diversos materiales documentales contenidos en el acervo de sus colecciones de manera física o en sus variados soportes digitales que se integran en sus repositorios, sin dejar de atender su gran responsabilidad 
de facilitar el uso, creando y facilitando accesos a los usuario presenciales o a distancia.

Las bibliotecas actualmente cuentan con personal profesional y especializado, dependiendo del tipo de biblioteca, lo que representa un gran beneficio para el usuario al poder recibir orientación ante el creciente aluvión de información al que se enfrenta. Aun con las limitaciones que se padecen en las bibliotecas, se ha procurado modernizarlas en su infraestructura tecnológica; por ejemplo, se adquieren y se ofrecen accesos a las bases de datos de proveedores internacionales de prestigio en diversas áreas de especialización; éstas serían inaccesibles a los usuarios por sus altos costos, y sin bibliotecas no se tendría oportunidad de acceder a esta información.

Además, son el medio "democrático" por el cual fluye un alto porcentaje de información regional avalada, certificada y respaldada por nuestras universidades o instituciones académicas, generadoras de conocimientos de interés para la sociedad latinoamericana, con el plus de que en la mayoría de los casos es de manera gratuita para su disponibilidad y su acceso; claro, si así lo permiten los que tiene los derechos de autor, y en aquellos casos en que llega a tener un costo, se puede considerar simbólico u operativo, en ningún caso es lucrativo para su acceso.

La biblioteca derriba barreras para muchos, y más en nuestro contexto en donde son las que proporcionan y facilitan la posibilidad de una conexión a Internet. Si consideramos que en el mundo y en nuestro continente aún se dan casos en que la ubicación geográfica constituye una limitante por la falta de cobertura tecnológica, aún enfrentamos situaciones extremas, como la carencia de energía eléctrica que agrava la situación, y a ello se suman analfabetismo y 
el desconocimiento de las TIC, carencias inaceptables en la actualidad para la humanidad.

Navegamos a contracorriente en un mundo sumergido en un sistema capitalista global, incapaz e indiferente a nuestra realidad, que no ofrece soluciones a ninguno de nuestros problemas sociales, ni para mejorar las condiciones de una vida digna de los seres en latitudes menos favorecidas; por supuesto que no les corresponde esa responsabilidad, sin embargo, la indiferencia por atender estos problemas puede llevar a toda la humanidad a enfrentar altos costos.

Es importante buscar una mayor cooperación para el funcionalismo de la información en la región, organizar foros colegiados por áreas, establecer acciones y programas de políticas acordes a nuestras sociedades, para una transformación y un desarrollo hegemónico en Latinoamérica.

\section{SOCIEDAD ACTUAL}

Información y conocimiento son piedras angulares en la educación, la investigación y la productividad para el crecimiento económico en todas las naciones que se ven beneficiadas con los accesos a la red, mejorando sus oportunidades de trabajo e ingresos, con servicios de calidad y, por ende, alcanzando una realización del ser humano en un estado de bienestar personal y social. En la otra cara de la moneda, tenemos obstáculos, como pobreza y polarización social, que desembocan en fricciones que limitan el crecimiento; si el avance de la población es lento para integrarse a la sociedad del conocimiento, se frena la región.

Nos enfrentamos ahora a una sociedad de biperinformados (Savater, 2014), y con la avalancha de información hay la probabilidad de incertidumbre. Un dato importante sobre 
el particular consultado en Internet hace referencia a que México cuenta con más de 51 millones de cuentas activas en Facebook, de las cuales 31 millones se conectan diario (Mercadotecnia portal, 2014); somos el sexto mercado para la empresa, lo que nos obliga a adaptar y buscar nuevos servicios en el esquema de las redes para satisfacción del usuario. Aun en la turbulencia, las bibliotecas han identificado obstáculos y presentan soluciones de servicios; aplicando el potencial y las bondades de la tecnología, han hecho llegar más información a un número mayor de usuarios en la población y en el mundo.

México tiene 120 millones de habitantes, y apenas 500 mil llegan a ser considerados como lectores habituales; es una sociedad en la cual los libros no pueden competir contra los medios masivos de comunicación (radio, televisión e Internet), y lo grave es que la sociedad llega a sopesar esa información como "útil".

A los bibliotecarios profesionales nos toca defender al libro, resaltar su valor artístico, intelectual, social, histórico, económico e incluso físico ante la sociedad; si no es así, la pregunta es ¿quién lo hará? El libro, por siglos, ha sido el soporte, el medio para difundir el conocimiento, el entretenimiento, las pasiones y sentimientos para la humanidad, de la manera más democrática que se ha conocido.

Fernando Savater señala que los libros son un mundo de libertad y que la biblioteca no es un simple almacén, sino una forma de liberación a través de la lectura (Savater, 2009), también se dice que: "[...] un hombre necesita acceso a los documentos" (Illich, 2006: 318) para su plena realización; en este sentido las bibliotecas apoyadas en las TIC facilitan a la humanidad el acceso al conocimiento universal.

También se ha presentado una demanda para una renovación en educación, desde los planes y programas de estudio; 
para ello se exige mayor presupuesto, así como infraestructura tecnológica con más y mejores accesos a la información en todos los niveles de educación. Tenemos que reflexionar sobre la importancia de los valores desde su teoría, aplicación y práctica en la realidad que vivimos, reafirmando que todos tenemos una responsabilidad desde los ámbitos políticos y académicos para una sociedad más justa.

Actualmente se requiere interactuar más con otras disciplinas; tenemos que buscar una especialización profesional permanente, involucrarnos con la difusión de la información, participar en el diseño de accesos, aprender el manejo de nuevas tecnologías que nos faciliten desarrollar estrategias de búsqueda, tener la habilidad de identificar requerimientos de los usuarios, ser autosuficientes ante la gran cantidad de información a la que nos enfrentamos.

Un reto más es la alfabetización informativa: dotar al usuario de habilidades básicas para el conocimiento de las herramientas existentes para su beneficio. El bibliotecario profesional debe enfocarse en ser un apoyo para los usuarios de la información, incorporando al trabajo actitudes y aptitudes que se requieren en una sociedad del conocimiento, no convertirse en un obstáculo entre usuarios e información.

\section{CONCLUSIONES}

La integración de América Latina presupone negociación entre instituciones, bibliotecas y usuarios, y también entre muchos de los actores sociales para beneficio de las partes; hay que lograr un funcionalismo de la información encaminado a la integración y el desarrollo de la región basado en un proceso coordinado de transfronterización entre los interesados para compartir recursos. 
La integración latinoamericana y el funcionalismo de la información harán que nuestra presencia en tratados o en el mismo proceso de globalización tenga representatividad y equidad en la participación. Termino con una idea planteada por Jorge Luis Borges: "Siempre imaginé que el paraíso sería como una biblioteca."

\section{REFERENCIAS BIBLIOGRÁFICAS}

Díaz de Cossío, R. (2012), "El futuro (que quisiéramos) para la educación en México", en Educación 2001: revista de educación moderna para una sociedad democrática, núm. 25, jun.

"Facebook reporta 51 millones de usuarios en México" (2014), en P. Portada [en línea], http://mercadotecnia.portada-online. com/2014/05/30/facebook-reporta-51-millones-de-usuariosen-mexico/

Fernández Lamarra Norberto (2010), Hacia una nueva agenda de la educación superior en América Latina: Situación y perspectivas, México, ANUIES, Dirección de Medios Editoriales.

Gentili, Pablo, Campaña ClACSO por el acceso abierto al conocimiento [en línea], http://biblioteca.clacso.edu.ar/accesoabierto/

Goméz Salazar, Mónica (editora) (2010), Reflexiones sobre la sociedad del conocimiento y la interculturalidad en México, México, UNAM / Coordinación de Humanidades.

Illich, Iván (2010), Obras reunidas, 2 v., México, Fondo de Cultura Económica.

Infante Bonfiglio, José María et al. (2007), Hacia la sociedad del conocimiento, México, Edit. Trillas. 
La información entre funcionalismo e integración, un dilema...

Matsuura, Koichiro (2006), "Hacia las sociedades del conocimiento" [en línea], http://davidhuerta.typepad.com/files/hacia_sociedades_conocimiento-1.pdf

Negrete Gutiérrez, María del Carmen (2008), “Tensiones en el desarrollo de colecciones ante la brecha digital", en Ibersid, vol. 2, pp. 15-22 [en línea], http://ibersid.eu/ojs/index.php/ibersid/ article/view/2197/1958

Sánchez Daza, Germán (editor) (2009), América Latina y el Caribe en la economía y sociedad del conocimiento: una revisión crítica a sus fundamentos y políticas, Puebla-Buenos Aires, BUAP, CLACSO.

Savater, Fernando (2009), "Agonía y resurrección del libro", en Granados Salinas T. (coord.), Congreso Internacional del Mundo del Libro (2009, septiembre 7-10, ciudad de México) Memoria, México, Fondo de Cultura Económica.

Stewart, Lou Ann (2000), "Choosing Between print and electronic Resources: the selection dilema”, en Reference Librarian, núm. 71, pp. 79-97. 


\title{
Los actores en el libre acceso a la información en Internet
}

\author{
JONATHAN HERNÁNDEZ PÉREZ \\ Universidad Nacional Autónoma de México
}

$\tau$ as últimas décadas del siglo $\mathrm{XX}$ estuvieron marcadas por importantes descubrimientos científicos y tecnológicos que han transformado distintos sectores de la sociedad. Indudablemente, los avances en el campo de la tecnología de la información han moldeado la manera en la que interactuamos. Como apunta Castells: la revolución de la tecnología de la información, de forma un tanto consciente, difundió en la cultura material de nuestras sociedades, el espíritu libertario que floreció en los movimientos de la década de los sesenta. ${ }^{1}$ Y fue precisamente en la década de los sesenta cuando se esbozaron los inicios de Internet, en el cual intervinieron distintos personajes, lo que dio como resultado una arquitectura de red que, como querían sus inventores, no podía ser controlada desde ningún centro, y que estaba compuesta por miles de redes informáticas autónomas que tienen modos innumerables de conectarse, sorteando las barreras electrónicas. ${ }^{2}$ De esta manera, la arquitectura de Internet siempre ha sido impulsada por un grupo de actores, pero la forma del grupo cambia conforme

1 Manuel Castells (2005), La Sociedad Red.

2 Ibíd. 
crecen los alcances y el número de partes interesadas. Con el avasallante éxito de Internet en los terrenos económicos, sociales y políticos, también hubo una avasallante proliferación de interesados.

Pero las tendencias y las posibilidades actuales parecen estar muy lejos de la idea original de Internet, ya que poco a poco se ha difuminado la imagen en la que concebíamos a Internet como un extraordinario entorno digital interconectado, ajeno al alcance de mecanismos de censura y control, totalmente libre. En la actualidad no nos sorprende el hecho de que nuestro comportamiento en Internet sea regulado y monitoreado constantemente, pues técnicamente es posible estructurar este entorno y la información que fluye en él, mediante los diferentes actores involucrados en el libre acceso a la información.

Antes de referirnos a los actores involucrados en el libre acceso a la información, conviene mencionar un aspecto fundamental de Internet: su naturaleza física, pues aunque llevamos a cabo una comunicación virtual, a menudo olvidamos su materialidad, damos por hecho su infraestructura y nos concentramos en el rápido proceso de comunicación y en los beneficios de la transferencia de información, olvidando que lo anterior depende en gran medida de organismos intermediarios que operan bajo determinadas jurisdicciones legales.

Internet es una tecnología, la cual no es libre ni gratuita en su totalidad, pues combina la libertad y el control en diferentes niveles; el nivel físico es fundamentalmente controlado; los cables, energía y las computadoras de todo el mundo en general son propiedad de gobiernos, empresas o particulares, y por otro lado, una parte del nivel de contenido en Internet también es controlado, ya que no todo se 
puede tomar con libertad, pues lo anterior involucra aspectos del derecho de autor, propiedad intelectual, etcétera.

Lo anterior da pie a que podamos comprender a Internet, también, como un espacio físico, y es precisamente la naturaleza material de Internet la que puede trazar los límites e imponer barreras a los flujos de información.

En este sentido, en el Internet que hoy conocemos, que hoy utilizamos, intervienen numerosos actores que hacen posible su funcionamiento. La Red no es estática; es un sistema complejo que se encuentra en continuo desarrollo, y con este desarrollo también crece el número de personajes que interactúan entre ellos de forma interdependiente.

La presente contribución se centra en los actores del libre acceso a la información en el contexto de la infodiversidad en Internet, los cuales se pueden dividir en dos grandes grupos. Por una parte, se encuentran los que se dedican a proveer, mediar, y proporcionar la infraestructura tanto física como virtual para que la información circule -o no- en Internet; a este primer grupo lo denominaremos legisladores e intermediarios.

Por otro lado, se encuentran los que nutren a Internet con información, la comparten, la editan y llevan a cabo acciones en pro del libre acceso a la información, acciones que pueden nacer de forma digital para después trasladarse al espacio físico y viceversa; a este otro grupo lo llamaremos defensores y ciberactivistas.

La gama de todos los actores involucrados en el libre acceso a la información es muy amplia; la definición de todos estos actores conllevaría a una investigación mayor, por lo que en este documento únicamente se enfatizará en el primer grupo: sobre el Estado y los intermediarios, particularmente en las plataformas de redes sociales y los motores de búsqueda. Mientras que por el lado de los defensores y ci- 
beractivistas se acotará a los usuarios, las universidades y las asociaciones, y la biblioteca y las asociaciones bibliotecarias.

\section{LEGISLADORES E INTERMEDIARIOS}

\section{El Estado}

El Estado se puede definir como una sociedad humana, establecida en el territorio que le corresponde, estructurada y regida por un orden jurídico, creado, definido y sancionado por un poder soberano, para obtener el bien público temporal, formando una institución con personalidad moral y jurídica. ${ }^{3}$ En este sentido, conviene recalcar que el Estado se posiciona como uno de los principales proveedores y sostenedores de los sistemas educativos y también como aquel que establece las normas que guían una determinada población.

Bajo lo anterior, el Estado tiene un papel fundamental en el libre acceso a la información en Internet, pues de él depende en gran medida lograr una adecuada infraestructura de banda ancha, la cual no sólo debe ser considerada como una herramienta de conectividad, sino también como un medio para lograr una mayor inclusión social, productividad, competitividad económica, mayor cobertura en educación, mayor transparencia en los procesos democráticos y, sobre todo, como una oportunidad para el desarrollo social y la innovación. El Estado, en sus tres niveles (federal, estatal y local) tiene la posibilidad de establecer políticas que abarcan desde la implementación de Internet hasta su uso.

Sin embargo, al proveer banda ancha y permitir el acceso a Internet, el Estado adquiere otras responsabilidades en aspectos que si bien los trata de manera física, se trasladan al

3 Francisco Porrúa Pérez (2003), Teoría del Estado, pp. 26-27. 
escenario virtual, como la privacidad, la seguridad, la protección de datos personales, el anonimato, y aspectos que nacen como consecuencia de la implementación de banda ancha, como la neutralidad de la Red.

\section{Intermediarios}

La interactividad y la comunicación a través de Internet, independientemente de su contenido, requieren atravesar por una infraestructura tecnológica compleja, compuesta por diferentes elementos físicos y lógicos, cada uno de los cuales está a cargo de un operador, es decir, un intermediario. La participación de estos intermediarios está sujeta a las regulaciones establecidas en cada jurisdicción, ya sea dentro de la normativa general de servicios de telecomunicación o específicamente para la prestación de aquellos servicios que son propios de Internet.

Diversas disciplinas realizan investigaciones sobre los intermediarios en Internet, y es probable que bajo el contexto de sus propias investigaciones definan a los intermediarios de manera diferente. Así, podemos encontrar diferencias conceptuales en disciplinas como el derecho, la economía, la política, la sociología, etcétera.

Es importante mencionar que los conceptos aquí utilizados se enmarcan en el contexto de la libertad de expresión, y desde esta perspectiva los intermediarios realizan un nuevo tipo de actividad y crean un espacio para que los individuos se expresen en línea, una función que puede ser examinada con mayor profundidad.

De esta manera, la Organización para la Cooperación y Desarrollo Económico (OCDE) define a los intermediarios en Internet como aquellos que reúnen o facilitan las transacciones entre terceras partes. Dan acceso para hospedar, 
transmitir e indexar contenido, productos y servicios originados por terceros, o proporcionan servicios basados en Internet. ${ }^{4}$

Por otra parte, el Centro de Estudios en Libertad de Expresión y Acceso a la Información (CELE) indica que los intermediarios en línea son todos los agentes que de una $u$ otra manera posibilitan y determinan nuestra actividad en Internet, enfatizando que no todos se ubican en el mismo nivel de la Red ni ofrecen los mismos servicios, ya que en una arquitectura de niveles como la de Internet, unos están en la capa física y otros en la de aplicaciones. ${ }^{5}$

La organización Article19 se refiere a los intermediarios en Internet como aquellas entidades que permiten a las personas conectarse a Internet y transmitir contenido. Asimismo, menciona los diferentes tipos de intermediarios, tales como los proveedores de acceso a Internet, los proveedores de servicio de alojamiento en la web, plataformas de redes sociales así como los motores de búsqueda, y enfatiza que los intermediarios se distinguen de los "productores de contenido" siendo estos últimos aquellas personas u organizaciones que se encargan de la producción de información y su publicación en línea. ${ }^{6}$

Diversos autores han establecido sus propias categorizaciones de intermediarios; sin embargo, Lara y Vera ${ }^{7}$ establecen una clasificación específica para los intermediarios que

4 OECD (2010), The Economic and Social Role of Internet Intermediaries [en línea].

5 Centro de Estudios en Libertad de Expresión y Acceso a la Información (CELE), "Las llaves del ama de llaves: la estrategia de los intermediarios en Internet y el impacto en el entorno digital" [en línea].

6 Article 19, "Los intermediarios del Internet: Dilema de responsabilidad -sesión de preguntas y respuestas" [en línea].

7 Juan Carlos Lara y Francisco Vera, Responsabilidad de los prestadores de servicios de internet, ong Derechos Digitales [en línea]. 
participan en el proceso de intercambio de información, agrupándolos de la siguiente manera:

a) Proveedores de acceso, que prestan el servicio que conecta al equipo del usuario final, mediante cables o señales inalámbricas;

b) Proveedores de tránsito, que permiten la interacción entre el equipo final y el proveedor de acceso con los proveedores de alojamiento, sin tener más función que la de mero transporte de datos.

c) Proveedores de alojamiento, que cuentan con uno o varios equipos con espacio disponible o "servidores", con acceso a los proveedores de tránsito, a fin de utilizarlos con sus propios fines o de ponerlos a disposición de terceros, para mantener contenido accesible a través de los otros proveedores [...]

d) Proveedores de servicios en línea, que permiten la puesta en línea de contenidos por parte de usuarios, tales como: plataformas de publicación de blogs o noticias, servicios de correo electrónico, redes sociales, servicios de alojamiento de imágenes, audio y vídeo; sitios de comercio electrónico; foros de discusión, etcétera.

e) Proveedores de búsqueda y enlaces, que permiten localizar contenidos en línea, y que en la entrega de tal servicio cumplen el rol de intermediarios en tanto facilitan el acceso a contenidos provistos por terceros mediante la entrega de enlaces que permiten su más fácil ubicación.

Estas categorías pueden seguir ramificandose según la evolución de los servicios en Internet; sin embargo, está contribución hará énfasis en los motores de búsqueda y las 
plataformas de redes sociales, como ejemplos puntuales de proveedores de servicios en línea y proveedores de búsqueda respectivamente.

\section{Plataformas de redes sociales}

Las redes sociales son servicios basados en Web que permiten a los usuarios construir un perfil público o semipúblico dentro de un sistema acotado, articular un vínculo con otros usuarios con los que pueden interactuar, e intercambiar información; la naturaleza y la nomenclatura de estos vínculos pueden variar de un sitio a otro. ${ }^{8}$ La importancia de éstas en el libre acceso a la información radica en la posibilidad de la interacción social y la expresión en línea, ya que proporcionan una plataforma que puede permitir la democratización de la información.

Los contenidos que se publican en las redes sociales reflejan la pluralidad de temas, de ideas y de usuarios que conviven y comparten información, de tal forma que existe una gran cantidad de redes sociales y su tipología varía dependiendo del público al que está enfocado o contenido que se comparte.

Al permitir el intercambio y la agregación de contenidos generados por los usuarios, las redes sociales se posicionan como actores que transforman audiencias tradicionalmente pasivas en audiencias productoras de información.

Las redes sociales están siendo ampliamente utilizadas en muchas partes del mundo, no sólo para la comunicación personal, sino también con la finalidad de abordar cuestiones políticas, críticas o incluso temas tabú, que no siempre son accesibles a través de los medios tradicionales. De tal

8 d. m. Boyd y N. B. Ellison (2008), "Social Network Sites: Definition, History and Scholarship" [en línea]. 
forma que se han convertido en poderosas herramientas de comunicación de masas y principalmente en una vía para la movilización, y en algunos casos para eludir la censura. La apropiación social de Internet se está convirtiendo en una parte importante de los procesos de democratización.

Sin embargo, las amplias posibilidades de las redes sociales también conllevan riesgos y desafíos de diversa índole; entre ellos, por mencionar algunos, se encuentran la calidad y los estándares éticos de contenido generado por el usuario, la privacidad y seguridad de los usuarios, el contenido no apto para menores de edad, los mensajes de odio y discriminación, y particularmente, la vigilancia y la intervención del Estado.

\section{Motores de búsqueda}

La búsqueda de información, junto con el correo electrónico y las redes sociales son los tres servicios mayormente utilizados en Internet. Los motores de búsqueda vienen a ser la puerta de entrada para los usuarios; pueden ser un intermediario eficaz para obtener información o pueden ser, también, un mecanismo de control. Éstos resultan ser actores imprescindibles en el libre acceso a la información, ya que actúan como un intermediario entre los usuarios que buscan información y aquellos que la producen, determinando en gran medida lo que vemos y consultamos en la Red; incluso si los sitios web rastreados no están disponibles al momento de la consulta, la memoria caché de algunos buscadores hace posible el acceso a la última versión guardada.

Los motores de búsqueda merecen un especial reconocimiento en el libre acceso a la información; sin su implementación y desarrollo, la recuperación de información en 
Internet sería prácticamente imposible, incluso se puede afirmar que los buscadores posicionaron a la Web como una poderosa herramienta para el acceso a la información.

Sin embargo, pese al desarrollo tecnológico, la mayor parte de las páginas web no son indexadas por los motores de búsqueda y, por lo tanto, dificultan su recuperación. Incluso Google, el motor de búsqueda más grande y popular del mundo, reporta que sólo ha indexado un pequeño porcentaje de las páginas web mundiales, cuyas estimaciones van de $0,4 \%$ a $12 \%$.

El proceso de búsqueda y recuperación de información en un motor de búsqueda se lleva a cabo mediante complejos algoritmos que hacen posible que los resultados sean lo más cercano a nuestras necesidades informativas. Los motores de búsqueda han tenido una importante evolución no sólo en cuanto a sus algoritmos, sino también en los servicios que ofertan.

La abundante información disponible en Internet, aunada a la constante innovación en los algoritmos de búsqueda y a la necesidad de las corporaciones por obtener consumidores, ha hecho que los motores de búsqueda sean cada vez más personales, más inteligentes; basta teclear un par de datos básicos para que se desplieguen resultados de acuerdo a nuestras necesidades; datos que incluso no ingresamos de manera manual, como el lugar en el que hacemos la búsqueda o el idioma. Incluso los resultados pueden ser aún más específicos si creamos un perfil en los buscadores, el cual recolecta nuestro comportamiento en las búsquedas para ofrecernos únicamente lo que estamos buscando, basado en nuestras huellas de búsqueda.

9 R. MacKinnon; E. Hickock; A. Bar, y H. Lim (2014), Fostering Freedom Online: The Role of Internet Intermediaries [en línea]. 
Sin embargo, esta personalización ha sido objeto de críticas en cuanto al acceso a la información, ya que podría tener un impacto negativo en la diversidad informativa que circula en Internet. Poco a poco, los motores de búsqueda dominantes se han inclinado hacia los resultados de búsqueda cada vez más personalizados. Esta personalización del proceso de búsqueda -y los servicios de información en línea en general- puede orillar a tener una visión parcial de la información que circula en Internet, al dejar a la deriva contenidos que podrían ser importantes, o peor aún, como advierte Sunstein, podría dar lugar a los "capullos de información", en los cuales los usuarios sólo tendrían acceso a la información y a las ideas basadas únicamente en sus intereses y no se verían confrontados con otros temas o perspectivas. ${ }^{10}$

Pero existe otro tipo de "personalización" en los motores de búsqueda y no es precisamente para que el usuario obtenga información concisa y de acuerdo a sus necesidades, sino para que visualice la información que corresponde a los intereses de un tercero, ya sea la empresa que provee el servicio de búsqueda o el gobierno, a través de marcos normativos que pueden obligar al motor de búsqueda a censurar, filtrar y controlar la información que indexan.

\section{DEFENSORES Y CIBERACTIVISTAS}

En el otro lado de internet se encuentran otros actores, aquellos que también forman parte de la infodiversidad, pues de ellos depende en gran medida su equilibrio.

10 J. V. J. van Hoboken (2012), Search engine freedom: on the implications of the right to freedom of expression for the legal governance of Web search engines [en línea]. 


\section{Usuarios}

La base de estos defensores y ciberactivistas son los usuarios; en el contexto de Internet, aunque se generaliza el nombre de usuario, también se utilizan otros términos como internauta y cibernauta. Estos términos eran mayormente utilizados cuando a Internet se le conocía como la supercarretera de la información o el ciberespacio, respectivamente. Sin embargo, debido a la creciente interactividad como consecuencia de la utilización de redes sociales, se ha comenzado a hablar de sujetos, actores o ciudadanos, enfatizando que estos no slo usan Internet, ino que producen e interactúan en él, llamándolos netizen o cybercitizens: ciudadanos de Internet, y ciberciudadanos, respectivamente. ${ }^{11}$

Sin embargo, la colaboración en la Red no se limita a la producción e intercambio de información, sino que también se lleva a cabo mediante acciones gestadas en línea y que pueden trasladarse al espacio físico o viceversa. En estas acciones, los usuarios se organizan para llevar a cabo diversas actividades, generalmente orientadas hacia la defensa de sus derechos, ya sea a nivel local, regional o incluso global.

Esta colaboración puede dar como resultado dos actividades en las cuales la defensa por el libre acceso a la información es uno de sus estandartes: el activismo digital y el hacktivismo.

El activismo digital de acuerdo con Denning ${ }^{12}$ se refiere al uso no disruptivo de Internet en apoyo de un programa o causa; entre las operaciones de esta área se incluyen la navegación por la web para obtener información, la construc-

11 Es importante mencionar que si bien estos términos no son nuevos, se han comenzado a abordar nuevamente como consecuencia de la gran actividad de los usuarios particularmente a través de las redes sociales. Cf. Columbia University. "Netizens: An Anthology" [en línea].

12 Dorothy E. Denning (2000), "Activism, hacktivism, and cyberterrorism: the Internet as a tool for influencing foreign policy”, pp. 15-35. 
ción de sitios web y la publicación de información sobre las causas; la información se comparte a través del correo electrónico y las redes sociales, y el uso de la Red esencialmente es para discutir temas, formar coaliciones, y planificar y coordinar las actividades. El activismo digital se basa en cinco criterios: recopilación de información; publicación de contenidos; diálogo; coordinación de acciones, y cabildeo. Y puede utilizarse con tres finalidades: para informar; para concientizar; denunciar y movilizar a otros ciudadanos; y en su función más sofisticada, como herramienta para incidir en políticas públicas. ${ }^{13}$ En algunos casos, la diferencia radica en haber previsto determinado objetivo para lograr cualquiera de los resultados anteriores, en otros, se puede dar por la inmediatez y de igual forma se pueden lograr cualquiera de las tres opciones o ninguna.

El activismo digital ha dado pie a diversos movimientos sociales que se han extendido a lo largo del mundo. Manuel Castells, en su obra Redes de indignación y esperan$z a$, relata los movimientos sociales en Red más importantes, afirmando que éstos se extendieron primero en el mundo árabe, los cuales corrieron suerte diversa: de la victoria y las concesiones a numerosas matanzas y guerras civiles; posteriormente, surgieron movimientos en Europa y Estados Unidos, y recientemente en América Latina. El autor afirma que:

En nuestra sociedad, el espacio público de los movimientos sociales se construye como espacio híbrido entre las redes sociales de Internet y el espacio urbano ocupado: conectando el ciberespacio y el espacio urbano en una interacción incesante y constituyendo tecnológica y culturalmente comunidades instantáneas de prácticas transformadoras. ${ }^{14}$

13 Maite Azuela y Mónica Tapia Álvarez (2013), "Construyendo ciudadanía desde el activismo digital [en línea].

14 Manuel Castells (2012), Redes de indignación y esperanza, p. 28. 
Por otra parte, los hacktivistas, de acuerdo con Taylor, ${ }^{15}$ emergieron a mediados de la década de los noventa, y marcaron la fusión de la actividad hacker con una postura política abierta, es decir, como resultado de la convergencia de dos tendencias diferentes: a) los hackers son políticamente más conscientes y b) los activistas se volvieron más informados tecnológicamente.

Estas dos tendencias se reflejan en los dos principales tipos de protesta hacktivista: el hackeo Web y de computadoras, y la Desobediencia Civil Electrónica.

De igual forma, se han creado comunidades virtuales, como Anonymous, el cual es comúnmente asociado a la actividad hacktivista, junto con otros dos grupos importantes en su momento: el Cult of the Dead Cow (cDc), establecido en 1980, y el Electronic Disturbance Theatre, iniciado en 1997. Estos grupos comparten la sensación de que la tecnología informática es algo más que una herramienta para lograr fines políticos. Al respecto, Goode nos indica que el ethos de Anonymous es tecnofílico y que la tecnología digital se proclama no sólo como una forma de vida para los miembros del grupo, sino también como una fuerza impulsora para la remodelación de la sociedad. ${ }^{16}$

Asimismo, se han creado organizaciones mediáticas, como Wikileaks, que han tomado relevancia por la publicación de documentos sensibles cuyo estandarte es el anonimato de sus fuentes. Recientemente, en México se desarrolló una plataforma similar a Wikileaks, llamada MéxicoLeaks, la cual se define como una plataforma independiente de denuncia ciudadana y transparencia, al servicio de la sociedad mexicana para revelar información de interés público.

15 Paul A. Taylor (2001), "Editorial: Hacktivism" [en línea].

16 Luke Goode (2015), "Anonymous and the Political Ethos of Hacktivism", pp. 74-86 [en línea]. 
Otra organización importante a nivel internacional es la Internacional de Partidos Pirata (PPI), la cual es una organización no gubernamental y sin fines de lucro fundada en 2010 y con sede en Bruselas, Bélgica, que sirve como una organización que coordina a los Partidos Piratas alrededor del mundo, con miembros de 41 países.

Los Partidos Pirata son representaciones políticas de la libertad de movimiento de expresión, aunque ellos tratan de alcanzar sus objetivos por medio del sistema político en lugar del activismo digital.

\section{Universidades y asociaciones}

Las universidades y las asociaciones dedicadas al estudio de Internet son importantes actores en la defensa del libre acceso a la información; sus funciones pueden ser vistas desde tres dimensiones: formación, investigación e innovación tecnológica.

La formación de cuadros profesionales es uno de los principales objetivos de toda universidad; una adecuada formación universitaria puede incidir positivamente en el desarrollo económico, social y cultural de un país. El libre acceso a la información en Internet necesita de la interacción entre diversos especialistas. Por una parte necesita de ingenieros que construyan sistemas robustos para que los usuarios accedan de una manera eficaz a la información, así como de bibliotecólogos que incidan en el desarrollo de repositorios, bases de datos, motores de búsqueda, y que fomenten las habilidades informativas. Por otra parte, también necesita de sociólogos que expliquen y estudien las consecuencias derivadas del uso de las redes sociales, así como de abogados que busquen un equilibrio entre el derecho de autor, la propiedad intelectual y el derecho a 
la información, entre muchas otros. Estas interacciones han dado pie a los Estudios de Internet, los cuales han sido uno de los campos interdisciplinarios más dinámicos y de rápida expansión que han surgido en la última década; éstos se basan en disciplinas que abarcan los factores sociales, políticos, económicos, culturales, psicológicos, así como estudios en el ámbito de la computación, ciencias de la información e ingeniería. ${ }^{17}$

Estos estudios han ofrecido una oportunidad en el que académicos de distintas disciplinas afines se han unido con académicos interdisciplinarios para formar comunidades de investigación en crecimiento, lo cual se traduce en centros e institutos de investigación a lo largo del mundo. Como ejemplo de los más representativos se pueden mencionar: el Oxford Internet Institute (OII) de la Universidad de Oxford; el Berkman Center for Internet and Society de la Universidad de Harvard; el Center for Internet and Society (CIS) de la Universidad de Stanford; el Institute of Networks Cultures (INC) de la Universidad de Ciencias Aplicadas de Ámsterdam; el Centro de Estudios en Libertad de Expresión y Acceso a la Información (CELE) de la Universidad de Palermo en Argentina, entre otros.

Sin embargo, el papel de las universidades en el libre acceso a la información en Internet va más allá del establecimiento de centros e institutos de investigación dedicados a este tipo de aspectos, ya que también establecen herramientas tecnológicas, como repositorios, bases de datos y motores de búsqueda que ponen a disposición del usuario una amplia gama de documentos producto de la investigación de dichas universidades, enmarcados en el movimiento de Acceso Abierto, el cual busca garantizar la apertura y di-

17 William H. Dutton (2013), "Internet Studies: The Foundations of a Transformative Field" [en línea]. 
seminación sin restricciones económicas y legales, que con los años ha impuesto el circuito donde se mueve la información científico-técnica, representado principalmente por la Revista y todas sus restricciones económicas y legales. ${ }^{18}$

Existen numerosas iniciativas a nivel internacional; en América Latina se destacan: la Scientific Electronic Library Online (Scielo), producto de la cooperación entre distintas instituciones y universidades en América Latina; la Red de Revistas Científicas de América Latina y el Caribe, España y Portugal (REDALyC), impulsada por la Universidad Autónoma del Estado de México (UAEM); y las diferentes iniciativas de la Universidad Nacional Autónoma de México (UNAM), como Latindex, Humanindex, Red de Acervos Digitales, Toda la UNAM en línea, entre otros.

Por otra parte, las asociaciones y organizaciones dedicadas a promover y proteger los derechos digitales en Internet se han hecho notar durante los últimos años por su importante participación en la lucha por la libertad de expresión y de información en Internet, convirtiéndose en plataformas de acción colectiva. Es importante mencionar que si bien la ONU, la UNESCO, la OCDE y otras ONG han realizado importantes esfuerzos para proteger y fomentar el acceso a la información, existen organizaciones que se han formado específicamente para defender este derecho; entre las que se destacan: la Electronic Frontier Foundation (EFF), Article 19, Derechos Digitales (Chile) y la Red en Defensa de los Derechos Digitales R3D (México).

18 Estela Morales Campos (2011), "La disponibilidad social del conocimiento: una responsabilidad del bibliotecario”, pp. 1-12 [en línea]. 


\section{La biblioteca y las asociaciones bibliotecarias}

La biblioteca se posiciona como un eslabón imprescindible en el libre acceso a la información en Internet, al ser un lugar de proximidad, neutral, y sin afán de lucro; la biblioteca es en muchos casos el único lugar en donde se puede acceder a Internet.

La biblioteca ha pasado de ser de un lugar de conocimiento a un lugar de acceso, ${ }^{19}$ particularmente de acceso compartido a Internet y especialmente para aquellas comunidades en las que el acceso a Internet es limitado, ya sea por el costo o por la falta de infraestructura.

Paralelamente, asociaciones como la ALA y la IFLA han manifestado su convicción sobre la importancia del acceso a la información en Internet a través de las bibliotecas, como un pilar para el desarrollo social de los países.

Particularmente, la IFLA ha emitido una serie de documentos en los que señala la importancia de este acceso. Se destacan: las Directrices IFLA/UNESCO para el desarrollo del servicio de bibliotecas públicas, la Declaración de Glasgow sobre las Bibliotecas, los Servicios de Información y la Libertad Intelectual, el Manifesto de Alejandría sobre Bibliotecas: la Sociedad de de la Información en Acción, entre otros.

La importancia de las bibliotecas en el libre acceso a la información en Internet se reflejó puntualmente en el manifiesto de la IFLA/UNESCO sobre Internet, elaborado en 2006, el cual declara, entre otros aspectos que la libertad de acceso a la información, sin tener en cuenta ni medios, ni fronteras, es una responsabilidad central de los profesionales de las bibliotecas y de la información. Asimismo, la provisión de acceso sin restricciones a Internet en las bibliotecas y

19 Kathryn Zickuhr (2014), "Public libraries and technology: From 'houses of knowledge' to 'houses of access"' [en línea]. 
servicios de información apoya a las comunidades y a los individuos en el logro de su libertad, prosperidad y desarrollo, y sobre todo, las bibliotecas que ofrecen acceso público a Internet tienen la responsabilidad específica de asegurar que el acceso esté disponible para grupos que de otro modo podrían estar en desventaja. ${ }^{20}$

\section{CONCLUSIONES}

El libre acceso a la información está siendo redefinido por los actores anteriormente expuestos; de ahí la importancia de conocer el desarrollo de sus funciones y alcances, y sobre todo el papel que desempeñan en la infodiversidad.

La libertad de acceso a la información en Internet debe ser respetada y protegida; el escenario ideal sería la articulación de estos actores con la finalidad de mejorar los marcos legales e implementar mecanismos que aseguren el flujo de información en Internet sin restricciones, sin censura y sin filtrado. Si se dan las condiciones, la información diversa y plural que ofrece Internet puede ser utilizada para que los usuarios se interesen en ella, la utilicen, produzcan más información y contribuyan a mejorar la sociedad.

20 International Federation of Library Associations and Institutions (IFLA) (2006), Manifiesto de la IFLA/UNESCO sobre Internet. Directrices [en línea]. 


\section{REFERENCIAS BIBLIOGRÁFICAS}

Azuela, Maite y Mónica Tapia Álvarez (2013), Construyendo ciudadanía desde el activismo digital. Guía práctica para multiplicar la incidencia en políticas públicas desde las tecnologías de la información y la comunicación [en línea], http://www. alternativasycapacidades.org/sites/default/files/publicacion_ file/GuiaDeActivismo\%20201403.pdf

Bertoni, Eduardo (comp.) (2012), Hacia una internet libre de censura: propuestas para América Latina, Buenos Aires, Universidad de Palermo [en línea], http://www.palermo.edu/cele/pdf/ internet_libre_de_censura_libro.pdf

Boyd, d. m. y Ellison, N. B., (2008), "Social Network Sites: Definition, History and Scholarship", en Journal of Computer-Mediated Communication, 13 [en línea], http://onlinelibrary.wiley. com/doi/10.1111/j.1083-6101.2007.00393.x/epdf

Castells, Manuel (2005), La Sociedad Red, Madrid, Alianza.

Castells, Manuel (2012), Redes de indignación y esperanza, Madrid, Alianza.

Centro de Estudios en Libertad de Expresión y Acceso a la Información (CELE), "Las llaves del ama de llaves: la estrategia de los intermediarios en Internet y el impacto en el entorno digital", CELE, [en línea], http://www.palermo.edu/cele/pdf/LasLlavesDelAmaDeLlaves.pdf

Denning, Dorothy E. (2000), "Activism, hacktivism, and cyberterrorism: the Internet as a tool for influencing foreign policy", en Computer Security Journal, vol.16, núm. 3, Jun., pp. 15-35.

Dutton, William H. (2013), "Internet Studies: The Foundations of a Transformative Field." Cap.1, en The Oxford Handbook of Internet Studies, Oxford, Oxford University Press [en línea], http://ssrn.com/abstract=2231188 
Gasser, Urs y Schulz, Wolfgang (2015), Governance of Online Intermediaries: Observations from a Series of National Case Studies, Berkman Center Research Publication [en línea], http:// ssrn.com/abstract $=2566364$

Goode, Luke (2015), "Anonymous and the Political Ethos of Hacktivism”, en Popular Communication: The International Journal of Media and Culture, núm 13, Feb. pp. 74-86 [en línea], http://www.tandfonline.com/doi/pdf/10.1080/15405702.2014 .978000

International Federation of Library Associations and Institutions (IFLA) (2006), Manifiesto de la IFLA/UNESCO sobre Internet. Directrices [en línea], http://www.ifla.org/files/assets/faife/publications/policy-documents/internet-manifesto-guidelines-es. pdf

Internet Society, "Breve historia de Internet", ISOC [en línea], http:// www.internetsociety.org/es/breve-historia-de-internet\# Origins

Lara, Juan Carlos y Francisco Vera, Responsabilidad de los prestadores de servicios de internet, ONG Derechos Digitales [en línea], https://www.derechosdigitales.org/wp-content/uploads/pp03. pdf

MacKinnon, R, Hickock, E, Bar, A. y Lim, H. (2014), Fostering Freedom Online: The Role of Internet Intermediaries, Paris, UNESCO [en línea],http://unesdoc.unesco.org/images/0023/002311/231162e. pdf

MéxicoLeaks [en línea], https://mexicoleaks.mx/

Morales Campos, Estela (2011), "La disponibilidad social del conocimiento: una responsabilidad del bibliotecario", en Estela Morales Campos (coord.), Acceso abierto a la información en las bibliotecas académicas de América Latina y el Caribe, México, UNAM / Centro Universitario de Investigaciones Bibliotecológicas [en línea], http://132.248.242.3/ publica/archivos/libros/ acceso_abierto_informacion.pdf 
Organización de las Naciones Unidas para la Educación, la Ciencia y la Cultura (UNESCO), "Free flow of information and social networks: a role for democracy and social participation" [en línea], http://www.unesco.org/new/en/communicationand-information/flagship-project-activities/unesco-and-wsis/ internet-governance/unesco-and-the-igf/6th-igfnairobi/freeflow-of-information-and-social-networks-a-role-for-democracyand-social-participation/

Organización para la Cooperación y el Desarrollo Económicos (OCDE) (2010), The Economic and Social Role of Internet Intermediaries, Paris, OECD, http://www.oecd.org/internet/ieconomy/44949023.pdf

Porrúa Pérez, Francisco (2003), Teoría del Estado, México, Edit. Porrúa.

Ronald J. Mann y Seth R. Belzley (2005), "The Promise of Internet Intermediary Liability”, en Wm. E Mary L. Rev. 47 [en línea], http://scholarship.law.wm.edu/wmlr/vol47/iss1/5

Rosas, Israel. "La responsabilidad de intermediarios en Internet" (2014), en FayerWayer [en línea], http://www.fayerwayer. com/2014/05/la-responsabilidad-de-intermediarios-en-internet/

Stuart Hamilton (2004), To what extent can libraries ensure free, equal and unhampered access to Internet-accessible information resources from a global perspective? (Tesis de doctorado), Royal School of Library and Information Science/FAIFE [en línea], http://www.ifla.org/files/faife/publications/StuartHamiltonPhD.pdf

Taylor, Paul A. (2001), "Editorial: Hacktivism”, en The Semiotic Review of Books, núm. 12. 
Van Hoboken, J. V. J. (2012), Search engine freedom: on the implications of the right to freedom of expression for the legal governance of Web search engines (Tesis de doctorado, FdR: Instituut voor Informatierecht) [en línea] http://dare.uva.nl/ document/2/104098

Zickuhr, Kathryn (2014), "Public libraries and technology: From 'houses of knowledge' to 'houses of access'”, en Pew Internet [en línea], http://libraries.pewinternet.org/2014/07/09/ public-libraries-and-technology-from-houses-of-knowledge-tohouses-of-access/ 


\title{
Actores de la infodiversidad en el siglo XX
}

\author{
ROSA MARÍA MARTÍNEZ RIDER
}

Universidad Autónoma de San Luis Potosí

\section{INFODIVERSIDAD Y SOCIEDAD}

"No conoces realmente a alguien hasta que caminas con él."

Atticus Finch

Película To kill a morning bird [Matar un ruiseñor], 1962

a infodiversidad se analiza desde varias dimensiones,
como la política, la económica, la social, la cultural, la
científica, la tecnológica, la técnica o la educativa, y se
establece como una de las condiciones "[...] que impactan
en las decisiones de nuestro tiempo y que, de manera natu-
ral, pueden afectar positiva o negativamente los programas
de trabajo y la vida de una persona o comunidad." (Morales,
2000: 13) Esto, en función de los contextos sociales en los
que se inscribe, que son polimórficos en cuanto a sentidos
y significados, y que además pueden comportarse dentro de
esquemas autoritarios o plurales.
La infodiversidad, entendida como "[...] el conjunto de
acciones y funciones que permiten y aseguran a todo ser
humano vivir en un ambiente de fuerzas y productos so- 
ciales que lo enriquecen con diversidad de ideas y pensamientos del pasado y del presente [...]" (Morales, 2008: 85), plantea un equilibrio en las diversas formas de pensamiento y en objetividad en la toma de decisiones; coadyuva además en el ejercicio del derecho a la información, y como tal, presenta algunas limitaciones de acceso a los datos confidenciales o reservados; por ejemplo, el respeto a las preferencias lectoras de los usuarios sin menoscabo de su libertad ideológica o de sus creencias.

Así, la infodiversidad ha modificado los escenarios rígidos e intolerantes, para dar apertura a nuevas formas de relación humana y de conocimiento, con base en "[...] la defensa de las múltiples y diversas expresiones del pensamiento [...]" (Morales, 2008: 87), considerando las nuevas formas del multiculturalismo, en las que se tejen mayorías con minorías y de las cuales surge el libro, el documento, la biblioteca y el archivo que son fuente de:

[...] El reconocimiento a las diferencias y la pluralidad de contenido. [...] El impulso a la producción de la información sin importar sus tendencias y sus enfoques. [...] La búsqueda de vías y medios para darle visibilidad a esa diversidad y pluralidad de la información. [...] La variedad de medios de acceso y uso de la información sin restricciones y censuras. [...] El respeto a los derechos conexos a la información y la diversidad: derecho a la información, a la lectura, a la libertad de expresión y a la libertad intelectual. (Morales, 2008: 87)

Es en el marco de la infodiversidad donde se tiene acceso a todo tipo de saberes, conocimientos, funciones y usos sociales de informaciones variadas, que tienen su génesis en distintas historias, idiosincrasias y cosmovisiones, las cuales proporcionan un mejor entendimiento de la naturaleza y del ser humano. 
A continuación se presentan tres casos de infodiversidad: Martin Luther King, Nelson Mandela y Rigoberta Menchú, quienes transformaron los escenarios de origen para promover la democracia en forma de equidad para el ejercicio de los derechos cívicos, políticos y sociales, y en los que la cultura escrita contribuyó a su realización mediante la difusión de ideologías contrahegemónicas en sociedades estereotipadas respecto a condiciones biológicas, culturales y de poder.

\section{ACTORES DE LA INFODIVERSIDAD Y LAS TRANSFORMACIONES SOCIALES}

\section{Martin Luther King}

"Nuestras vidas comienzan a terminar el día en que guardamos silencio sobre las cosas que importan."

Martin Luther King

La infodiversidad hace posible, hoy, el acceso al legado de Martin Luther King (1929-1968), pastor bautista, pacifista, que luchó hasta sacrificar su vida por el reconocimiento de los derechos civiles de la población de color en los Estados Unidos, a raíz de varios incidentes en pro de la igualdad social.

Las lecturas significativas en su vida fueron las obras de Gandhi (1869-1948), en relación con cambio social sustentado en la no violencia, y las de Henry David Thoreau (1817-1862), quien se destacó por los métodos pedagógicos innovadores que utilizó en la educación norteamericana, los cuales contrastaron con el tradicionalismo de la época; 
también influyeron en el pensamiento de King las obras de Hegel (1770-1831) y de Marx.

Thoreau se distinguió por "[...] el rechazo al conformismo social, al formalismo en la religión y al autoritarismo en la política [...]" (López y Cortés), pero en el aspecto religioso Martín Luther King difirió con Thoreau. Su familia contó con un próspero negocio de fabricación de lápices, el cual dejó para ser congruente con sus ideas sociales.

Publicó un libro determinante para él mismo denominado $\mathrm{La}$ desobediencia civil, en el cual expresa que "[...] el mejor gobierno es el que menos gobierna." Por cierto, siempre manifestó su rechazo contra la esclavitud y por la Guerra de Estados Unidos contra México.

Como consecuencia de la segregación racial, King se abocó a desarrollar un pensamiento a favor de la dignidad humana y de la no violencia, que se extendió a la población mediante sus libros, ensayos, discursos y sermones.

Hay quienes consideran a Martin Luther King como un Abraham Lincoln y su discurso titulado "I Have a Dream" ("Tengo un sueño"), leído en 1963 en la ciudad de Washington, le valió el Premio Nobel de la Paz en 1964.

Fundó la Conferencia del Liderazgo Cristiano del Sur (SCLC), y es el autor de Zancada hacia la libertad: la historia de Montgomery, donde analiza el contexto del boicot que sufrió la señora Rosa Parks, por no ceder su asiento a una persona caucásica dentro de un autobús en esa ciudad.

En su libro La fuerza de amar presenta un conjunto de sermones, en uno de cuales declara: "Nosotros, porque somos negros, tendremos que unir a la fortaleza de espíritu la ternura de corazón, si queremos avanzar positivamente hacia la meta de la libertad y de la justicia."

En Por qué no puede esperar narra el desarrollo del movimiento de los derechos civiles en Estados Unidos; en $L a$ 
medida de un hombre expresa su filosofía política, social y económica; en ¿A dónde vamos desde aquí caos o comunidad? describe una prospectiva personal del futuro en relación con el cambio pacífico en su país, que nunca llegó a ver, pues murió en 1968.

Su biblioteca resguardó alrededor de 1,000 libros y en su archivo personal, una gran cantidad de manuscritos, documentos y correspondencia, como la que entabló con el presidente Lyndon B. Johnson y los hermanos John y Robert Kennedy (presidente y el senador, respectivamente hacia principios de los sesenta). El resultado fue la inclusión del voto de la población de color en las elecciones públicas en 1965.

La difusión de estas ideas promovió una serie de movimientos ciudadanos mediante los cuales hoy se disfruta de una mayor y mejor equidad que en los tiempos de excesiva intolerancia racial, así como el arribo de otros líderes, en particular de Malcom X, que también fue asesinado por ideas similares.

Al desclasificarse algunos archivos públicos, se ha generado una polémica en torno a su personalidad. Por ejemplo, se le relacionó con el Partido Comunista, a través del militante Stanley Levison, quien fue su colaborador más cercano, por lo cual fue ferozmente perseguido por John Edgar Hoover, conocido por su anticomunismo recalcitrante.

Asimismo, se le ha acusado de plagio en referencia a algunos escritos de su producción intelectual.

\section{Nelson Mandela}

"Deja que la libertad reine. El sol nunca se pone sobre tan glorioso logro humano."

Nelson Mandela 
Nelson Rolihlahla Mandela (1918-2013) se convirtió en un líder que luchó contra la segregación racial en Sudáfrica, conocida como el Apartheid.

Al frente de La Lanza de la Nación (ANC), participó en varios incidentes hasta que se le condenó a cadena perpetua, y pasó 27 años en prisión, pero siempre fiel a sus ideales, a los cuales nunca sucumbió.

Finalmente, su perseverancia, liderazgo y las condiciones sociales, permitieron su liberación a instancia de Frederik De Klerk, presidente de la República Sudafricana por el Partido Nacional.

Galardonado con el Premio Nobel de la Paz en 1993, trabajó arduamente en el proyecto de una democracia multirracial. Finalmente ganó la elección y fue presidente de su país en 1994, gracias al apoyo y reconocimiento de su causa social.

Sus ideas se fundamentan en un socialismo particular, específico para una África nacionalista, donde "[...] se reformula el concepto de nación como [...] comunidad [que] pretende proteger los contextos culturales de los ciudadanos, como ámbitos proveedores de sentido [...] más que de ejercicio de la política democrática." (Maíz, 2002: 141)

Aunque fue anti-imperialista, su ideología se fundamentó, al igual que la de Luther King, en la no violencia de Gandhi.

Publicó algunos libros, como El largo camino hacia la libertad, una autobiografía que narra los momentos trascendentales de su vida. En Un ideal por el cual vivo señaló que ha peleado contra la dominación blanca y la dominación negra, con el ideal de una sociedad democrática y libre, destacando el respeto "al otro" y a sus derechos de expresión. En Mis cuentos africanos compiló la tradición oral africana: las fábulas, las parábolas, los mitos y las leyendas. En Con- 
versaciones consigo mismo recolectó los pensamientos que escribió durante el tiempo que se le confinó en prisión.

Aunque se le ligó al movimiento comunista y a los actos violentos, finalmente, y a diferencia de King, cristalizó su sueño democrático; además, fue acreedor de varios premios internacionales.

\section{Rigoberta Menchú}

"Yo estoy completamente segura de que la mayoría de la humanidad no cuida su fortuna espiritual."

Rigoberta Menchú

Rogoberta Menchú Tum es una mujer que ha luchado por los derechos humanos y los de los pueblos indígenas. Oriunda de Guatemala, es descendiente del grupo quiché-maya.

En el libro Me llamo Rigoberta Menchu y así me nació la conciencia se narra la explotación, injusticias y discriminación hacia los indígenas de Guatemala.

El poder abusivo de los terratenientes y la guerra contra el ejército de ese país, quien despojó de su casa a la familia Menchú, quemó vivo a uno de los hermanos de Rigoberta y persiguió a su padre, Vicente, motivo que la obligó a aprender a leer y a escribir.

Se le concedió el Premio Nobel de la Paz en 1992, entre algunas controversias; por ejemplo la del antropólogo David Stoll, quien concluye en su libro que la historia de Rigoberta está basada en la mentira. Por ejemplo, menciona que ella sí tuvo acceso a la educación a temprana edad.

Otro documento de Menchú Tum que pasó a la historia fue la carta que turnó a George W. Bush después de los actos terroristas del 11 de septiembre, en la que expresa su sentir al afirmar que: 
No habrá paz, si no hay justicia;

No habrá justicia, si no hay equidad;

No habrá equidad si no hay desarrollo;

No habrá desarrollo si no hay democracia;

No habrá democracia si no hay respeto por la identidad y la dignidad de los pueblos y las culturas.

Ha escrito algunos libros, como Agua y bumanidad, una experiencia recíproca, en la cual refiere la cosmovisión maya del hombre y la naturaleza. Expresa su preocupación por la contaminación del agua. Al respecto,

A juicio del indígena, el globalismo es una ideología rechazable porque tiende a la uniformización planetaria de todos los seres humanos, basada en criterios organizativos (utilitaristas, de mercado), pautas culturales (propias de la sociedad moderna de occidente), valores contextuales (individualismo, privatismo, tecnologismo, cientificismo, secularismo) y una concepción política (representativa, liberal), que atenta contra los modos organizativos, culturales y políticos de las distintas comunidades del planeta. (Moreno, 2002: 184)

Las etnias indígenas tratan de preservar su identidad, costumbres y tradiciones, su unidad en la diversidad, con un profundo respeto hacia la naturaleza; por ejemplo, veneraron a Yun Kaax, dios del maíz y a Chaak, dios del agua y de la lluvia.

Menchú promueve el pacifismo social en su libro Hacia una cultura de la paz y centra su atención en la educación pluricultural para alcanzarla. En Rigoberta, la nieta de los mayas alude a la presencia del ejército guatemalteco en su tierra sagrada, donde diversos actores han abusado de su condición hegemónica. En El clamor de la tierra denuncia la pobreza y el abuso en Guatemala. Se trata de una obra colegiada escrita por los miembros del Comité de Unidad Campesina, que repudia la explotación y la miseria. 
Las ideas de Menchú Tum recorrieron el mundo y sacudieron a los jóvenes estadounidenses. Fue así como "Llegó a ser una lectura preferencial en cursos de letras y ciencias sociales donde se trataba de desarrollar una actitud crítica o de introducir perspectivas no-hegemónicas." (Pratt)

Estas voces no sólo han sido escuchadas, sino que han fructificado en cambios y propuestas desde los organismos internacionales, organizaciones gubernamentales y no gubernamentales, que han impactado en beneficios para el multiculturalismo.

\section{CONSIDERACIONES FINALES}

La infodiversidad amplía el espectro en materia de información y coadyuva en la modificación de estereotipos, patrones culturales y modelos hegemónicos que parcializan las relaciones sociales.

La infodiversidad fundamenta posiciones y criterios desde una perspectiva holística, considerando diversas formas de pensamiento, conocimiento y acceso a la información.

Los planteamientos de Martin Luther King, Nelson Mandela y Rigoberta Menchú marcaron una diferencia social para obtener el respeto a la diferencia en un marco de equidad inserta en el reconocimiento a las minorías.

A los tres personajes se les ha ligado con la izquierda comunista, pero no hay que olvidar que vivieron en épocas y lugares caracterizados por unas derechas intolerantes y sin opciones para quienes se han considerado como "los otros."

A través de la infodiversidad lograron abrir las conciencias hacia la diversidad y la diferencia en las sociedades multiculturales dominadas por las mayorías. 


\section{REFERENCIAS BIBLIOGRÁFICAS}

Burgos, E. (1989), Me llamo Rigoberta Menchu y así me nació la conciencia, México, Siglo XXI.

King, M. L. (1999), La fuerza de amar, Madrid, Acción Cultural Cristiana [en línea] http://www.accionculturalcristiana.org/pdf/ fue_ama.pdf

King, M. L. (1958), Stride toward Freedom: the Montgomery story, New York, Harper \& Brothers.

King, M. L. (1959), The measure of a man, Philadelphia, Christian Education Press.

King, M. L. (1967), Where Do we go from here: Chaos or community?, New York, Harper \& Row.

King, M. L. (1964), Why we can't wait, New York, Harper \& Row.

López, Ch. y Cortés, O. "Nota editorial: Henry David Thoreau" [en línea], http://www.antorcha.net/biblioteca_virtual/

Maíz, R. (2002), "Las ideologías nacionalistas contemporáneas: funcionalidad, estructura y tipología”, en J. A. Mellón (coord.), Las ideas políticas en el Siglo XXI, Barcelona, Ariel.

Mandela, N. (2010), Conversaciones conmigo mismo, Barcelona, Planeta.

Mandela, N. (2010), El largo camino a la libertad, Madrid, Aguilar.

Mandela, N. (2007), Mis cuentos africanos, Madrid, Siruela.

Mandela, N. (2005), Un ideal por el cual vivo, Tafalla, Navarra, Txalaparta.

Menchú T., R. (2008), Agua y humanidad. Una existencia recíproca, Zaragoza, Expoagua Zaragoza. 
Menchú Tum, R. (2001), "Carta al Sr. Presidente George W. Bush" [en línea] http://erroreshistoricos.com/curiosidades-historicas/ documentos-historicos/1248-carta-de-rigoberta-menchu-ageorge-w-bush.html

Menchú T., R. (1993), El clamor de la tierra: luchas campesinas en la historia reciente de Guatemala, Donostia, Gipuzkoa, Tercera Prensa.

Menchú T., R. (2002), Hacia una cultura de la paz, Buenos Aires, Lumen.

Menchú T., R. (1998), La nieta de los mayas, Madrid, El País-Aguilar.

Morales Campos, Estela (2000), "El fin de siglo, la globalización y la infodiversidad”, en Investigación Bibliotecológica, 14 (28), pp. 11-33.

Morales Campos, Estela (2008), "La infodiversidad, un canal de expresión de nuestra diversidad", en Ma. de los Ángeles Rivera y Sergio López Ruelas (comp.), Infodiversidad. La biblioteca como centro multicultural. Memoria del XIV Coloquio Internacional de Bibliotecarios, Guadalajara (Jal.), Universidad de Guadalajara.

Moreno del Río, C. e Ibarra Güell, P. (2002), "Indígenas, indigentes e indigestos. Los nuevos sujetos de la izquierda radical frente al neoliberalismo global", en Las ideas políticas en el siglo XXI, Barcelona, Ariel.

Pratt, M. L. (1999), "Rigoberta Menchú y sus críticos en el contexto norteamericano", en Nueva sociedad, núm. 162, jul.-ago., pp. 24-39 [en línea], http://nuso.org/media/articles/downloads/2779_1.pdf

Stoll, D. (1999), Rigoberta Menchu and the Story of All Poor Guatemalans, Boulder, Co., Westview Publisher Press.

Thoreau, H. D. "La desobediencia civil" [en línea], http://www.antorcha.net/biblioteca_virtual/ 


\section{Las políticas gubernamentales como promotoras del Acceso Abierto, los servicios de información y la alfabetización informativa}

\section{CELIA MiReles CÁRDENAS}

Universidad Autónoma de San Luis Potosí

\section{INTRODUCCIÓN}

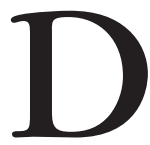

esde hace por lo menos dos décadas, el mundo vive una época en la cual el cambio es la constante. En el ámbito académico, las exigencias del entorno requieren de la revisión de cada uno de los elementos que inciden en la producción del conocimiento; el propósito radica en que se distinga la esencia para fortalecerla y enriquecerla con las oportunidades que ofrecen las tecnologías de la información con el fin de optimizar el tiempo, los costos y reducir las barreras para su acceso y recuperación.

Desde la aparición del Acta Eruditorum de Leipzig, en 1682, y más tarde del Journal des sçavans en 1692, hasta el surgimiento de JoVE, la primera revista científica en forma- 
to video, ${ }^{1}$ tanto autores como editores se han encontrado en un proceso de adaptación a los principios considerados como tradicionales para la creación y difusión del conocimiento.

Así es como los principales retos para la creación de repositorios de Acceso Abierto se centran en la definición de políticas en relación con los tipos de documentos que van a integrar, de acuerdo a la productividad académica de cada institución, los costos que conlleva su mantenimiento en relación con personal cualificado y equipo tecnológico, derechos de autor, así como lo relacionado con la calidad de los contenidos. Si bien el Acceso Abierto promueve la visibilidad de la producción científica en general, no quiere decir que toda esta información tenga los requisitos de calidad deseados.

Por ello, definir las políticas para la reproducción, distribución, comunicación pública y transformación de las obras sin que se afecten los derechos morales y patrimoniales del autor y editor, en su caso, es una labor en la que se encuentran trabajando los especialistas y responsables de los repositorios. Aun cuando es difícil llegar a un acuerdo único, sí se pueden establecer principios comunes que conlleven a lograr beneficios mutuos.

Recordemos que uno de los objetivos de las ciencias de la información es la búsqueda de mecanismos que apoyen el acceso a la información a partir de procesos de organización y transmisión eficientes, por lo que, sin duda alguna, analizar en qué medida se corresponden las políticas de Acceso Abierto del CONACyT con los servicios de informa-

1 JoVE, acrónimo de The Journal of Visualized Experiments, es un recurso y herramienta para estudiantes e investigadores con un enfoque innovador para el aprendizaje de experimentos. Según sus editores, la posibilidad de visualizar el proceso de investigación facilita la transferencia del conocimiento [en línea], http://www.jove.com/ 
ción y la alfabetización informativa en México representa una oportunidad para que los profesionales de la información en el país identifiquen oportunidades de inserción y asuman un papel de liderazgo significativo, con base en la larga experiencia en la organización y puesta en marcha de colecciones documentales en cualquier formato, así como en la oferta de servicios de información creados para facilitar la disponibilidad, manejo y uso de la información por parte de los usuarios.

Es innegable que la disponibilidad y el acceso en línea a documentos digitales han cambiado la relación entre las bibliotecas, los editores y los usuarios, en beneficio de una mayor disponibilidad de oferta, en horarios más amplios y sin limitaciones de espacio. Por lo que, además de participar con la gestión de colecciones, la organización de materiales documentales, el establecimiento de medidas para su descripción y criterios para la digitalización, el esquema de Acceso Abierto demanda de la biblioteca ampliar los servicios que se ofertan; por ejemplo, con servicios de citas basados en web, ya que se considera que la mayor disponibilidad de la información aumentará el impacto de los documentos incluidos en los repositorios.

Se debe tener presente que los actores del Acceso Abierto se refieren a las universidades, los investigadores, las asociaciones académicas, los editores, las bibliotecas, los bibliotecarios y los usuarios, por lo que diferentes mecanismos de comunicación deben ser implementados para llegar a consensos e identificar soluciones viables a cada contexto que intervenga en ese esquema. 


\section{ACCESO ABIERTO Y REPOSITORIOS INSTITUCIONALES}

"El éxito o el fracaso del movimiento de Acceso Abierto dependerá de las acciones locales de los investigadores individuales."

\section{Carl Drott}

Es innegable que los avances tecnológicos, sus efectos en la economía mundial y las nuevas concepciones sobre la justicia social, son la base a partir de la cual el Acceso Abierto a las publicaciones científicas han potenciado las posibilidades de que un mayor número de personas pueda acceder a todo tipo de contenidos, lo cual ha apoyado, a su vez, la generación y edición de materiales y documentos digitales, principalmente en el ámbito científico y educativo, en beneficio de la producción de nuevos conocimientos. ${ }^{2}$ García refiere que: "Hacia 1940 el físico Leo Szilard anticipó el concepto de Acceso Abierto al proponer que los trabajos de los científicos se publicaran junto con cien vales institucionales para pagar el costo de la publicación y así ponerlos al alcance de la comunidad científica."3

Posteriormente, diferentes iniciativas y organismos buscaron soluciones para asegurar la disponibilidad y acceso de la producción documental generada a partir del financiamiento público. Destaca la Budapest Open Access Initiative presentada en 2001, que analizó los proyectos existentes hasta ese momento, con la finalidad de conjuntar esfuerzos para incrementar la disponibilidad libre de la literatura científica disponible en línea. ${ }^{4}$

2 Carl M. Drott (2006), "Open Access", p. 79.

3 Jesús Francisco García Pérez (2013), Derechos de autor en Internet, p. 56.

4 Ten years on from the Budapest Open Access Initiative: setting the default to open (2015) [en línea], http://www.budapestopenaccessinitiative.org/boai10-translations/spanish 
Esa iniciativa configura un nuevo panorama para la producción, distribución y circulación de la información, por lo que representa una gran oportunidad para lograr el tan anhelado y noble propósito de contribuir a una sociedad más informada mediante la socialización y el uso compartido del conocimiento. En este sentido, Drott hace referencia al lema ecologista, "Piensa globalmente, actúa localmente", para expresar que el éxito o el fracaso del movimiento de Acceso Abierto dependerá de las acciones locales y de la participación individual de los investigadores en el proceso de publicación bajo ese esquema. ${ }^{5}$

Si bien el significado y las posibilidades de un fácil y real acceso a las publicaciones científicas todavía está en discusión, un tema que no se ha resuelto es el uso y formas de apropiación total o parcial que el público puede dar a la información contenida en las publicaciones, especialmente en relación con los derechos de autor y de propiedad intelectual en donde se hace la diferencia entre libre para leer y libre para más tipos de uso y reúso. En este tenor, García refiere los cuatro principales modelos que se han desarrollado en este sentido: Open Access, Copyleft, Fair use y Creative commons, los cuales difieren en los aspectos que implementan para el uso de la información. ${ }^{6}$

Por lo anterior, es importante realizar una evaluación de los modelos de Acceso Abierto, y analizar las diferentes perspectivas y contextos socio-políticos que afectan la comunicación científica, tanto tecnológicas, económicas, legales en materia de derechos de autor y propiedad intelectual, además de las variaciones que existen en la transferencia de los derechos de autor requeridos por la mayoría de las revistas como condición para su publicación, ya que un do-

5 Carol. M. Drott, Op. cit., p. 104.

6 Jesús Francisco García Pérez, Op. cit., pp. 72 -73. 
cumento que se encuentra bajo derechos de autor no es un documento abierto por completo.

Los derechos de autor y propiedad intelectual deben quedar muy claros en los materiales que la biblioteca ponga al acceso público, tanto si son productos propios como productos con licencia, además de considerar la localización de los autores de una colección ya establecida que se quiera poner en Acceso Abierto y los criterios sobre depósito legal que guarden esos documentos.

En la actualidad se distinguen dos modelos para el Acceso Abierto: la ruta "dorada", que se refiere a la publicación en revistas cuyos contenidos son libremente accesibles en el Internet desde el momento de su publicación; y la ruta "verde", vía repositorios, en donde, con las políticas apropiadas, se puede captar más rápidamente un mayor número de material, ya que puede realizarse mediante el depósito directo del investigador de sus trabajos en los archivos establecidos, lo cual también se denomina autoarchivado.

Así, los repositorios responden a la necesidad de conservar, preservar y poner a disposición de la comunidad académica y de investigación el patrimonio intelectual que se genera en las instituciones de carácter público. Surgen como una opción para poner a disposición de sus comunidades la información resultado de las investigaciones, en contraparte a los altos precios de las suscripciones de revistas científicas. Conviene recordar que las universidades son importantes generadoras de información documental, como monografías, tesis, artículos de revistas, capítulos de libros, comunicaciones en congresos, informes de investigación, textos literarios, textos docentes, programas informáticos y desarrollos similares como videos y composiciones musicales, entre otros. 
Las políticas gubernamentales como promotoras del Acceso Abierto...

El origen de los repositorios se remota a 1991, cuando Paul Ginsparg fundó ArXiv en los Álamos, Estado Unidos, para la física de altas energías, las matemáticas y las ciencias de la computación. ${ }^{7}$ Posteriormente, numerosas iniciativas originan que en la actualidad existan alrededor de 2, 860 repositorios, distribuidos como se muestra en la Gráfica 1.

\section{Gráfica 1}

Distribución de repositorios por continente

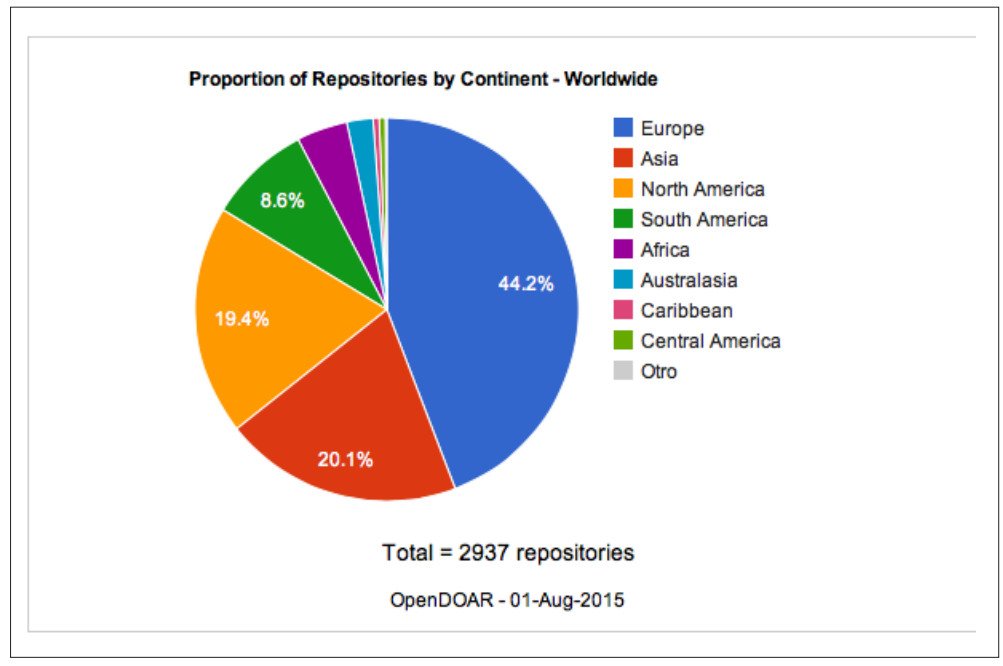

Fuente: "Proportion of Repositories by Continent - Worldwide", en The Directory of Open Access Repositories - OpenDOAR [en línea], http://www.opendoar.org/find. php?format=charts

POLÍTICAS DE GOBIERNO PARA EL DESARROLLO

DE LA CIENCIA Y LA TECNOLOGÍA 2013-2018

Las políticas gubernamentales se refieren a un conjunto ordenado y coherente de antecedentes, valores, criterios generales, intenciones y objetivos, expresados en normas de

7 Ibid., p. 116. 
corto y mediano plazo y en términos de procedimiento y medidas operacionales, que orientan sus decisiones y líneas de acción más inmediatas en un campo determinado de la vida social, y de un sector que se considera prioritario, lo cual beneficia a los ciudadanos al contar con un instrumento común que fundamenta y orienta su acción en temas sociales. $^{8}$

Las actuales políticas gubernamentales para el desarrollo del país se refieren a la necesidad de establecer estrategias y acciones que promuevan la transición hacia una sociedad del conocimiento, por lo que, en diversos apartados, se establece como estrategia fomentar sistemas para el uso, generación y aplicación del conocimiento en beneficio de la comprensión y solución de los problemas que aquejan al país y que le permitan insertarse en una economía del conocimiento.

De esta forma, el Plan Nacional de Desarrollo (PND) plantea como objetivo general: Llevar a México a su máximo potencial, a partir de cinco metas nacionales y tres estrategias transversales. ${ }^{9}$ Para los propósitos de este documento, destacamos la meta 3. México con Educación de Calidad, en donde se establece que un concepto clave para transitar hacia una sociedad del conocimiento radica en el impulso a la ciencia y la tecnología, la difusión de la cultura y el desarrollo de las habilidades que se requieren para tener éxito dada la abundancia de información de fácil acceso que existe hoy en día, en parte gracias al Internet, lo cual requiere que los ciudadanos estén en condiciones de manejar e interpretar esa información. ${ }^{10}$ Así, para lograr una sociedad

8 Egbert Sánchez Vanderkast (2013), Apuntes de taller "Políticas de Información", San Luis Potosí, SLP.

9 Un México en paz; un México incluyente; un México con educación de calidad; un México próspero, y un México con responsabilidad global.

10 Plan Nacional de Desarrollo 2013-2018. Gobierno de la República, pp. 5968 [en línea]. 
más justa y próspera, articular la educación, la cultura, la ciencia y el desarrollo tecnológico son:

[...] la base para garantizar el derecho de todos los mexicanos a elevar su nivel de vida y contribuir al progreso nacional mediante el desarrollo de sus habilidades, conocimientos y capacidad innovadora e impulsando valores cívicos y éticos, que permitan construir una ciudadanía responsable y solidaria con sus comunidades. [...] Es preciso hacer del conocimiento un activo que sea palanca para lograr el progreso individual y colectivo, que permita conducir al país hacia una nueva etapa de desarrollo sustentada en una economía y en una sociedad más incluyentes así como situar a la cultura como servicio básico para ampliar su acceso como un medio para la formación integral de los ciudadanos. ${ }^{11}$

Con estas bases, se establecen los lineamientos que se relacionan con el Acceso Abierto, como se muestra en el Cuadro 1.

Cuadro 1

Meta 3. México con Educación de Calidad

Plan Nacional de Desarrollo 2013 -2018

Meta 3. México con Educación de Calidad.

Objetivo 3.5. Hacer del desarrollo científico, tecnológico y la innovación pilares para el progreso económico y social sostenible.

Estrategia 3.5.5 Contribuir al fortalecimiento de la infraestructura científica y tecnológica del país.

\section{Líneas de acción}

Fortalecer la infraestructura de las instituciones públicas de investigación científica y tecnológica, a nivel estatal y regional.

Extender los canales de comunicación y difusión de la investigación científica y tecnológica, con el fin de sumar esfuerzos y recursos en el desarrollo de proyectos.

Fuente: Plan Nacional de Desarrollo 2013-2018, p. 129.

11 Meta 2. Punto III.2. Plan de acción: articular la educación, la ciencia y el desarrollo tecnológico para lograr una sociedad más justa y próspera, Ibíd., p. 67. 
A partir del PND, se generó el Programa Especial de Ciencia, Tecnología e Innovación (PECiTI), el cual refiere que, para que el país transite hacia la economía del conocimiento, es necesario que la ciencia, la tecnología y la innovación se encuentren vinculadas con los sectores productivos y académicos; por tanto, es necesario destinar más recursos para crear y fortalecer el capital humano nacional y la infraestructura que conlleva este fin (Cuadro 2).

\section{Cuadro 2}

Programa Especial de Ciencia, Tecnología e Innovación 2014 -2018. (PECITI)

Estrategia 5.2 Fortalecer las capacidades físicas y virtuales para la apropiación sociales del conocimiento.

\section{Líneas de acción}

5.2.1 Crear programas y espacios públicos y virtuales para la apropiación social de la ciencia.

5.2.2 Establecer mecanismos para que la sociedad tenga Acceso Abierto al conocimiento generado con financiamiento público.

5.2.3 Impulsar programas masivos de acceso público para fomentar la cultura científica y tecnológica de la sociedad.

Estrategia 5.3 Promover el Acceso Abierto a información científica, tecnológica y de innovación.

\section{Líneas de acción}

5.3.1 Promover que las IES y CPI generen repositorios estandarizados de Acceso Abierto.

5.3.2 Crear infraestructura para la conectividad de los repositorios de información científica y tecnológica.

Fuente: Programa Especial de Ciencia, Tecnología e Innovación. 2014 -2018, p. 58.

Posteriormente, el Programa Institucional CONACyT 20142018 establece lo señalado en el Cuadro 3. 
Las politicas gubernamentales como promotoras del Acceso Abierto...

Cuadro 3

\begin{tabular}{|l|}
\hline \multicolumn{1}{|c|}{ Programa Institucional CONACyT 2014-2018 } \\
\hline $\begin{array}{l}\text { Objetivo 5. Contribuir a la creación, mantenimiento y mejora de la infraestructura } \\
\text { científica y tecnológica del país. }\end{array}$ \\
\hline $\begin{array}{l}\text { Estrategia } 5.2 \text { Fortalecer las capacidades de acceso a la información de CTI para el } \\
\text { uso de estudiantes, académicos, investigadores y la sociedad. }\end{array}$ \\
\hline \multicolumn{1}{c|}{ Líneas de acción } \\
\hline $\begin{array}{l}\text { Promover que la inversión de las instituciones para adquisición de recursos de infor- } \\
\text { mación sean de acuerdo a sus necesidades. }\end{array}$ \\
\hline $\begin{array}{l}\text { Contribuir a la formación de personal especializado en las IES para la selección y } \\
\text { adquisición de recursos de información. }\end{array}$ \\
\hline $\begin{array}{l}\text { Fomentar la utilización de las nuevas tecnologías en el consumo de la información } \\
\text { científica. }\end{array}$ \\
\hline $\begin{array}{l}\text { Contribuir al fortalecimiento institucional y apoyo financiero para profesionalizar las } \\
\text { publicaciones científicas de las instituciones editoras. }\end{array}$ \\
\hline Apoyar la producción científica regional. \\
\hline
\end{tabular}

Fuente: Programa Institucional CONACyT 2014-2018, pp. 31-37.

Así que, por ejemplo, para atender las problemáticas locales, se avanza en la consolidación de las agendas estatales de innovación y en el establecimiento de oficinas para la transferencia de conocimiento, además de que otros programas del Consejo, como el Sistema Nacional de Investigadores (SNI), se encuentran en la búsqueda de mecanismos para vincularse con el sector empresarial y la promoción de las Cátedras CONACyT, entre otras acciones.

\section{LEGISLACIÓN DEL CONACYT PARA EL ACCESO ABIERTO Y REPOSITORIOS}

Con la finalidad de fortalecer la capacidad científica, tecnológica y de innovación del país, así como para democratizar el acceso a la información, la Ley de Ciencia y Tecnología 
del Consejo Nacional de Ciencia y Tecnología (CONACyT) sustenta las bases para ampliar, consolidar y facilitar el acceso a la información científica, tecnológica y de innovación nacional e internacional en texto completo y formatos digitales, y define el Acceso Abierto como:

[...] el acceso a través de una plataforma digital y sin requerimientos de suscripción, registro o pago, a las investigaciones, materiales educativos, académicos o científicos, tecnológicos y de innovación, financiados con recursos públicos o que hayan utilizado infraestructura pública para su realización, sin perjuicio de las disposiciones en materia de patentes, protección de la propiedad intelectual o industrial, seguridad nacional y derechos de autor, entre otras, así como de aquella información que, por razón de su naturaleza o decisión del autor, sea confidencial o reservada. ${ }^{12}$

La estrategia establecida se basa en la creación, por parte de las instituciones y centros de investigación, de repositorios que integren y diseminen la información científica y tecnológica que derive de sus productos educativos, académicos y de investigación en cualquier presentación, así como de las bases de datos que contienen los registros de citas e información bibliográfica con los requisitos de calidad y estándares técnicos que resulten del proceso de publicación formalizada con revisión de pares del autor y evaluadas por CONACYT. Los sujetos de esta disposición son:

Los investigadores, tecnólogos, académicos y estudiantes de maestría, doctorado y posdoctorado, cuya actividad de investigación sea financiada con recursos públicos o que hayan utilizado infraestructura pública en su realización, por decisión personal podrán, depositar o en su caso autorizar expresamente el depósito de una copia de la versión final aceptada para publicar en Ac-

12 Capítulo X. Del Acceso Abierto, Acceso a la Información Científica, Tecnológica y de Innovación y del Repositorio Nacional, artículo 65, en Ley de Ciencia y Tecnología (2014), pp. 34-35 [en línea]. 
ceso Abierto a través del Repositorio Nacional, comprobando que ha cumplido con el proceso de aprobación respectivo, lo anterior bajo términos que al efecto establezca el CONACyT. ${ }^{13}$

Derivados de las reformas y disposiciones de la Ley citada, el 20 de mayo del 2014 se expidieron los Lineamientos Generales para el Repositorio Nacional y los Repositorios institucionales, lo que representa un parteaguas en el país; ahí se establece que la principal función del Repositorio Nacional será el acopio, preservación, gestión y acceso electrónico de información y contenidos de calidad, incluyendo aquellos de interés social y cultural que se producen en México con infraestructura pública, lo cual permitirá "[...] brindar certeza a los contenidos y seguridad a los procesos de diseminación del conocimiento."14

Importante en este apartado es mencionar que el Consejo ha apoyado las iniciativas de Acceso Abierto que han surgido en el país y en América Latina, como Latindex, RedALyC y Scielo, por lo que las publicaciones del índice de Revistas del CONACyT están en Acceso Abierto.

\section{JORNADAS DE CAPACITACIÓN DE CONRICYT}

Si bien muchos de los costos para la compilación, organización y mantenimiento de las colecciones y bases de datos son absorbidos por la biblioteca, los aumentos en los costos de suscripción de revistas han propiciado la organización de las universidades para la adquisición cooperativa y, posteriormente, la creación de consorcios.

13 Artículo 69, Ibíd., p. 35.

14 Art. 15. Finalidad de los repositorios institucionales. Cap. IV. Repositorios Institucionales, en Lineamientos generales para el Repositorio Nacional y los Repositorios Institucionales (2014) [en línea] 
Pero además del factor económico y tecnológico, acceder a la información requiere de la infraestructura necesaria para preparar y fortalecer el capital humano especializado en diferentes disciplinas, así como de especialistas en el uso, manejo, difusión e intercambio de información, ya que su comunicación efectiva es una condición necesaria para que la sociedad pueda apropiarse del conocimiento; de lo contrario, será difícil lograr estos fines tan deseados, que llevarían a la democratización de la información y del conocimiento.

Con esta finalidad, el CONACyT organizó, con las instituciones miembro, el Consorcio Nacional de Recursos de Información Científica y Tecnológica (CONRICyT), que contribuye a dar acceso al conocimiento científico y tecnológico universal a estudiantes, académicos, investigadores y otros usuarios, los cuales se expresan en las líneas de acción establecidas en la estrategias ya referidas en los apartados anteriores. Desde 2013, el CONRICyT ha llevado a cabo las Jornadas de Capacitación como una estrategia, con la finalidad y objetivos mostrados en el Cuadro 4.

\section{Cuadro 4}

Jornadas de Capacitación CONRICyT

Finalidad: crear un espacio de encuentro entre los usuarios de la información científica y las principales editoriales científicas internacionales para capacitarlos en el uso y recuperación de información en las diferentes plataformas de los editores suscritos al Consorcio.

Objetivo: 1.Fortalecer las habilidades informativas de los estudiantes, académicos, investigadores, bibliotecarios y referencistas, para ampliar, consolidar y facilitar el acceso a la información científica en formatos digitales.

Público objetivo. Las Jornadas de Capacitación están dirigido a la comunidad científica nacional: estudiantes de posgrado, profesores, investigadores, bibliotecarios y referencistas.

Fuente: Consorcio Nacional de Recursos de Información Científica y Tecnológica. Jornadas de capacitación 2015 [en línea] http://jornadascapacitacion.conricyt.mx/ 
De esta forma, se han realizado varias sesiones en diferentes universidades del país, y en las Jornadas realizadas en la Universidad Autónoma de San Luis Potosí (UASLP), se presentó la intención para que las escuelas de bibliotecología y ciencias de la información se incorporen a estas jornadas, con el fin de integrar personal especialista en el uso y manejo de las bases de datos, en las diferentes áreas temáticas, que permitan cumplir los objetivos establecidos, lo que sin duda alguna representa una oportunidad histórica para la profesión. ${ }^{15}$

\section{PROBLEMÁTICA, DISCUSIÓN Y OPORTUNIDADES}

Las expectativas que ocasiona el Acceso Abierto se basan en ampliar las oportunidades para que cualquier ciudadano recupere la información que requiera de una forma relativamente fácil y gratuita. Es evidente que lo anterior no es tan sencillo ni tan gratuito, ya que para lograrlo se requiere de un ciudadano alfabetizado en el uso de la información, es decir, una persona que sea consciente de que la información le puede apoyar en sus actividades cotidianas, con conocimientos sobre cómo buscarla, recuperarla, valorarla, asimilarla y, por último, aplicarla acorde a sus necesidades.

Por ello se requiere cambiar la mentalidad sobre los beneficios y el uso común que la información científica que se genera con recursos públicos; considerarla como un bien público, en el entendido de que el financiamiento viene dado a través del pago de impuestos, además de que la falta de información abierta reduce las posibilidades de apropiación social del conocimiento.

15 Sistema de Bibliotecas de la UASLP, 23 de abril de 2015. 
A partir de las políticas establecidas por CONACyT, las universidades están transformando sus formas de financiamiento y de adquisición documental, reajustando sus procesos. El gran reto es llegar a que esa información sea utilizada y usada adecuadamente en términos de generación de nuevos conocimientos; por tanto, el esquema tradicional de los mediadores de la información, como el mercado editorial, los sistemas bibliotecarios y en particular el trabajo profesional del bibliotecario, se encuentra en revisión.

Fomentar la democratización de la información requiere de un amplio esquema de repositorios, con la calidad suficiente para soportar y atender las necesidades científicas y que brinde verdaderas opciones de darle visibilidad nacional e internacional a la productividad que se genera en el país. Por ello, un aspecto que hay que cuidar es el de la calidad, ya que no toda la información que se produce resulta valiosa en términos de impacto; basta recordar que el esquema actual de evaluación requiere de un proceso editorial que incluye editores, consejeros, árbitros, entre otros, los cuales generan un costo.

Por último, la Ley de Ciencia y Tecnología en su apartado de Acceso Abierto tiene como uno de sus propósitos principales el acopio de esta información, con la finalidad de ponerla a disposición pública; pero un aspecto que no se ha discutido todavía es la situación que guardan las universidades respecto al depósito legal de su producción académica, aspecto que marca el decreto vigente en el país y de algunos estados de la República. Por lo tanto, se hace necesario establecer una comunicación y una coordinación entre las entidades depositarias y las entidades universitarias y de investigación, para no duplicar funciones, sino al contrario: 
complementarlas en beneficio de una mejor eficiencia en el uso de los recursos destinados para tal fin.

Sobre este aspecto, Drott refiere que la Biblioteca Británica y varias bibliotecas nacionales europeas han acordado aceptar el archivo electrónico del New Journal of Physics Elsevier, por lo que han celebrado acuerdos con entidades depositarias nacionales para proporcionar copias de todos sus archivos de revistas electrónicas. ${ }^{16}$

\section{CONCLUSIONES}

"Se crea el futuro, aun cuando esto se escribe, y el resultado final sigue siendo incierto."

M. Carl Drott

Si bien los avances para consolidar el Acceso Abierto en las instituciones universitarias y de investigación no han sido tan rápidos como muchos esperaban, es evidente que en la comunicación y la colaboración de los actores involucrados reside gran parte de las soluciones que permiten no duplicar funciones, hacer uso eficiente de los recursos destinados y, con ello, llegar al ideal planteado para que el conocimiento se constituya en el pilar de una sociedad más equitativa e incluyente.

Es deseable aprovechar las actuales políticas definidas por el gobierno que establecen el fomento de la investigación e innovación como bases para el establecimiento de una sociedad y economía del conocimiento; hecho que requiere de una sólida infraestructura de información, además de, entre otras cuestiones, solventar aspectos que conlleven a la consolidación de los repositorios institucionales, prin-

16 Carol. M. Drott, Op. cit., p. 91. 
cipalmente los relacionados con la calidad y disponibilidad de la información y los relativos a los derechos de autor y propiedad intelectual.

Por tanto, la profesión bibliotecaria, en estos momentos, tiene una oportunidad histórica de inserción a partir de su experiencia en el tratamiento de materiales documentales pero, sobre todo, para la promoción del uso y manejo eficiente de la información, principios de lo que se conoce como alfabetización informativa.

\section{REFERENCIAS BIBLIOGRÁFICAS}

Bermúdez Arboleda, P. (2011), "Acceso Abierto, el nuevo paradigma de la sociedad de la información”, en Filiberto Felipe Martínez Arellano (coord.), Acceso Abierto a la información en las bibliotecas académicas de América Latina y el Caribe, México, UNAM / Centro Universitario de Investigaciones Bibliotecológicas.

Bowering M., L. (2011), "Open access and academic library public services. Roles for reference and instruction”, en Open access to STM Information. Trends, models and Strategies for Libraries, Germany, IFLA Publications, 153.

Consorcio Nacional de Recursos de Información Científica y Tecnológica. Jornadas de Capacitación 2015 [en línea], http://jornadascapacitacion.conricyt. $\mathrm{mx} /$

Consorcio Nacional de Recursos de Información de Ciencia y Tecnología [en línea], http://www.conricyt.mx/index.php

Estudio Comparativo de Universidades Mexicanas. Explorador de datos [en línea], http://www.execum.unam.mx/

García Pérez, Jesús Francisco (2013), Derechos de autor en Internet, México, UNAM / Coordinación de Estudios de Posgrado (Colección posgrado). 
Drott, Carol M. (2005), "Open Access", en Annual Review of Information Science and Technology, edited by Blaise Cronin, ARIST, 40 [capitulo 3].

Ley de Ciencia y Tecnología (2014), Cámara de Diputados del H. Congreso de la Unión, México, Última reforma publicada en DOF 20-05-2014 [en línea], http://www.diputados.gob.mx/LeyesBiblio/pdf/242.pdf

Lineamientos Generales para el Repositorio Nacional y los Repositorios institucionales (2014), México, Gobierno de la República / CONACyT [en línea], http://www.conacyt.gob.mx/siicyt/images/Lineamientos-Repositorio-Nacional.pdf

Plan Nacional de Desarrollo 2013 -2018. México, Gobierno de la República [en línea], http://pnd.gob.mx/

Programa Especial de Ciencia, Tecnología e Innovación. 2014-2018, México, CONACyT [en línea], http://www.conacyt.gob.mx/siicyt/images/pdfs/programas/PECiTI.pdf

Programa Institucional CONACyT 2014-2018 (2014), México, CONACyT [en línea], http://www.conacyt.mx/images/conacyt/ normatividad/interna/PROGRAMA_INSTITUCIONAL_CONACYT_2014-2018.pdf

Rodríguez Gallardo, Adolfo (2007), "Acceso Abierto y bibliotecas académicas", en Revista Interamericana de Bibliotecología, vol. 30, núm. 1, ene-jun., pp. 93-104.

Vives i Gràcia, Josep (2005), "Aspectos de propiedad intelectual en la creación y gestión de repositorios institucionales", en $E l$ profesional de la información, vol. 14, núm. 4, julio-ago., pp. 267-278. 


\title{
Desarrollo de redes ciudadanas en un entorno de infodiversidad
}

\author{
ALEJANDRO RAMOS CHÁVEZ \\ Universidad Nacional Autónoma de México
}

\section{INTRODUCCIÓN}

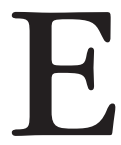

tema de la construcción de ciudadanía conlleva al análisis de los elementos que coadyuvarían a que ésta se diera de forma cooperativa y colectiva en redes participativas e involucradas en los asuntos públicos. En este sentido, la información es un pilar esencial en la formación de opinión y conocimiento, por lo que el libre acceso a ella, así como los flujos que permiten la interacción de ideas y posturas entre las redes ciudadanas y los demás actores -como lo pueden ser los tomadores de decisiones públicas-, son temas de nodal importancia para el análisis.

En este trabajo, tales elementos serán vinculados con el concepto de infodiversidad, el cual ofrece planteamientos muy útiles en el entendimiento de la información en un contexto heterogéneo, en el que pueden impactar los ámbitos económicos, culturales, políticos y sociales. Y en este último entorno es donde se inserta el tema de interés para 
desarrollar el presente documento: el de la construcción de redes ciudadanas participativas en el ámbito de lo público.

El capítulo está dividido en cuatro apartados. En el primero, se discute y se abordan las temáticas generales de la participación ciudadana, así como los elementos que pueden diferenciar una ciudadanía representativa, o de baja intensidad, con una ciudadanía participativa o deliberativa vinculada constantemente con los asuntos públicos. En el segundo, se aborda la discusión del concepto de infodiversidad, tomando en consideración la necesidad de información que requiere la ciudadanía, así como que esta información sea de utilidad y actualidad para su contexto político, social, económico y cultural específico. En el tercero, se realiza el análisis de cómo, en un contexto de infodiversidad, se pueden construir redes ciudadanas para que éstas tengan una acción colectiva encaminada a intentar solucionar sus problemáticas y necesidades específicas. Finalmente, en el cuarto, se concluye con algunos comentarios sobre la necesidad de impulsar la generación de redes ciudadanas participativas en el marco de la infodiversidad.

\section{TENDENCIAS EN EL ANÁLISIS DE}

\section{LA PARTICIPACIÓN CIUDADANA}

Desde hace ya algunas décadas se ha mantenido la discusión de la temática relacionada con el vínculo actor/estructura en el plano social. En este sentido, la principal reflexión se ha centrado en debatir sobre si los actores, mediante sus acciones, son capaces de moldear y modificar la estructura social, o si bien la estructura controla las formas y pautas en las que intervienen los mismos actores sin que se vea realmente alterada su forma (Giddens, 1998). De estas dis- 
cusiones se han desprendido, principalmente, dos formas de interpretar el orden o el cambio en lo social. Por un lado, los "estructuralistas" ponen mayor importancia en la estructura social; y por el otro, los "individualistas" destacan las acciones individuales como variables que permiten ese orden, o cambio.

En este punto, y para los propósitos particulares del documento, es oportuno señalar algunos de los aportes de Ostrom en el entendimiento de la acción colectiva (1994, 1998, 2000, 2003, 2009), pues menciona que hay otras formas de concebir las interacciones colectivas que no necesariamente nos llevan al entendimiento estructuralista o individualista de lo social. En este punto, señala que las interacciones y relaciones sociales pueden generar una "racionalidad superior" (Ostrom, 2008) que puede permitir la interiorización de la necesidad de la cooperación en los individuos para lograr y alcanzar objetivos comunes, más allá de los intereses grupales (de unos cuantos) o individuales.

De lo anterior, se pueden destacar ciertos elementos de la teoría del capital social, como las instituciones, la reciprocidad, el sentimiento de pertenencia y las redes, que pueden contribuir a alcanzar una acción colectiva positiva, pues suelen acrecentar la confianza entre los actores que se encuentran insertos en los mismos procesos de acción colectiva, alcanzando con ello la "racionalidad superior" mencionada por Ostrom.

Ejemplo de lo anterior es la conformación de redes ciudadanas, las cuales mediante objetivos comunes, muchas veces, luchan y buscan su visibilidad ante las autoridades gubernamentales, con objeto de ser escuchadas y de que se atiendan sus demandas específicas. Este tipo de personas, que se relacionan con otras para alcanzar objetivos comunes, ejercen su ciudadanía desde un plano más ac- 
tivo y participativo, y no se quedan exclusivamente en el entendimiento de una ciudadanía representativa o de baja intensidad, caracterizada por la participación exclusiva en periodos electorales en los que se eligen a representantes a ocupar puestos públicos (de gobierno). A diferencia de la idea de democracia representativa, en donde se podría hablar más de población o sociedad civil -que adquiere un papel meramente legitimador o de censura, mediante la emisión del voto, de las acciones del gobierno-, en la propuesta de democracia participativa, activa o deliberativa, sobresale la utilización del concepto de ciudadano, el cual debería tener como características estar informado y participar activamente mediante la argumentación de sus ideas en el espacio público.

En ese mismo sentido, a pesar de que en la década de los setenta del siglo pasado se llegó a argumentar que el concepto de ciudadanía había perdido interés en los estudios relacionados con lo social y lo político (van Gunsteren, 1978), desde la década de los noventa del mismo siglo el concepto se convirtió en una noción incluida en muchos estudios sobre la sociedad y de teoría política, así como una palabra común en prácticamente todos los debates políticos (Heater, 1990). Inclusive, se llegó a definir como una "verdadera explosión" a ese renovado interés que retomó el concepto (Kymlicka y Norman, 1994: 352).

En este mismo sentido, el concepto de participación ciudadana ha adquirido un carácter polisémico debido a las formas tan diversas en las que ha sido abordado, lo que, a la par de que dificulta dar una noción general, ha permitido un enriquecimiento debido a las perspectivas tan diversas en su tratamiento. Un primer intento de entendimiento de ese concepto nos puede indicar que, partiendo de la identificación de los individuos como ciudadanos por pertenecer 
a una comunidad política y social, se da un proceso de injerencia e intervención en los asuntos que atañen al colectivo, es decir, en los asuntos públicos.

El tipo de participación puede variar, en primer lugar, según el tipo de gobierno así como según el grado democrático con el que cuente, pero también de acuerdo a otros factores, como el desarrollo institucional, la capacidad organizativa con la que cuente la sociedad y en la forma en la que se vincule esa sociedad entre ella misma y el gobierno.

Por otro lado, el plano de la participación ciudadana política que interesa más en este documento -pues es la que puede alcanzar un cambio social más amplio- tiene como principal rasgo intervenir y tener injerencia en el tratamiento de las temáticas públicas y en los balances sociales amplios. Sin embargo, para alcanzar este segundo plano de participación, es necesario que los ciudadanos estén bien informados, pues tiene como característica el ser una participación que se da mediante la expresión y la manifestación de argumentos racionales (Cunill, 2008); por lo tanto, surge la necesidad de ahondar en el análisis de la importancia y la relevancia de la información, pero sobre todo de la perspectiva de la infodiversidad y su relación con el fortalecimiento de la participación ciudadana.

Con todo lo anterior, podemos ubicar dos grandes perspectivas interpretativas del entendimiento del concepto de ciudadanía: una con una visión más conservadora, y la segunda más progresista. La primera se vincula con un estatus, igualdad y capacidad de participación en la elección de autoridades gubernamentales, acotada a los periodos electorales de las naciones; mientras que la segunda se relaciona con un principio fundamental de los gobiernos democráticos, así como con el reconocimiento y aceptación de las diferencias y la capacidad de participar a partir de las 
mismas diferencias, además de que la participación sea cotidiana en los asuntos y temáticas públicos. En esta segunda visión se inserta el análisis del entendimiento del concepto en relación con su faceta más dinámica y colaborativa, es decir: con la participación ciudadana.

\section{EL CONCEPTO DE INFODIVERSIDAD}

Como se mencionó con anterioridad, la información es un elemento que resulta esencial en la conformación de individuos que cuenten con elementos necesarios para actuar colectivamente. En este sentido, en un contexto democrático, se puede entender a la información como un elemento esencial mediante el cual los ciudadanos pueden incrementar sus conocimientos y, con ello, su capacidad de acción frente a los asuntos públicos; es decir, la información como un pilar de la construcción de la esfera pública.

Sin embargo, en el escenario actual de la región latinoamericana nos encontramos con que los grupos marginados, pobres y vulnerables, en muchas ocasiones carecen de información importante y oportuna para tener un mejor modo de vida, tal como información relacionada con sus derechos, opciones de empleo, servicios públicos de salud, vivienda y educación, así como el desconocimiento de los programas y políticas públicas. Lo anterior deriva en una nula presencia y participación en los asuntos públicos y en la definición de la agenda, de estrategias y utilización de recursos públicos.

Lo anterior es todavía más interesante de analizar si también se toma en consideración la discusión de los conceptos conocidos como la era de la información y el posterior sociedad del conocimiento. Aquí, es necesario mencionar que se puede relacionar la era de la información con un de- 
sarrollo que impacta directamente a la sociedad; dicho desarrollo amplía considerablemente la potencialidad de los individuos de obtener, generar y compartir información de forma instantánea, prácticamente desde cualquier ubicación y de muy diversas formas.

Sin embargo, se debe tener en consideración que, con el uso de este concepto, se "[...] hace referencia a un nuevo paradigma, cuyos criterios orientadores dan cuenta del camino hacia un tipo de sociedad emergente y en construcción, resultante de la acción de los sistemas tecnológicos y de los progresivos procesos de digitalización.” (BernalMeza y Masera, 2007: 94) Ese tipo de sociedad emergente es denominada por muchos autores como la sociedad del conocimiento.

En este punto, resultan muy útiles los aportes de Morales Campos cuando señala que:

Esta sociedad de la información no sólo incluye usar la información y tenerla disponible y de fácil acceso, también cuenta con una contraparte muy importante: estimular la producción informativa de los múltiples grupos sociales que forma la diversidad que enriquece la globalidad en la que todos tendríamos que estar representados; la riqueza local es muy importante para que la global sea más valiosa. La infodiversidad objetiviza esa diversidad cultural y pluralidad ideológica que equilibra los esfuerzos que conviven en la sociedad y que hace más complejos los alcances de la Sociedad de la Información. (Morales, 2000: 5)

En este punto entramos directamente con el concepto de infodiversidad, al contextualizarlo en el sentido de que: "[...] asociada directamente a la existencia de la diversidad cultural, existe una infodiversidad, que tiene que ver con la pluralidad de conocimientos y saberes. El mayor porcentaje de dicha infodiversidad lo componen los saberes locales, 
los más variados, pero, al mismo tiempo, los más minoritarios y amenazados." (Civallero, 2007: 4)

Para intentar acercarnos a una definición adecuada de la infodiversidad, resulta oportuno dar cuenta de los aportes realizados por Morales Campos, pues fue esta autora la que incluyó el debate del concepto en los círculos académicos. En este sentido, un primer acercamiento a la definición del concepto arrojaría que:

[...] la infodiversidad es pluralidad, es rescate, es conservación, es disponibilidad y libre acceso a la información. La infodiversidad es el conjunto de acciones y funciones que aseguran a todo ser humano la posibilidad de vivir en un ambiente de fuerzas y productos sociales que lo enriquecen con la diversidad de ideas y pensamientos del pasado y del presente, del norte y del sur, del oriente y del occidente, y que establecen un equilibrio en su vida como individuo y en la del grupo social al que pertenece. (Morales, 2001: 43-44)

La anterior definición introduce elementos muy interesantes en el marco del análisis de la participación de las redes ciudadanas, pues en primer lugar toca elementos como el de la variedad de posturas y puntos de vista tan diversos que puede contener la información en su elaboración. En este punto, en algunas de las definiciones más recientes de la ciudadanía, el concepto mismo hace referencia a lo plural y diverso en el que puede ser entendido al ciudadano y a las redes ciudadanas, y la necesidad de que a partir de esa pluralidad y diversidad tengan voz para hacerse presentes en la toma de decisiones públicas y en los asuntos que les competen. Por otro lado, de muy poco serviría esa información si no fuera difundida y compartida con otros actores sociales, salvaguardando sus posturas originales e intentando enriquecer las discusiones públicas. 
Precisamente en este último punto es donde se vincula el concepto de infodiversidad con el concepto de construcción de redes de participación ciudadana que se toca en este trabajo, pues da cuenta de la necesidad de que los individuos se alleguen a información que les resulte útil dentro de su ámbito social, económico, político y cultural específico, y de esta forma puedan actuar de forma colectiva mediante la racionalización superior definida por Ostrom. En el siguiente y último punto de este trabajo se abordará esa discusión, y se continuará destacando la importancia de la información en el actuar colectivo de los individuos.

\section{PARTICIPACIÓN CIUDADANA Y ACCIÓN COLECTIVA EN UN CONTEXTO DE INFODIVERSIDAD}

En la región latinoamericana han existido cambios en cuanto a los tipos de gobierno, que en general apuntan a formas que amplían la posibilidad de participación en contextos más democráticos, lo cual permite la generación de nuevas formas de asociacionismo y de vinculación ciudadana. Lo anterior, a la par de permitir que los ciudadanos ejerzan sus derechos políticos de forma más libre, puede generar un ambiente de participación más activa en los espacios, tareas y ámbitos de la esfera pública (Prats, 1996; Giddens, 2000; Fleury, 2004).

De lo anterior, y vinculándolo con el tema de la infodiversidad y la necesidad específica de información para la formación de redes de participación ciudadana, resulta necesario mejorar y ampliar los canales de participación que permitan un mejor intercambio de ideas entre los ciudadanos y entre éstos con el gobierno. Sin embargo, previo a este momento, resulta igualmente necesario mejorar los 
espacios que ofrece, a públicos amplios, información y documentos para la formación de opinión y ciudadanía; por lo que surge el reto de las bibliotecas públicas, en su carácter social y plural, de constituirse en espacios públicos que coadyuven a la formación ciudadana.

En este sentido, algunos autores han buscado novedosas características que deberían tener una "auténtica participación", vinculada con nuevos elementos que permitan adoptar un nuevo sentido a las tradicionales formas de participación, y que permitan a su vez la institucionalización amplia del establecimiento de decisiones públicas. En este punto, Colino y del Pino (2008) han mencionado que un modelo de democracia participativa debe de tener la capacidad de proporcionar por lo menos tres tipos de beneficios, relacionados con:

1. Un beneficio de tipo funcional, donde se revalore la importancia de la co-responsabilidad ciudadana con las autoridades gubernamentales de orden local, en distintas materias de interés social, lo cual puede redundar de forma positiva en el empleo, y llegar a representar un ahorro en las tareas organizacionales y de gestión del gobierno.

2. Un beneficio de tipo social, que tenga por objetivo el reforzamiento de la idea de colectividad y comunidad, y que pueda servir como contrapeso a fenómenos de individualización y tendencias de comportamiento no cívicas, mediante la implementación de estrategias que permitan la generación de capital social.

3. Por último, un beneficio de tipo político, caracterizado por procesos de formación educativa y cultural tendiente a mejorar y fortalecer la cooperación y los esfuerzos en la definición de intereses comunes. 
Ahora bien, el concepto de infodiversidad podría ser un elemento muy importante al considerar la necesidad de que los ciudadanos se alleguen de más y mejor información que les brinde mejores elementos para participar social y políticamente. En este marco, Morales Campos en su libro Infodiversidad y cibercultura (2006) refiere una serie de elementos que enmarcan el entendimiento del concepto de infodiversidad; entre ellos destacan:

1. La diversidad y riqueza cultural que genera una amplia gama de información que, de igual forma, es producto de la diversidad y la pluralidad de ideas y puntos de vista. En este sentido, al hablar de infodiversidad, se conlleva a la necesidad de reconocer las diferencias, entre otras cosas, de contenido y de estilo en las que se crea información.

2. La infodiversidad implica, a su vez, defender y proteger la existencia de las tan variadas y diversas manifestaciones de la creación de información y, al mismo tiempo, la conservación de las ideas y las propuestas del hombre en todos los tiempos.

3. La infodiversidad también se vincula con la pluralidad, rescate, preservación, disponibilidad y libre acceso a la información, pues es el conjunto de acciones y funciones que pueden asegurar a todo individuo la posibilidad de vivir en un ambiente de fuerzas y productos sociales que lo enriquecen con el conocimiento y entendimiento de la diversidad de ideas y pensamientos.

4. La infodiversidad se puede traducir en ideas que propician la comunicación, la discusión, la aceptación y la discrepancia, así como la comparación, la exclusión y la generación del nuevo conocimiento y la 
nueva información. Lo anterior se relaciona directamente con la idea de ciudadanía participativa, pues para que la propia participación se dé, se necesita de una correcta y clara argumentación de las ideas.

5. La infodiversidad, de igual forma, abarca toda la amplia gama de los saberes, las ideas y los conocimientos que se registran como información y que, al ser multiculturales, permiten el conocimiento y reconocimiento de sí mismo y de su grupo, así como la importancia y valoración de los otros.

6. Finalmente, la infodiversidad busca un equilibrio social que requiere la convivencia y aceptación de los múltiples pueblos, etnias, culturas, gobiernos, personas, sin importar la forma, la procedencia o la cualidad de la información.

En este mismo sentido, la misma autora menciona una tendencia a una participación ciudadana más libre y democrática en los procesos sociales (Morales, 2006). Pero también una serie de elementos que las redes ciudadanas deberían de perseguir, tanto en la búsqueda de información, así como en las formas en las que se difunde y genera, relacionados puntualmente con:

1. Observar y denunciar la falta de cumplimiento de leyes y de políticas, o de atropellos a ciertos sectores específicos de la sociedad. Lo cual puede denotar una ciudadanía crítica, interesada y vinculada con los asuntos públicos.

2. Vigilar aspectos inherentes a la oferta y uso de información, con objeto de que los canales para allegarse de información y para difundir la nueva, sean los adecuados y funcionen correctamente en la sociedad. 
3. Respetar y conservar la infodiversidad, lo cual denota una importancia y valorización de las formas de pensar que pueden ser muy diversas.

4. Permitir la pluralidad de ideas reflejada en la información, que se puede relacionan con la democratización de posturas y opiniones que inciden en la forma en la que se atienden los asuntos públicos.

5. Finalmente, respetar los aspectos éticos de la información, lo que también se vincula con el respeto a un código de ética tanto del observador como del prestador de servicios de información, el cual tiene un papel muy importante en la elaboración de políticas públicas de información que permitan a los individuos su participación en el desarrollo local y global.

En términos generales los puntos antes mencionados dan cuenta de la estrecha relación que guardan los conceptos de infodiversidad con el de redes ciudadanas, y cómo ambos conceptos se pueden retroalimentar, pues en ambos el tema de la información resulta esencial para su entendimiento.

\section{CONCLUSIONES}

Como se pudo apreciar en este documento, la información se constituye como un elemento que impacta de forma transversal los diferentes momentos de la formación ciudadana: desde las temáticas relacionadas con los canales y fuentes de consulta de información veraz, pertinente y oportuna, pasando el proceso de entendimiento y asimilación de la información, hasta la fase de aparición en la esfera pública mediante la argumentación y expresión de ideas; 
en todas estos momentos, la información resulta esencial para ayudar al paso de una democracia representativa a una participativa. Asimismo, se debe tomar en consideración la infodiversidad, pues sólo aquella información trascendente para una realidad concreta resultará provechosa para la acción colectiva mediante la generación de redes de participación ciudadana. En este sentido, y como lo argumenta Morales Campos (2000: 6):

El ciudadano de hoy se convierte en un usuario de información sin necesidad de estar asociado a la academia, a la investigación o a una biblioteca; pasa rápidamente de la consulta de un diario impreso a analizar la información de una página Web o a comentar vía Internet con un colega lejano los movimientos de la bolsa; el niño de la escuela elemental hace sus tareas consultando los recursos de la red y comenta sus resultados con sus compañeros reales y virtuales.

Por lo cual resulta muy oportuno seguir debatiendo y aportando ideas en cuanto a la forma más apropiada en la que los ciudadanos (y redes ciudadanas) se alleguen de la mejor y más oportuna forma de información posible, con el objetivo de que su presencia en la discusión y puesta en agenda de asuntos públicos sea realmente tomada en consideración, y con ello, intentar mejores niveles de desarrollo.

La propuesta del ejercicio de la participación en redes ciudadanas del presente documento parte de que, como indica Ostrom (1998), estas redes pueden ser utilizadas por los distintos actores, mediante distintas lógicas y pautas de integración y conducta, donde no solamente es necesaria una racionalidad de intereses e instrumental sino también una perspectiva más amplia. De esta forma, en las redes ciudadanas no sólo se persiguen resolución de problemáticas específicas, recursos tangibles o económicos, sino también recursos intangibles, como el compartir formas de 
pensamiento, ideología, identidad, confianza, pertenencia y responsabilidad, por citar algunos, además de que en la elaboración de estos proyectos de participación colectiva se trabaja con elementos constructivistas e intersubjetivos que atañen directamente a informaciones específicas, y que muy difícilmente podrían ser alcanzados con elementos netamente economicistas.

De igual forma, es preciso recalcar el señalamiento relativo a que el análisis de la formación de redes ciudadanas conlleva al estudio de otros elementos y características de acciones sociales, culturales, de infodiversidad y políticas que superan a las meras cuestiones de la elección racional.

En este mismo sentido hay retos, como el de la necesidad de avanzar a una participación ciudadana más libre y democrática, donde, como lo menciona Morales Campos (2006), las redes ciudadanas se vuelvan observadoras y denunciantes de la falta de cumplimiento de leyes y políticas, entre otras cuestiones que se relacionen con el equilibrio social. De igual forma se abre un nuevo campo de acción de las redes ciudadanas, "[...] un ámbito donde la participación ciudadana se hace imprescindible, y ése es precisamente el de la información." (Morales, 2006: 99).

Finalmente, en el contexto de los elementos antes señalados, resulta necesario hacer referencia a algunos elementos aglutinadores que dan pie a una construcción de redes ciudadanas que tengan vínculos más sólidos para la acción colectiva, los cuales se vinculan con: el sentimiento de comunidad; identidad colectiva; el sentimiento de pertenencia; el sentimiento de dependencia recíproca, es decir, que uno es parte de un conjunto en donde importa tanto el todo como las partes; y finalmente, con un elemento sociocultural que enmarca saberes, formas de comportamiento, ideologías y formas de comprender al mundo. 


\section{REFERENCIAS BIBLIOGRÁFICAS}

Bernal-Meza, R. y Masera, G. (2007), "Sociedad de la información: etapa posterior de la globalización/mundalización. Desafíos y riesgos para América Latina”, en Realidad Económica, 227, pp. 90-116.

Morales, E. (2000), "La sociedad de la información en el siglo XXI y la biblioteca universitaria", en XI Seminario Nacional de Bibliotecas Universitarias, Universidade Federal de Santa Catarina.

Morales, E. (2001), La diversidad informativa latinoamericana en México, México, UnAm / Centro Coordinador y Difusor de Estudios Latinoamericanos.

Morales, E. (2006), Infodiversidad y cibercultura, Buenos Aires, Editorial Alfagrama.

Colino, C. y del Pinto, E. (2008), "Democracia participativa en el nivel local: debates y experiencias en Europa", en Revista catalana de dret públic, 37, pp. 247-283.

Civallero, E. (2007), Infodiversidad: Globalización, información y sociedad; el papel de las bibliotecas, Universidad Nacional de Córdoba, Argentina.

Cunill, N. (2008), "La construcción de ciudadanía desde una institucionalidad pública amplia”, en R. Mariani (coord.), Contribuciones al debate: Democracia/Estado/Ciudadanía Hacia un Estado de y para la democracia en América Latina, vol. II, PNUD-UE., pp. 113-138.

Fleury, S. (2004), "Construcción de ciudadanía en entornos de desigualdad”, en C. Binetti y F. Carrillo (eds.), ¿Democracia con desigualdad? Una mirada de Europa hacia América Latina, Nueva York, Banco Interamericano de Desarrollo, pp. 133-169.

Giddens, A. (1998), La Tercera Vía. La renovación de la socialdemocracia, Madrid, Taurus. 
Giddens, A. (2000), Un mundo desbocado. Los efectos de la globalización en nuestras vidas, Madrid, Taurus.

Heater, D. (1990), Citizenship: Tire Civic Ideal in World History, Politics, and Education, Londres, Longman.

Kymlicka, W., y Norman, W. (1994), "Return of the Citizen: A Survey of Recent Work on Citizenship Theory", en Ethics, 104, pp. $5-42$.

Ostrom, E. (1994), "Constituting Social Capital and Collective Action", en Journal of Theoretical Politics, 6, pp. 527-562.

Ostrom, E. (1998), "A Behavioral Approach to the Rational Choice Theory of Collective Action (Presidential Address, American Political Science Association, 1997)", en American Political Science Review, 92, pp. 1-22.

Ostrom, E. (2000), "Social Capital: A Fad or a Fundamental Concept?", en Partha Dasgupta e Ismail Serageldin (comp.), Social Capital: A Multifaceted Perspective, Washington, D.C., The World Bank, pp. 172-214.

Ostrom. E. (2009), "A General Framework for Analyzing Sustainability of Social-Ecological Systems”, en Science, 325, pp. 419-422.

Ostrom, E. y Ahn, T. K. (2003), "Una perspectiva del capital social desde las ciencias sociales: capital social y acción colectiva”, en Revista Mexicana de Sociología, 65, pp. 155-233.

Prats y Catalá, J. (1996), Gobernabilidad democrática en América Latina finisecular, Washington, BID.

Van Gunsteren, H. (1978), "Notes on a Theory of Citizenship", en P. Birnbaum; J. Lively y G. Parry (comp.), Democracy, Consensus and Social Contract, Londres, Sage, pp. 14-15. 


\title{
La biblioteca como factor crítico en las redes de infodiversidad
}

\author{
JAIME RÍOS ORTEGA \\ Universidad Nacional Autónoma de México
}

"Sólo hay un ver perspectivístico, solo un conocer perspectivístico, y cuantas más emociones dejemos que tomen la palabra acerca de una cosa, cuantos más ojos, ojos diferentes, sepamos emplear para la misma cosa, tanto más completos serán nuestro concepto de esa cosa y nuestra objetividad [...]"

F. Nietzsche, Genealogía de la Moral, Tercer tratado, p. 82

\section{INTRODUCCIÓN}

7 ecientemente, ha cobrado peso intelectual el concepto de la información socialmente valiosa como uno de Los fundamentos del trabajo disciplinario y profesional de la bibliotecología. Cabe señalar que la biblioteca es una institución con tareas de enorme valor social, ${ }^{1}$ vinculadas a la organización de la información, la preservación y su disponibilidad para la sociedad o los individuos. Se ha tran-

1 Existe una amplia gama de reflexiones teóricas, entre las cuales sobresale la postura de Saracevic respecto a la tradición cognoscitiva de la bibliotecología; Saracevic señala que la solución de los problemas ligados al registro y la transmisión del conocimiento ha ampliado el trabajo de las ciencias de la información (Saracevic, 1992). 
sitado del soporte libro o revista, como distintivos del quehacer bibliotecario, a un ámbito cuya naturaleza basada en la tecnociencia presenta, desde hace décadas, una perspectiva diferente de la información. En efecto, esta última es polisémica y su análisis abarca la esfera pública, privada, comercial, económica, cultural, así como algunas otras. Por lo anterior, la biblioteca se ha constituido, principalmente desde el siglo $\mathrm{XX}$, en un actor cuyas acciones repercuten en prácticamente toda la vida social y científica de las sociedades.

Precisamente, el impacto de la tecnociencia en la conformación de la sociedad informacional ha puesto de relieve la necesidad de reflexionar nuevamente acerca de las aportaciones de la biblioteca como un ser institucional activo y de vanguardia. El ejemplo más claro se hace presente en la interacción de las redes sociales apoyadas en la tecnociencia, así como en la apertura y acceso abierto a la información generada por la propia sociedad. Lo anterior no se trata únicamente de fenómenos de estudio, sino de tendencias ${ }^{2}$ concretas en las cuales se desenvuelve la vida cotidiana de las personas, las instituciones y los países articulados a la globalización.

Con base en las consideraciones antes expuestas, a continuación se analizará el rol de la biblioteca en el siglo XXI, su vinculación con las redes de infodiversidad, así como las consecuencias sociales del acceso abierto en la sociedad. De igual modo, se mencionarán algunos retos para los bi-

2 Respecto a este punto, ha emergido una interrogante: ¿cómo se inserta la biblioteca en el marco de los nuevos entornos de información? Esta pregunta es muy importante ya que, en estos entornos, la interacción virtual es un factor crítico en el acceso y transferencia de información. Por lo anterior, la IFLA ha propuesto cinco tendencias que sugieren directrices sobre el trabajo que las bibliotecas deben hacer para consolidar sus aportaciones en beneficio de las diversas comunidades que componen el mundo actual. (Cfr. IFLA Trend Report, 2013.) 
bliotecólogos que deberán innovar su trabajo de cara a las tendencias enunciadas.

\section{LA BIBLIOTECA COMO SER SOCIAL METAMÓRFICO}

Es conveniente subrayar que la biblioteca es fundamentalmente una institución orientada a resolver los problemas de transferencia de información socialmente valiosa; esta última entendida como una necesidad de naturaleza social. Desde hace siglos, la biblioteca ha instituido prácticas profesionales con el objetivo de describir recursos de información y la recuperación de éstos, en contextos básicamente institucionales. Lo anterior es imprescindible para el diseño y mantenimiento de sistemas de información. En consecuencia, es posible afirmar que la información organizada y recuperable a través de sistemas elaborados ex profeso, es un distintivo de orden cultural y científico de las bibliotecas, que esencialmente se ocupan de la información socialmente valiosa.

En este punto es indispensable diferenciar entre la información de naturaleza general respecto a la información que hemos denominado valiosa, ya que si bien la biblioteca ha desarrollado capacidades teóricas y profesionales para trabajar con una gama muy amplia de recursos de información, específicamente está interesada en la información calificada como valiosa. Esto es así porque dicha información forma parte de la cultura de los países y sus capacidades científicas, además de constituir un elemento imprescindible para la educación de todo tipo. Evidentemente, se hace patente la herencia cognoscitiva de orden social, político, económico y científico sobre la cual se articulan innovaciones científicas y de cambio social. Por lo tanto, la biblioteca no tiene bajo su responsabilidad la preservación y orga- 
nización del infinito mundo de información contenido en Internet; ${ }^{3}$ antes bien, sólo se ocupa de la información a la cual ya hemos hecho referencia. De esta manera es claro que es absolutamente indispensable contar con el bagaje teórico y profesional contenido en las bibliotecas para que los países avancen social y científicamente.

Adicionalmente, el entorno que circunda a las bibliotecas se mueve continuamente y genera efectos deseados y no esperados, los cuales obligan a reconstituir las funciones sustantivas de la biblioteca. El entorno está constituido de dimensiones económicas, políticas, culturales, tecnológicas y científicas que en su conjunto determinan la capacidad de interacción de las bibliotecas en la sociedad. Esto explica por qué países que muestran altos Índices de Desarrollo Humano $^{4}$ normalmente cuentan con sistemas bibliotecarios sólidos, competitivos y ricos en materia de recursos de información y servicios para los usuarios.

En esencia, puede decirse que las funciones sustantivas de la biblioteca no han cambiado desde hace siglos; no obstante, sí es posible afirmar que estas funciones se han vuelto más complejas, abstractas, profesionales e inclusivas, que además requieren en mayor medida de infraestructuras

3 Es evidente que Internet contiene cantidades difícilmente mesurables de información que se incrementa, por lo que oportunamente fue juzgado por Morales, quien enunció la existencia y permanencia de la información original y la información reciclada. (Cfr. Morales, 2006: 85.) Esto implica que la coexistencia de estas dos facetas en el universo de la información se presenta como un componente adicional derivado de la retroalimentación de ideas y que el escenario deseado requiere adoptar dinámicas de carácter colegiado que enriquezca la producción científica.

4 En relación con el contexto que afecta a América Latina en materia del insuficiente acceso a la educación formal y los profundos niveles de desigualdad, los bibliotecólogos deben tomar en consideración que la información es uno de los pilares que posibilita el mejoramiento progresivo de la calidad de vida en nuestros países; con lo anterior, se coadyuvará en la consolidación de una espiral virtuosa que garantice mejores estándares de vida y desarrollo humano. 
tecnocientíficas, así como de la construcción de teorías explicativas $^{5}$ y normativas de mayor envergadura.

Por otra parte, es interesante observar que, de acuerdo con las diferentes perspectivas de explicar la sociedad, en gran parte de ellas la biblioteca frecuentemente tiene asignados roles muy precisos, pero que no modifican en lo fundamental las funciones a las que en párrafos anteriores nos hemos referido. En todo caso, matizarán alguna de ellas, pero siempre estarán articuladas al conjunto de tareas que implica la construcción de sistemas de información. Dicho de otro modo, las denominaciones de sociedad posindustrial, sociedad de la información y sociedades del conocimiento, constituyen diferentes modos de observar a la sociedad, explicarla y asignarle objetivos determinados. En función de ello, las bibliotecas han actualizado su imagen y función pública, pero sin dejar de lado el conjunto de actores y elementos que conforman el circuito de transferencia de información socialmente valiosa. ${ }^{6}$ Por ello, es posible constatar que las bibliotecas pueden estar principalmente orientadas a la conservación y preservación de materiales, la difusión de la ciencia y la cultura, o bien, al trabajo de la academia científica o grupos epistémicos de las diferentes ciencias, sin dejar de lado el papel preponderante que jue-

5 Un buen ejemplo de teoría explicativa de gran envergadura es la aportación de los bibliotecólogos para comprender el complejo universo de las entidades de información. La respuesta que plantearon los bibliotecólogos en su devenir a través del tiempo y la experiencia fue la empresa de cartografiar el complejo universo de las entidades de información, la cual culminó una de sus etapas con el surgimiento del modelo Entidad-Relación FRBR. (Cfr. Tillet, 2004.)

6 Las interpretaciones más interesantes provienen del enfoque económico que plantea la Teoría de los Bienes Comunes, de acuerdo con la cual las bibliotecas pueden entenderse como instituciones sociales que funcionan bajo el modelo de common-pool resources. Bajo este argumento, Hess y Ostrom han afirmado que los recursos de información en las bibliotecas se gestionan a partir del uso e interés común de los propios involucrados; en nuestro caso incluye a los usuarios o ciudadanos. (Ostrom, 1995: 40.) 
gan actualmente como bibliotecas públicas vinculadas a la educación y a la ciudadanía.

Sin importar el énfasis del tipo de biblioteca del que se trate, para esta institución social no hay margen para renunciar al conjunto de actividades profesionales y disciplinarias expuestas anteriormente. Por el contrario, su trabajo se ha vuelto más complejo ya que la trascendencia de sus tareas posee un gran peso cultural, científico y tecnológico. Así pues, la biblioteca cumple funciones de depuración de la herencia cultural, ${ }^{7}$ entendida esta última como información, así como del conocimiento considerado válido y de impacto social. Adicionalmente, la naturaleza de su trabajo le permite llevar el registro de nuevos elementos culturales y científicos, o bien, permite y posibilita la integración de conocimientos novedosos producidos desde la academia o de diversas expresiones sociales a sistemas de información a través de los cuales es posible tener acceso a ellos.

Difícilmente se encontrará en la sociedad un organismo que realice este tipo de tareas, y de ello se desprende la necesidad de impulsar y fortalecer los sistemas bibliotecarios, así como la infraestructura que los sustenta, además de acrecentar la formación de recursos humanos altamente especializados en la disciplina bibliotecológica y en la producción de teoría disciplinaria.

En este orden de exposición, resulta paradójico e inexplicable que las bibliotecas no siempre estén ubicadas en el eje de las acciones de los planes y políticas públicas de

7 Una parte de nuestra herencia cultural está contenida en los acervos bibliográficos que las bibliotecas ponen al alcance de las comunidades. Respecto a ello, retomo la afirmación hecha por Hess y Ostrom sobre el conocimiento registrado, entendido como un "[...] recurso compartido, un complejo ecosistema que constituye un bien común, compartido por un grupo de personas que se sujetan a dilemas sociales.” (Hess y Ostrom, 2007: 3.) 
los gobiernos latinoamericanos. Por ello, es indispensable subrayar la importancia de este organismo social.

\section{ACCESO ABIERTO A LA INFORMACIÓN}

El costo de la información socialmente valiosa ha sido costosa desde hace varios siglos, ya sea por su codificación, los soportes que la contienen, por lo codificadores que la estructuran, o bien, por los medios a través de los cuales se suministra. El ejemplo más claro son los servicios de información que agrupan a las revistas de investigación más importantes producidas por la academia. Otro ejemplo son las empresas editoriales de prestigio mundial, en las cuales publican los líderes de opinión de diversos ámbitos. El foco de tensión que se ha venido expandiendo en los últimos años radica básicamente en el derecho de los individuos a la información y el conocimiento de relevancia social o científica frente a quienes se consideran los propietarios titulares de la información; no obstante que los autores en algún momento lo consideren injusto. El hecho es que a escala mundial se ha desarrollado un movimiento que esencialmente postula el derecho humano irrestricto de tener acceso a la información, consultarla y hacer uso de ella. Desde hace por lo menos dos décadas, los derechos privados de propiedad sobre la información contra quienes consideran que es un bien público ${ }^{8}$ han tenido en medio de la disputa a la biblioteca como una entidad con capacidad de mediación,

8 Entre sus tantos aportes, el Premio Nobel de Economía de 1970, Paul Samuelson, también abordó la dimensión conceptual de los bienes públicos (commons), en cuyo enfoque se introdujo un dilema social que describió Garret Hardin en 1968, conocido como Tragedy of the commons, el cual es un referente para comprender la discusión que se ha suscitado en los años recientes, adoptando una postura a favor o en contra. 
que, por una parte, respeta el derecho de los titulares sobre la información y, por la otra, trata de suministrar sin ningún tipo de obstáculo a quienes requieren de ella. Existen diversas iniciativas mundiales que promueven la desaparición del costo de la información, basadas en el argumento de su producción social y que en tanto herencia común del ser humano, no puede ser un producto cultural sometido a reglas del mercado. La discusión seguramente llevará más años antes de lograr acuerdos definitivos; en tanto, la biblioteca incrementará su valor social y cognoscitivo gracias a que es una mediadora y proveedora de información valiosa. En paralelo, y más bien como consecuencia de lo anterior, frente a nosotros tenemos un escenario mundial que promueve o trata de sentar las bases para un acceso abierto a la información y al conocimiento sin trabas de ninguna especie.

Existe demasiada literatura especializada que aborda esta temática; sin embargo, me interesa matizar que, más allá de constituirse en un conflicto representado de modo polarizado entre propietarios y desposeídos, el contexto orientado hacia la democracia ha marcado las discusiones recientes sobre este problema. De modo sintético, puede afirmarse que ha quedado en claro lo siguiente:

1. El acceso abierto es un pilar de la democratización del conocimiento. Es decir, la igualdad y el derecho que los individuos pueden ejercer debido al carácter de bien público de la información socialmente valiosa.

2. Gracias al acceso abierto es posible coadyuvar en la reducción de las brechas culturales. En realidad, este acceso puede concretarse si se apoya el desarrollo de infraestructuras de Tecnologías de la información y la Comunicación (en lo consecutivo, TIC), junto con el flujo de conocimiento valioso contenido o repre- 
sentado por la información. Cabe considerar que las TIC son cada día más globales; de tal modo que gracias a los dispositivos móviles ya no son necesarias construcciones materiales y adquisición de acervos cuyo costo, con mucho, son mayores respecto a la colocación de puntos de acceso y teléfonos o tabletas, o bien, computadoras personales de bajo costo, pero eficientes para conectarse a la web a través de la cual transitan la información.

3. En este sentido, la reducción de brechas de información y culturales han encontrado soluciones eficaces, las cuales pueden implementarse en tiempo relativamente cortos. Es así que las brechas culturales y de información cada vez más estarán ubicadas en el dominio cognoscitivo por parte de los sujetos y no propiamente en la disponibilidad de información.

4. El acceso abierto también ha contribuido al análisis de la información como un bien público, cuya resonancia se hace sentir en el ámbito de la justicia social. De tal modo que no basta con tecnología disponible, también se requiere de información valiosa, además de las capacidades de los individuos para decodificarla y hacer uso eficiente de ella, ya sea para el mejoramiento de la vida individual, grupal, comunitaria o del país.

5. La UNESCO ha destacado en diferentes foros la necesidad de comprender el desarrollo social como un ideal sustentado en el conocimiento compartido. Como es obvio, para compartir es necesario el acceso abierto, ya que de otro modo resulta falaz señalar que es posible propiciar el desarrollo social con base en el conocimiento que de origen implica gastos económicos que las naciones pobres o los grupos vul- 
nerables no pueden pagar. Por tal razón, el Estado también ha revalorado su función respecto a la distribución de la información como un bien público, particularmente cuando éste ha sido producido con impuestos que el propio Estado recauda y son invertidos en la producción de nuevo conocimiento, que a su vez se concreta en la producción de nuevas informaciones con valor cognoscitivo o social.

6. Gracias, pues, al acceso abierto el Estado ha cobrado conciencia de que los impuestos públicos son devueltos a la sociedad en calidad de conocimiento o información y cuya distribución se hace a través de las bibliotecas y las instituciones educativas.

En síntesis, el acceso abierto no es tan sólo una bandera o slogan que retóricamente vende muy bien, que en la vida cotidiana es difícil beneficiarse de éste. De nueva cuenta, la biblioteca procura y promueve un estatus institucional material y relevante que facilita el acceso a la información, independientemente que sea comprada o pública, en beneficio de los usuarios.

Vale destacar que gracias a la biblioteca, la cual concentra recursos de información y sistemas de recuperación, es posible acercar a los ciudadanos o jóvenes escolares a cantidades de información antes inimaginables, pero que hoy son asequibles dentro de las bibliotecas. Es así que la biblioteca es revalorada como un lugar de igualdad de información, ya sea para su consulta o uso.

\section{ESCENARIOS NOVEDOSOS PARA AMÉRICA LATINA}

En años recientes y gracias a la publicación de los Informes de Desarrollo Humano se han hecho y documentado 
de modo explícito las profundas desigualdades y carencias de los países en materia cultural y económica, así como de esperanza de vida.

Un rubro especialmente relevante tiene que ver con los esfuerzos derivados del mercado de las TIC que a su vez ha permitido la socialización de tecnologías de información. Si fuera posible que los gobiernos de los países latinoamericanos trabajaran orientados a explotar culturalmente los bienes de información que a través de las tecnologías han logrado penetrar un sinnúmero de comunidades pobres, entonces cabría esperar mayor interés en el uso de la información con miras al desarrollo social, económico y cultural de los individuos o las comunidades.

En este contexto, es particularmente deseable llamar la atención sobre la necesidad de impulsar políticas públicas de información ${ }^{9}$ que sean serias, ordenadas y con respaldo tanto económico como legislativo. En este rubro es crucial mencionar a la información con valor social y lo que se ha denominado como aprendizaje a lo largo de la vida. Ya que, como es obvio, además del recurso de información se necesita utilizarlo y obtener de éste el mayor provecho cognoscitivo o social. Es así que el aprendizaje a lo largo de la vida como política pública de educación debe incluir esfuerzos sostenidos para que la sociedad desarrolle habilidades informativas que repercutan benéficamente en los distintos roles profesionales que los individuos ejecutan a través de los años.

De nueva cuenta, la biblioteca emerge como un organismo autónomo, integrador y con capacidad de expresión comunitaria que recibe democráticamente a todos los indi-

9 En nuestra región, cada país establece sus propias políticas públicas orientadas al fomento a la cultura y a la universalidad de la educación. Si bien existen diversos enfoques para la formulación de políticas, el acceso a la información se ha visto favorecido y continúa en la agenda de discusión mundial. 
viduos o ciudadanos con necesidades de información, las cuales deben ser satisfechas. ${ }^{10}$ De lo anterior se desprende que los individuos cuentan con una institución social diseñada para ellos que alberga aprendizajes cognoscitivos y sociales que de un modo u otro son determinantes para configurar el destino de los individuos o las comunidades. Es por todo esto que las bibliotecas deben situarse como actores fortalecidos con capacidad de exigir nuevas relaciones para la asignación de fondos públicos y reconocimiento de mayor autonomía para su autogestión. De igual modo, se hace necesario establecer nuevos escenarios y diseños de servicios de información para comunidades y usuarios cada vez más diversos, independientes y ubicuos.

Las bibliotecas son instituciones sociales que requieren ser apoyadas con fondos públicos o privados suficientes, a fin de integrarse totalmente en el desarrollo social de los individuos y las comunidades. No se trata tan sólo de recursos económicos, que evidentemente son indispensables; se trata también de establecer vasos comunicantes con las diferentes secretarías de Estado o gobierno responsables del uso público de recursos obtenidos a través de los impuestos de los ciudadanos y que, por lo tanto, están obligados a rendir cuentas de modo transparente y, de ser posible, inmediato.

Además, se requieren fuertes dosis de creatividad para transformar a las bibliotecas en espacios cívicos y con áreas lúdicas tradicionales, o bien, nuevas plataformas de convivencia social constructiva. Hasta ahora, las bibliotecas no han sido consideradas como espacios de formación ciudadana y uso de fuentes de información pública, ya que en el imaginario gubernamental eran instituciones vinculadas secundariamente a la cultura. Por fortuna, la biblioteca cada vez más, en

10 Es necesario que los bibliotecólogos amplíen la reflexión acerca de favorecer la información como un bien público y las capacidades de los individuos para acceder a éste. 
muchos países de gran desarrollo humano, ocupa un lugar central en la vida de los individuos o los grupos que asisten, o bien, están conectados a ella. Por lo tanto, la biblioteca se vislumbra cada vez más como un medio de aprender a enseñar conocimientos de diverso tipo, junto con el fomento del valor de la privacidad y el respeto de los individuos. Adicionalmente, esta institución centenaria denominada biblioteca ha mostrado su carácter indispensable para utilizar la información no sólo de modo adecuado, sino también para incorporar aquella que resulta ineludible y coadyuvante para la creación de conocimiento original, la autoformación o la toma de decisiones vinculadas al ejercicio de la democracia.

Por todo lo anterior, hoy día en los países desarrollados y con conciencia y cultura bibliotecarias se ha renovado el valor social de la biblioteca, ya que es el punto de partida de los individuos y es el punto de llegada de las comunidades; ambos enriquecidos por los circuitos de información socialmente valiosa. ${ }^{11}$

\section{DEL BIBLIOTECÓlOGO}

Desde la tercera década del siglo Xx, el trabajo del bibliotecólogo se ha profesionalizado y se ha impulsado su formación disciplinaria a través de la academia, es decir, se ha buscado la obtención de grados, así como la institucionalización de la investigación original.

Debido a los vínculos sociales que los bibliotecólogos mantienen en sus respectivos entornos, se ha constatado que no son suficientes las competencias técnicas y teóricas obtenidas a través de la formación profesional para desem-

11 La biblioteca contribuye también a los patrones de distribución, visibilidad global y coexistencia virtual como paradigmas de la infodiversidad donde las personas interactúan colectivamente. 
peñar roles realmente protagónicos y de intervención social (incluidos los rasgos de liderazgo asociados a la promoción de la cultura y la educación). Esta insuficiencia también es matizada por el desarrollo de la tecnociencia, la cual ha repercutido permanentemente en el trabajo y funciones de los bibliotecólogos.

Lo anterior se explica en términos de requerir dominio de carácter abstracto y tecnológico; en consecuencia, totalmente especializado en el campo de la bibliotecología. En este sentido, la literatura especializada da cuenta de cómo las innovaciones tecnológicas aplicadas a las bibliotecas, los nuevos enfoques teóricos para tratar los recursos de información en ambientes virtuales, así como las dinámicas de cambio social y cultural, han exigido a las escuelas profesionales y entidades de investigación el desarrollo de nuevos currículos, así como la construcción de escenarios explicativos de mayor alcance, de tal suerte que éstos se materialicen en la enseñanza de la bibliotecología y la profesionalización de las bibliotecas.

Es así que los bibliotecólogos deben desarrollar capacidades altamente especializadas con base en tres ámbitos cognoscitivos y disciplinarios:

1. La teoría bibliotecológica, tanto normativa como explicativa.

2. Los fundamentos teóricos y aplicaciones en el campo de las TIC.

3. Las competencias de interacción social, liderazgo, organización, innovación e intervención en la sociedad a través de la biblioteca.

En esta línea de análisis, tanto las escuelas de bibliotecología como la academia preocupada por la creación de 
conocimiento original en la disciplina, no pueden soslayar la creación de vínculos e instancias de colaboración para reflexionar teóricamente, proponer nuevos modelos de intervención social e innovaciones insertas en las TIC, con lo cual se logre acrecentar el valor social de la biblioteca, así como su papel imprescindible para la democracia y el desarrollo social.

El ejemplo inmediato lo tenemos en las fuerzas sociales a las cuales ya se hizo referencia, es decir, las redes de infodiversidad y el acceso abierto, pues, precisamente, la biblioteca y los bibliotecólogos son actores vinculantes que poseen el conocimiento necesario para dar cauce y articulación a dichas fuerzas. Visto así, la biblioteca es el espacio de convergencia múltiple en términos de profesión y disciplina bibliotecológica, además de la incorporación permanente de las TIC. Asimismo, por todo lo antes expuesto, es plausible que la biblioteca sea con mayor frecuencia una institución de atracción social y enriquecimiento cultural, cívico y democrático.

\section{CONSIDERACIÓN FINAL}

Sobre la base de todo lo antes expuesto resulta lógico que actualmente las bibliotecas aprovechen al máximo la tecnología móvil y el software que hace posible acercar a los individuos de toda clase y condición social, nacional y mundial. Pero más allá de convertirse en un centro de diversión tecnológica, la biblioteca tiene claro que lo vital o esencial es acercar a los individuos que componen las redes de infodiversidad hacia los recursos de información que ha integrado en sistemas orientados al aprovechamiento de dichos recursos. En la actualidad, y seguramente en lo inmediato, 
observaremos el desarrollo de múltiples aplicaciones destinadas a los usuarios de información socialmente valiosa.

Por otra parte, las redes de infodiversidad deben considerar un aliado estratégico a las bibliotecas para fortalecer su identidad local, regional y mundial, así como su expansión y acción colectiva. Como ya se ha establecido, la información que pone en movimiento la biblioteca posee características únicas de valor social y cognoscitivo que repercuten en los individuos, las comunidades y los países. De tal suerte que es promisorio pensar en un escenario compuesto de dimensiones tecnológicas, culturales y democráticas que convergen en el espacio formativo y ciudadano de las bibliotecas, cuya condición de trascendencia es, sin duda, el desarrollo humano y el conocimiento compartido de los individuos y los países.

\section{REFERENCIAS BIBLIOGRÁFICAS}

Berry, J. (1985), "Library \& book: a Public Good", en Library Journal, 110.

Hess, C. y E. Ostrom (2003), "Ideas, artifacts and facilities: Information as a Common-Pool Resource", en Law and Contemporary Problems, 66 (1-2), pp. 111-145.

(2007), "Introduction: An Overview of the Knowledge Commons", en Hess, C. y E. Ostrom (eds.), Understanding Knowledge as a Commons: from theory to practice (pp. 3-26), Cambridge, Massachusetts, MIT.

Heylighen, F. (2002), "Complexity and Information Overload in Society: why increasing efficiency leads to decreasing control", en The Information Society [en línea], http://pespmc1.vub. ac.be/papers/info-overload.pdf 
La biblioteca como factor crítico en las redes de infodiversidad

IFLA (2013), Riding the Waves or Caught in the Tide? Navigating the Evolving Information Environment. Insights from the IFLA Trend Report [Netherlands], IFLA [en línea], http://trends.ifla. org/files/trends/assets/insights-from-the-ifla-trend-report_ v3.pdf

Levitan, K. B. (1982), "Information Resources as Goods in the Life Cycle of Information Production", en Journal of the American Society for Information Science, 33(1), pp. 44-54.

Morales Campos, E. (2006), "La información ante la globalización en América Latina: un tema de políticas públicas", en E. Morales Campos (coord.), Infodiversidad y cibercultura: globalización e información en América Latina (pp. 83-104), Buenos Aires, Alfagrama.

Ostrom, E. (2000), El gobierno de los bienes comunes. La evolución de las instituciones de acción colectiva, México, UNAM / CRIMFCE.

Saracevic, T. (1992), "Information Science: Origin, evolution and relations”, en P. Vakkari y B. Cronin (eds.), Conceptions of library and information science. Historical, empirical and theoretical perspectives (pp. 5-27), Londres, Taylor Graham.

Tillett, B. (2004), What is FRBR? A Conceptual Model for the Bibliographic Universe [Washington D.C.], Library of Congress, Cataloging Distribution Service [en línea], www.loc.gov/cds/downloads/FRBR.PDF 


\title{
Visibilidad de revistas y autores peruanos en repositorios de acceso abierto: el caso de la Pontificia Universidad Católica del Perú (PUCP)
}

\author{
ANA MARÍA TALAVERA IBARRA \\ Pontificia Universidad Católica del Perú \\ JUANITA JARA DE SÚMAR \\ McGill University, Montreal, Canadá
}

\section{INTRODUCCIÓN}

a presente investigación bibliométrica es un estudio de
casos que se centra en cinco revistas de acceso abier-
to disponibles a través del repositorio de la Pontificia Universidad Católica del Perú (PUCP).

Este tema fue seleccionado con el fin de determinar la relación entre el acceso abierto y la visibilidad que tienen las revistas y los autores de la PUCP. Consideramos que medir la visibilidad alcanzada por los autores y revistas que se encuentran en un entorno abierto o de acceso libre, contribuye a determinar la infodiversidad y la representatividad de la producción científica y cultural del país. 
Entendemos por infodiversidad "[...] el acceso a una información diversa como insumo básico para las actividades diarias del ser humano, pero además con la posibilidad de acceder a ella de una forma pública y abierta."

Podemos decir que el repositorio de la PUCP contribuye a la infodiversidad, ya que agrega constantemente información que se produce en la universidad; y esta información refleja pluralidad de orígenes. El repositorio pone la información al alcance de todos para su uso inmediato y para que sea citada en nuevas publicaciones. La interfaz de búsqueda es fácil de utilizar, si bien no proporciona mayores datos administrativos sobre el uso, ni permite tener una idea de la filiación de quiénes son los usuarios que descargan los documentos.

Gracias al repositorio, muchas publicaciones de la PUCP se encuentran ahora preservadas en formato digital. Encontramos allí, entre otros, tesis, revistas, documentos y publicaciones de la Universidad y de los diversos Departamentos Académicos. El contenido del repositorio no solamente está disponible en el sitio web de la Universidad sino que, además, parte de él ha sido indizado por herramientas tales como Google Scholar, Scielo y WorldCat.

En este sentido, Hernández Pérez ${ }^{2}$ menciona que el acceso gratuito a la información a través de repositorios es un factor clave para la existencia de una infodiversidad equilibrada. Mientras que S. Pieraldi, ${ }^{3}$ un consultor de empresas en aspectos de tecnología, considera que el futuro está en la diversidad, y que repositorios diversificados con contenido

1 E. Morales Campos (2003), Infodiversidad, globalización y derecho a la información, p. 68.

2 J. Hernández Pérez (2013), "Internet infodiversity: State of the art and future trends", pp. 479-485

3 S. A. Pieraldi (2014), "Info Diversity not Big Data" [en línea]. 
de conjuntos heterogéneos de datos pueden constituir la llamada Big data.

\section{VISIBILIDAD E INFODIVERSIDAD}

La idea de este estudio se apoya en algunos trabajos latinoamericanos previos ${ }^{4}$ todos relacionados con visibilidad de las publicaciones científicas latinoamericanas, cuyos autores coinciden en señalar que la visibilidad de las publicaciones periódicas latinoamericanas es limitada y que se requiere trabajar mucho para mejorarla.

La mayor parte de estudios de visibilidad se centra en revistas del área científica, y principalmente del área biomédica. Muy poco se estudia la visibilidad de publicaciones de humanidades y ciencias sociales Es decir, no hay un trato equilibrado del conocimiento publicado. Si consideramos, además, que en ciertas disciplinas el medio de publicación más importante sigue siendo el libro y no el artículo, vemos que estamos bastante lejos de lograr el control bibliográfico de la infodiversidad, tal como se ha definido.

Según Ochoa, "[...] sin visibilidad no hay uso del conocimiento que es en definitiva la razón de ser de su producción." Entonces, si queremos que el conocimiento creado por nuestra Universidad en sus diversos soportes sea utilizado, es preciso asegurarnos que tenga visibilidad entre la comunidad de intelectuales peruanos, latinoamericanos y del mundo ente-

4 S. López Leyva (2011), "The visibility of Mexican knowledge: The participation of Mexican scientific publications in the international context", pp. 151-164.

S. Miguel (2011), "Revistas y producción científica de América Latina y el Caribe: su visibilidad en SciElO, RedAlYC y SCOPUS”, pp. 187-199.

H. Ochoa Henríquez (2004), "Visibilidad: El reto de las revistas científicas latinoamericanas”, pp. 131-138.

5 H. Ochoa Henríquez, Op. cit., p. 163. 
ro. Y no es suficiente que los documentos sean indizados, deben ser citados, pues en el mundo académico presente son los análisis de citas los que determinan la influencia o impacto de los autores y sus publicaciones.

López Leyva se refiere a una visibilidad directa cuando los documentos se encuentran en publicaciones a las cuales se deben suscribir los usuarios; y una visibilidad indirecta, a través de bases de datos, directorios, catálogos y bibliotecas virtuales. Pero consideramos que estudiar el problema de visibilidad es más complejo. ${ }^{6}$

Pensamos que la visibilidad se da en varios niveles. Una publicación indizada en directorios o bases de datos de gran uso alcanza un nivel básico de visibilidad, que simplemente da a conocer la existencia del trabajo científico mediante sus datos bibliográficos acompañados de un sumario. Si además estos directorios y bases de datos proporcionan acceso mediante un enlace al documento digitalizado, se incrementa el nivel de visibilidad. Si el documento es accesible en texto completo, a través de un repositorio de acceso libre o de una de las grandes bases de datos por suscripción (Proquest, EBSCO), disponibles en la mayoría de centros de educación superior e investigación, el documento ha logrado mayor visibilidad. Si, finalmente, el documento es citado por otros documentos que se publican en revistas con alto factor de impacto y por lo tanto figuran en las bases de datos de citas (citation indexes), entonces alcanzará el mayor nivel posible de visibilidad.

La digitalización de documentos y su depósito en bases de datos y repositorios es sólo el primer paso hacia la visibilidad. Por ello, no es suficiente que el documento se ofrezca gratuitamente en un repositorio institucional; es necesario que una o más de las grandes bases de datos lo incluyan en

6 S. López Leyva, Op. cit. 
su contenido, y que la información del documento sea de tal calidad que merezca ser citada por otros autores.

Se ha avanzado bastante en estos últimos años en términos de contar con índices y bases de datos de publicaciones de formatos diversos. A las herramientas tradicionales sólo accesibles por suscripción (ISI Web of Knowledge, Scopus) se han sumado otras gratuitas, como Google Scholar (de cobertura internacional) y Redalyc, Latindex, Scielo (de alcance regional). Pero antes de que una publicación sea aceptada, tiene que superar innumerables barreras, tanto para ser indizada como para que el material sea usado. Todas estas herramientas establecen requisitos mínimos para incorporar una publicación a su directorio o base de datos, tanto las de alcance regional como las internacionales. ${ }^{7}$

Vemos también que hay un desbalance entre la visibilidad de la información presentada en forma de artículos en publicaciones periódicas, fácilmente digitalizables e indizables, y la visibilidad de la información en otros medios. Google Books y WorldCat, dos grandes herramientas gratuitas que proporcionan información sobre libros, están muy lejos de tener una cobertura universal.

Una gran barrera que enfrentamos en América Latina, muy difícil de superar y que nos impide alcanzar mayor visibilidad y contribuir a la infodiversidad, es que la mayoría de herramientas de búsqueda han sido desarrolladas en el mundo anglosajón y dan un trato preferencial a los materiales en idioma inglés.

La barrera del idioma se traduce en varios resultados negativos para la visibilidad y la infodiversidad. Un estudio que presenta entrevistas cualitativas realizadas a quince investigadores de habla hispana que trabajan en universida-

$7 \quad$ S. Miguel, Op. cit., p. 197.

A. De la Vega Ramírez y A. M. Talavera Ibarra (2011), "Las revistas de humanidades y ciencias sociales de la PUCP”. 
des de los Estados Unidos, da una visión bastante clara del impacto del idioma sobre estos investigadores, pues ellos se ven obligados a usar el idioma inglés para investigar, redactar y publicar sus investigaciones, con el fin de ser citados. ${ }^{8}$

Esta barrera no sólo afecta a los autores, sino también a los usuarios potenciales de los documentos. Éstos sólo podrán ser leídos por aquellas personas que conocen el inglés, y consecuentemente en muchos casos no se difunden en el país de origen. Y cuando los investigadores publican en español, sus resultados pasan desapercibidos para investigadores extranjeros que no conocen este idioma.

En relación con la infodiversidad, R. Corrigan ${ }^{9}$ sugiere que la infodiversidad sostenible está en peligro y que se puede diseñar un plan de cinco puntos similar al propuesto por Edward O. Wilson para evitar la destrucción de la biodiversidad. Aplicándolo a la situación de Perú, este plan podría consistir en:

1. Tener un registro integral de los depósitos de conocimiento e información del país.

2. Continuar generando, conservando y difundiendo la riqueza de información teniendo en cuenta los mejores intereses de la sociedad que deberá utilizarla.

3. Promover el desarrollo de información sostenible. Que la producción y explotación de información satisfaga necesidades del presente sin comprometer el uso de las futuras generaciones para generar nuevo conocimiento.

8 M. Suárez-Ortega; E. García-Mingo y J. A. R. San-Román (2012), "When 'Espanol' Is Not Enough: Research, Write, Translate and Publish or...Perish", pp. $463-482$.

9 R. Corrigan (2007), Digital decision making back to the future, p. 75. 
4. Salvaguardar la información existente, evitando que la legislación y tecnología privaticen el conocimiento e información disponible en el dominio público.

5. Recrear zonas libres, por ejemplo redes de universidades e instituciones públicas en las que se puede realizar un intercambio de ideas sin someterse a las demandas del control de la propiedad intelectual.

Corrigan, de manera optimista, piensa en la importancia de poder compartir la información, siempre y cuando se pueda tener un equilibrio entre las nociones complementarias de que la información debe ser compartida y a la vez controlada, para el mejor interés de la sociedad como un todo.

\section{ALCANCE Y METODOLOGÍA}

Existen ya numerosos estudios de visibilidad de la producción académica en el ámbito latinoamericano, especialmente sobre la visibilidad por inclusión en índices y catálogos. Pero hay menos estudios sobre los repositorios institucionales que ofrecen automáticamente medidas del número de documentos consultados y descargados. Estos datos no permiten medir directamente el impacto, pues son únicamente cuantitativos y no especifican los títulos de los artículos ni sus autores.

Es únicamente la medida tradicional de referencias a fuentes consultadas la que permite conocer exactamente el uso, mediante el análisis de citas bibliográficas.

\section{VISIBILIDAD DE LAS PUBLICACIONES Y SUS ARTÍCULOS}

Con el propósito de cuantificar la visibilidad de los artículos de acceso abierto publicados por la PUCP en su repositorio 
institucional, se hizo una búsqueda en los índices más conocidos en el área latinoamericana, Redalyc, Latindex y Scielo. El resultado fue desalentador para un trabajo comparativo, ya que sólo cinco títulos están incluidos en uno u otro de dichos índices. Esto se debe, en parte, a que la cobertura de los índices se orienta más al área biomédica, área que no existe en la PUCP.

Se analizaron también las bases de datos comerciales ISI Web of Science y Scopus, y se comprobó que ningún título PUCP logró su inclusión en la primera y solamente uno se encuentra en la segunda. Tampoco pudimos conseguir datos específicos de todas las publicaciones peruanas o de la PUCP en Google Scholar (GS), por lo que no hemos incluido ese servicio en esta parte del estudio (todos los datos que se presentan fueron actualizados al 9 de noviembre de 2014).

El directorio Ulrichsweb identifica 619 publicaciones periódicas peruanas ( 55 de ellas en línea). De ellas, 49 (11 en línea) son publicaciones PUCP, es decir, el 8\% de las publicaciones periódicas de nuestro país. El Cuadro 1 muestra la cobertura de los títulos peruanos y de la PUCP en las bases de datos analizadas.

Cuadro 1

Revistas peruanas incluidas en índices o bases de datos

\begin{tabular}{|c|c|c|c|}
\hline $\begin{array}{c}\text { Base de datos o } \\
\text { catálogo }\end{array}$ & $\begin{array}{c}\text { Títulos peruanos } \\
\text { activos }\end{array}$ & $\begin{array}{c}\text { Total de títulos } \\
\text { PUCP incluidos }\end{array}$ & \% PUCP \\
\hline Latindex & 369 (55 en línea) & 20 & 5 \\
\hline Redalyc & 14 & 2 & 14 \\
\hline Scopus & N.d. & 1 & N.d. \\
\hline Scielo & 17 & 3 & 18 \\
\hline
\end{tabular}

Latindex, que es la que incluye más publicaciones, apenas llega a indizar el 50\% de publicaciones peruanas y menos de 
5\% de ellas son de la PUCP. Una de las causas de esta baja presencia puede ser que la mayoría de las publicaciones no cumple con los requisitos mínimos que exigen los índices para ser incluidos en ellos. Felizmente, la mayoría de revistas de la PUCP sí cumple con los requisitos o están trabajando en ello, por lo que esperamos una mejor presencia muy pronto.

A continuación procedimos a comparar el número de fascículos peruanos analizados por las bases de datos con el total de fascículos publicados por la PUCP y disponibles en el repositorio. Decidimos concentrarnos únicamente en las cinco publicaciones para las que es posible obtener datos completos: Anthropologica, Areté, Contabilidad y Negocios, Lexis, Revista de Psicología.

Vemos en el Cuadro 2 que cada publicación, excepto Revista de Psicología, es indizada sólo por un una base de datos. Además sólo se ha incluido un período bastante reducido, la excepción es Contabilidad y Negocios, que es indizada en su totalidad por Redalyc. Sólo el 31.5\% de los fascículos publicados figura por lo menos en uno de los servicios de indización latinoamericanos. $\mathrm{Y}$ el porcentaje de fascículos de Lexis incluidos en Scopus no llega al 10\%.

Cuadro 2

Revistas y fascículos PUCP en bases de datos y Repositorio PUCP

\begin{tabular}{|c|c|c|c|c|c|}
\hline Título & $\begin{array}{c}\text { Bases de } \\
\text { datos que las } \\
\text { incluyen }\end{array}$ & $\begin{array}{c}\text { Años en la } \\
\text { base de datos }\end{array}$ & $\begin{array}{c}\text { Fascículos } \\
\text { incluidos }\end{array}$ & $\begin{array}{c}\text { Años en el } \\
\text { Repositorio }\end{array}$ & $\begin{array}{c}\text { Fascículos } \\
\text { incluidos }\end{array}$ \\
\hline Anthropologica & Scielo & $2004-2013$ & 10 & $1983-2014$ & 33 \\
\hline Areté & Scielo & $2007-2013$ & 14 & $1989-2014$ & 50 \\
\hline $\begin{array}{c}\text { Contabilidady } \\
\text { Negocios }\end{array}$ & Redalyc & $2006-2014$ & 17 & $2006-2014$ & 17 \\
\hline Lexis & Scopus & $2012-2014$ & 5 & $1977-2014$ & 70 \\
\hline Revista de & Scielo & $2005-2014$ & 9 & $1983-2014$ & 64 \\
\cline { 2 - 5 } & Redalyc & $2007-2013$ & 74 & & 234 \\
\hline
\end{tabular}


Si pasamos al siguiente nivel y analizamos comparativamente el número de artículos de estas mismas publicaciones, como aparece en el Cuadro 3, encontramos que sólo el $23.7 \%$ de los artículos es recogido por los servicios de indización.

Cuadro 3

Revistas y artículos PUCP en bases de datos y Repositorio PUCP

\begin{tabular}{|c|c|c|c|c|c|}
\hline Título & $\begin{array}{l}\text { Bases de } \\
\text { datos que } \\
\text { las incluyen }\end{array}$ & $\begin{array}{l}\text { Años en } \\
\text { la base de } \\
\text { datos }\end{array}$ & $\begin{array}{l}\text { Artículos } \\
\text { en las BD }\end{array}$ & $\begin{array}{l}\text { Años en el } \\
\text { Repositorio }\end{array}$ & $\begin{array}{l}\text { Artículos en } \\
\text { Repositorio }\end{array}$ \\
\hline Anthropologica & Scielo & $2004-2013$ & 69 & $1983-2014$ & 414 \\
\hline Areté & Scielo & $2007-2013$ & 88 & $1989-2014$ & 384 \\
\hline $\begin{array}{c}\text { Contabilidad y } \\
\text { Negocios }\end{array}$ & Redalyc & 2006-2014 & 110 & 2006-2014 & 110 \\
\hline Lexis & Scopus & $2012-2014$ & 31 & $1977-2014$ & 537 \\
\hline \multirow{2}{*}{$\begin{array}{l}\text { Revista de } \\
\text { Psicología }\end{array}$} & Scielo & 2005-2014 & 119 & \multirow{2}{*}{ 1983-2014 } & \multirow{2}{*}{377} \\
\hline & Redalyc & $2007-2013$ & 19 & & \\
\hline Total & & & 436 & & 1822 \\
\hline
\end{tabular}

\section{VISIBILIDAD DE LOS AUTORES PUCP}

En este análisis se han revisado todos los artículos de las cinco publicaciones seleccionadas, para determinar los autores individuales y múltiples de dichos artículos, y especialmente su filiación (PUCP, otros peruanos, extranjeros y sus países de origen).

Exceptuando el caso de Contabilidad y Negocios, indizada en Redalyc al 100\%, la cobertura total en las bases de datos estudiadas es de sólo 29\% de los autores, insuficiente para proporcionar visibilidad a nuestras publicaciones y los autores que contribuyen a ellas. El detalle de cobertura por título y base de datos se encuentra en el Cuado 4 . No se 
llegó a determinar el nivel de duplicación de la cobertura de la Revista de Psicología, la única indizada en dos bases de datos.

Cuadro 4

Total de autores en Repositorio PUCP y otras bases de datos

\begin{tabular}{|c|c|c|c|c|}
\hline Título & $\begin{array}{c}\text { Repositorio } \\
\text { PUCP }\end{array}$ & Scielo & Redalyc & Scopus \\
\hline Anthropologica & 450 & 109 & --- & -- \\
\hline Areté & 394 & 98 & --- & --- \\
\hline Contabilidad y Negocios & 164 & & 164 & --- \\
\hline Lexis & 559 & --- & --- & 39 \\
\hline Revista de Psicología & 691 & 141 & 269 & \\
\hline TOTAL & 2258 & 348 & 433 & 39 \\
\hline
\end{tabular}

Analizamos también qué autores de la PUCP (Cuadro 5) contribuyen a las revistas que publica la misma Universidad. Encontramos que la Revista de Psicología es la que recoge mayor cantidad de autores PUCP (45.8\%), mientras que Areté presenta el índice más bajo con $31.7 \%$.

Cuadro 5

Autores de la PUCP que publican en revistas PUCP

\begin{tabular}{|c|c|c|c|}
\hline Título & Total Autores & Autores PUCP & $\begin{array}{c}\text { Porcentaje de } \\
\text { Autores PUCP }\end{array}$ \\
\hline Anthropologica & 450 & 195 & $43.33 \%$ \\
\hline Areté & 394 & 125 & $31.73 \%$ \\
\hline $\begin{array}{c}\text { Contabilidad y Nego- } \\
\text { cios }\end{array}$ & 164 & 57 & $34.7 \%$ \\
\hline Lexis & 559 & 256 & $42.69 \%$ \\
\hline Revista de Psicología & 691 & 295 & $45.80 \%$ \\
\hline Total & 2258 & 928 & \\
\hline
\end{tabular}




\section{VISIBILIDAD EN RELACIÓN CON EL REPOSITORIO INSTITUCIONAL PUCP}

Los datos proporcionados por el Repositorio no permiten saber cuáles son los artículos más descargados. Únicamente podemos relacionar el total de descargas con el número de artículos de cada una de las revistas estudiadas.

Mostramos en el Cuadro 6 el número total de artículos de las revistas estudiadas y las veces que sus artículos fueron descargados desde la fecha en que se creó el Repositorio de la PUCP. El incremento de descargas en dos años es impresionante e inexplicable en estos momentos. Pensamos que las causas de las descargas y el uso de los documentos se deberán determinar en el futuro si continúa esta fuerte tendencia al crecimiento.

Cuadro 6

Total de artículos descargados del Repositorio PUCP

\begin{tabular}{|c|c|c|c|c|c|}
\hline Título & Artículos & \multicolumn{4}{|c|}{ Descargas } \\
\hline & & $2012^{*}$ & 2013 & $2014^{\star *}$ & TOTAL \\
\hline Anthropologica & 414 & 26631 & 38993 & 41019 & 106643 \\
\hline Areté & 384 & 12891 & 35706 & 44661 & 93258 \\
\hline Contabilidad y Neg. & 110 & 7099 & 16803 & 16333 & 40,235 \\
\hline Lexis & 537 & 7191 & 30964 & 36073 & 74228 \\
\hline $\begin{array}{c}\text { Revista de Psico- } \\
\text { logía }\end{array}$ & 377 & 10646 & 47528 & 51905 & 110079 \\
\hline Totales & 1822 & 64458 & 169994 & 189991 & 424443 \\
\hline
\end{tabular}

${ }^{*}$ Desde abril de 2012.

**Solamente hasta el 3 de noviembre de 2014.

Contabilidad y Negocios tiene, en promedio, el número más alto de descargas por artículo, 365.1, seguido de la Revista de Psicología con 292, Anthropologica con 257.6 y 
Areté con 242.9. Y si bien Lexis tiene el mayor número de artículos digitalizados, el promedio de descargas de 138.2 es el menor de las cinco revistas. Esto quizás se debe a que no es indizada ni por Redalyc ni por Scielo.

Quizás una herramienta de búsqueda más asequible y utilizada por el público en general es Google Scholar (GS). Ahí encontramos artículos de las cinco revistas elegidas. Una ventaja adicional de GS es que proporciona indicación del número de veces que el artículo ha sido citado.

La búsqueda avanzada en GS, por nombre de cada revista y de la institución, proporciona el número aproximado de entradas para cada una de las revistas estudiadas. El orden "por relevancia" no permite separar las entradas citadas de las que no lo han sido. Además, no siempre el sistema identifica todas las versiones para incluirlas en una sola entrada bibliográfica, y es posible encontrar más de una entrada, con y sin citas, para un mismo documento. De ahí que en algún caso encontramos más referencias que artículos publicados (Cuadro 7).

Cuadro 7

Artículos en el Repositorio PUCP y referencias en Google Scholar

\begin{tabular}{|c|c|c|}
\hline Título & $\begin{array}{c}\text { Artículos en Reposi- } \\
\text { torio PUCP }\end{array}$ & $\begin{array}{c}\text { Referencias en } \\
\text { Google Scholar }\end{array}$ \\
\hline Anthropologica & 414 & 343 \\
\hline Areté & 384 & 264 \\
\hline Contabilidad y Negocios & 110 & 63 \\
\hline Lexis & 537 & 343 \\
\hline Revista de Psicología & 377 & 453 \\
\hline Total & 1822 & 1466 \\
\hline
\end{tabular}

Fuente: Repositorio PUCP, 3 noviembre 2014 (elaboración propia). 


\section{VISIBILIDAD POR CITACIONES EN ARTÍCULOS DE REVISTAS}

Para esta parte del estudio revisamos las bases de datos que ofrecen información sobre qué autores son citados: ISI Web of Sciences, Scopus, Scielo y GS.

Pese a que los servicios de índices de citaciones ISI Web of Sciences y Scopus no indizan las publicaciones de la PUCP (excepto unos cuantos números de Lexis), es posible encontrar que un buen número de autores de nuestra Universidad figura en estos índices, ya que publican en revistas internacionales que son indizadas, solos o con coautores de otras instituciones. Se trata aquí de una visibilidad indirecta para la Universidad y sus investigadores, pues otros académicos pueden buscar luego a estos autores en el repositorio institucional.

1. En relación con ISI Web of Science, podemos dar algunos datos concretos: una búsqueda en todas las secciones encuentra 851 autores PUCP, habiendo sido citados 463 de ellos. 166 autores fueron citados 10 o más veces, y otros 99 fueron citados una sola vez.

Limitando la búsqueda sólo a la sección de Artes y Humanidades, encontramos 158 referencias con autores PUCP, de los cuales 29 han sido citados, 13 de ellos solo una vez. La mayor parte de las citas aparecen en revistas sobre historia de América.

En la sección de Ciencias Sociales, encontramos 235 referencias, predominando los temas de negocios, economía, antropología y derecho.

En la sección de Ciencias encontramos 532 artículos; sin embargo, ningún autor individual aparece entre los 30 más citados. 
2. En Scopus, encontramos que existen en la base de datos 13340 documentos cuyos autores tienen por filiación el Perú: de ellos, 2135 están en idioma español.

La única revista PUCP indizada, Lexis, con 31 documentos ( 25 artículos y 6 reseñas) sólo tiene un documento citado sólo una vez.

Encontramos 86 autores PUCP, 41 de los cuales han sido citados; y 934 entradas (607 artículos de revistas y 327 ponencias) en las cuales uno de los autores tiene filiación con la PUCP, habiendo sido citados 494 de ellos. Los dos autores más citados trabajan en el área de Física.

El área de Ciencias, cuyos documentos muestran gran cantidad de coautores de diversas nacionalidades y publican en revistas de gran circulación, recibe un alto número de citas: Física y Astronomía reciben 259 citas. Citas en otras áreas: Ciencias Sociales 179, Ingeniería 154, Computación 118, Artes y Humanidades 74, y Economía y Finanzas 72.

Constatamos que los autores de Ciencias sociales publican con un número mucho menor de coautores, por lo que no reciben tantas citaciones. Y que los autores de Artes y Humanidades normalmente no tienen coautores, lo que resulta en un número reducido de citaciones.

3. Scielo es otra base de datos que proporciona información sobre citaciones a nivel de publicación. Una particularidad de esta base de datos es que permite conocer la nacionalidad de las revistas donde se citan, si bien no proporciona la relación de artículos y autores citados. El Cuadro 8 muestra las citas de artículos en las tres revistas PUCP indizadas. 
Actores en las redes de infodiversidad y el acceso abierto

Cuadro 8

Citaciones recibidas por Revistas PUCP en Scielo

\begin{tabular}{|c|c|c|c|c|}
\hline $\begin{array}{c}\text { Países citantes } \\
\text { (ordenados por No. } \\
\text { de citaciones) }\end{array}$ & Anthropologica & Areté & $\begin{array}{c}\text { Revista } \\
\text { de Psicología }\end{array}$ & Total \\
\hline Brasil & 14 & 1 & 52 & 67 \\
\hline Chile & 1 & & 60 & 61 \\
\hline Colombia & 2 & 7 & 23 & 32 \\
\hline Perú & 5 & 2 & 21 & 28 \\
\hline España & 3 & 1 & 15 & 19 \\
\hline México & 5 & 0 & 9 & 14 \\
\hline Argentina & 0 & 0 & 11 & 11 \\
\hline $\begin{array}{c}\text { Otros 11 países } \\
\text { citantes con 5 o menos } \\
\text { citaciones }\end{array}$ & 5 & 2 & 21 & 28 \\
\hline No informante & 13 & 0 & 26 & 39 \\
\hline TOTALES & 48 & 13 & 238 & 299 \\
\hline
\end{tabular}

Los resultados nos muestran que las publicaciones peruanas solo citan 28 veces las revistas PUCP (21 citas son a la Revista de Psicología). Los tres países que más citan las publicaciones PUCP son Brasil, Chile y Colombia, con más de la mitad de las citaciones.

La que mayor número de citaciones recibe es la Revista de Psicología, que representa el $79 \%$ de citaciones. En cuanto a qué publicaciones peruanas citan las revistas PUCP, encontramos 16 revistas académicas citantes (11 de universidades y 5 de institutos de investigación o colegios profesionales), tanto de entidades públicas como privadas. Al considerar las temáticas principales de esas revistas, encontramos que la gran mayoría es de las áreas Médica, Psicología, Química y Ecología. Se encontró una del área de las Finanzas y una de las Humanidades. 
1. El último servicio bibliográfico analizado fue Google Scholar. Como ya mencionamos, los datos no son totalmente confiables, debido a que no se controlan las diversas versiones de un mismo documento, $y$, por lo tanto, se puede mostrar el número de citas a cada versión separadamente.

Con la búsqueda avanzada encontramos un total de 1466 resultados para la PUCP y las cinco revistas analizadas (ver Cuadro 7). Descubrimos que en la mayor parte de las referencias la fecha de publicación es incorrecta, porque se ha ingresado la fecha de digitalización y no la fecha original de publicación. Y la mayor parte de entradas que tienen citationes provienen obviamente, según la fecha de la publicación que se cita, de la consulta a la versión original impresa.

Encontramos también referencias no pertinentes a otros documentos y publicaciones con nombre similar, ya sea al de la institución o al título de la publicación.

Entonces concluimos que, si bien todas las revistas de nuestra muestra están en GS, no se puede obtener una conclusión válida respecto a la influencia sobre la visibilidad de las publicaciones PUCP, que puede derivar de haber colocado una versión de acceso libre en el repositorio institucional. Tampoco podemos saber si los autores citantes encontraron la referencia en línea en Scielo, Redalyc o Dialnet, pues estos índices son anteriores a la creación del repositorio PUCP. 


\section{CONCLUSIONES}

1. Las publicaciones periódicas de la PUCP tienen escasa visibilidad debido a que no son incluidas en los índices y bases de datos existentes, en algunos casos por no reunir todos los requisitos necesarios. Sólo cinco de las 49 publicaciones PUCP tienen cierta presencia en alguna base de datos. Se requiere actuar rápidamente para asegurarse de que todas las publicaciones sean incluidas en dichas bases de datos.

2. Actualmente no es posible obtener estadísticas y otras mediciones normalizadas del contenido y utilización de las bases de datos, índices y repositorios donde puedan figurar potencialmente las revistas y los autores PUCP. Esto dificulta los esfuerzos para obtener datos que permitan mejorar su rendimiento $\mathrm{y}$ efectuar comparaciones.

3. Esperamos que el Repositorio logre proporcionar otras mediciones, particularmente número de descargas por artículo, para determinar la correlación entre descargas y citaciones que permita una auténtica percepción del impacto que tienen los artículos en el panorama de la investigación y la infodiversidad en el Perú.

4. La digitalización masiva de las revistas PUCP es reciente y no ha sido recogida por los índices regionales. Además, Google Scholar, que ha empezado a integrar esa información, tiene problemas con los metadatos; por ejemplo, con la fecha de publicación errónea. Se requiere que los responsables del repositorio PUCP y los de la actividad editorial actúen proactivamente para garantizar una pronta y correcta indización del repertorio bibliográfico PUCP. 
5. La escasa presencia de los artículos en citas bibliográficas no se corresponde con la masiva descarga de artículos que indican las estadísticas del Repositorio PUCP. Es preciso en primer lugar comprender cómo se producen esas estadísticas. Luego debe verificarse en qué otros tipos de documentos se está citando a los documentos PUCP, especialmente en el área de humanidades. Y puede ser necesario recurrir a Altmetrics para obtener una visión total del impacto de las publicaciones.

Éste es un primer estudio y por lo tanto sus conclusiones son preliminares y sujetas a verificación. Somos conscientes de que falta mucho más trabajo de análisis para determinar con certeza si el acceso abierto puede contribuir significativamente a mejorar la visibilidad de nuestros autores y a su vez aportar a la infodiversidad. Esperamos poder continuar este estudio en el futuro.

\section{REFERENCIAS BIBLIOGRÁFICAS}

Corrigan, R. (2007), Digital decision making back to the future, New York, Springer.

De la Vega Ramírez, A. y Talavera Ibarra, A. M. (2011), "Las revistas de humanidades y ciencias sociales de la PUCP". Ponencia presentada en el Seminario internacional "Visibilidad de la Producción Científica", Lima, setiembre.

Hernández Pérez, J. (2013), "Internet infodiversity: State of the art and future trends", en Qualitative and Quantitative Methods in Libraries, 2(4), pp. 479-485. 
López Leyva, S. (2011), "The visibility of Mexican knowledge: the participation of Mexican scientific publications in the international context", en Revista de la Educación Superior, 2, pp. 151-164.

Miguel, S. (2011), "Revistas y producción científica de América Latina y el Caribe: su visibilidad en SciElo, RedALYC y SCOPUS" en Revista Interamericana de Bibliotecología, 34(2), pp. 187-199.

Morales Campos, E. (2003), Infodiversidad, globalización y derecho a la información, Buenos Aires, Sociedad de Investigaciones Bibliotecológicas.

Ochoa Henríquez, H. (2004), "Visibilidad: el reto de las revistas científicas latinoamericanas", en Opción, 20(43), pp. 131-138.

Pieraldi, S. A. (2014), "Info Diversity not Big Data” [en línea], http:// www.pieraldi.com/2014/02/info-diversity-not-big-data/

Suárez-Ortega, M.; García-Mingo, E., y San-Román, J. A. R. (2012), "When 'Espanol' Is Not Enough: Research, Write, Translate and Publish or... Perish", en International Journal of Leadership in Education, 15(4), pp. 463-482. 
Actores en las redes de infodiversidad $y$ el acceso abierto. La edición consta de 50 ejemplares. Coordinación editorial, Carlos Ceballos Sosa; revisión especializada, formación editorial y revisión de pruebas, Mercedes Torres Serratos. Instituto de Investigaciones Bibliotecológicas y de la Información/UNAM. Fue impreso en papel cultural de 90 g. en Ediciones del Lirio S. A. de C. V., Azucenas 10, Colonia San Juan Xalpa, Delegación Iztapalapa, México, D.F. en el mes de octubre de 2015. 